\title{
The Asymmetric Cyclical Behavior of the U.S. Labor Market
}

\author{
Domenico Ferraro* \\ Duke University \\ domenico.ferraro@duke.edu
}

February 15, 2014

\begin{abstract}
Cyclical fluctuations in the U.S. labor market and output exhibit a significant asymmetry. In this paper, I develop a search-and-matching model with endogenous job destruction and permanently heterogeneous workers (in skill/productivity) that accounts for this asymmetry while also generating (i) realistic volatility in unemployment and job-finding rates and (ii) preserving a downward-sloping Beveridge curve. The model delivers stark predictions for the time series of skill-specific unemployment rates that hold in CPS micro data once I sort workers by age and education. A general implication of the analysis is that the responsiveness of unemployment to stimulus policies increases substantially during recessions.
\end{abstract}

\section{J.E.L. Codes: E24; E32; J63; J64}

Keywords: Business cycles; Cyclical asymmetries; Search and matching; Unemployment; Job destruction; Job Rationing

* Address: Duke University, Department of Economics, 213 Social Sciences Building, Box 90097, Durham, NC 27708-0097. E-mail: domenico.ferraro@duke.edu. Acknowledgements: I am deeply indebted to my advisor Nir Jaimovich for his constant guidance and support. I owe special thanks to Pietro Peretto for many insightful discussions that greatly improved the paper. I also thank Craig Burnside, Giuseppe Fiori, and Cosmin Ilut as well as participants at the Duke Macro Lunch and TDM group. Any errors are my own. Please download the latest version of this paper at http://sites.duke.edu/domenicoferraropersonalpage/. 


\section{Introduction}

Labor market fluctuations are large and strongly asymmetric. The U.S. employment rate contracts deeper and sharper during recessions than it expands in booms. Output, as employment, falls deeper below trend in recessions, but it declines as sharply as it raises. ${ }^{1}$ These facts are well known, yet the literature lacks a quantitatively successful explanation.

Explaining these facts is interesting per se given the strong presence of asymmetry in U.S. macroeconomic series. Moreover, as I show in the paper, developing such an explanation leads to an explanation for the volatility of the U.S. labor market. In addition, understanding these nonlinearities is critical to address policy-relevant questions such as how the effectiveness of macroeconomic policies varies over the business cycle. By constructing a model in which asymmetries arise in equilibrium, one can study state-dependent effects of stimulus policies more rigorously.

To inform my theoretical analysis, Section 2 details new asymmetry facts. First, I show that total hours worked feature cyclical asymmetries comparable to those of the U.S. employment rate. However, the asymmetric behavior is not exhibited in the fluctuations of hours per worker. These two facts suggest that the extensive margin is critical to understand the asymmetries of the labor input. Second, fluctuations in the U.S. participation rate (fraction of the population in the labor force) are symmetric. This fact suggests I can safely abstract from movements in and out of the labor force. Third, through a counterfactual exercise based on Shimer (2012), I document that both the job creation and job destruction margin of the labor market are needed to fully account for the asymmetric dynamics of the U.S. employment rate.

Motivated by the facts above, Section 3 develops a search-and-matching model with endogenous job destruction and permanently heterogeneous workers (in skill/productivity) that accounts for the asymmetric fluctuations of the U.S. labor market and output. ${ }^{2}$ The fundamental properties of the model are that recessions are initiated by a burst of job losses leading to a spike in unemployment followed by recoveries that are driven by a low aggregate job-finding rate. ${ }^{3}$ In what follows, I detail the key mechanism of the model that generates

\footnotetext{
${ }^{1}$ See Mitchell (1913, 1927), Mitchell and Burns (1946), Neftci (1984), Sichel (1989, 1993), Long and Summers (1986), Falk (1986), Rothman (1991), McQueen and Thorley (1993), Verbrugge (1997), BelaireFranch and Peiro (2003), Bai and Ng (2005), Hamilton (2005), and McKay and Reis (2008).

${ }^{2}$ The permanent nature of heterogeneity is reasonable in the sense that over the cycle there is not much workers can do to change their skills/productivity.

${ }^{3}$ See Davis et al. (2006, 2010), Fujita and Ramey (2009), and Elsby et al. (2009) for evidence supporting this view.
} 
asymmetry in the labor market.

Consider first the scenario in which the economy rests at the steady state and it is hit by a positive shock to productivity. In this case, no endogenous separation occurs and job destruction is only due to exogenous separations. Therefore, unemployment dynamics are exclusively driven by a high aggregate job-finding rate. In this case, the distribution of skills in the unemployment pool closely replicates the distribution of skills in the economy. Consider now a negative shock to productivity. Given the heterogeneity in workers' skill/productivity, the model features a "reservation property" such that all matches with workers with productivity below a cutoff value are endogenously destroyed. Since laid-off workers are permanently low-skilled, they are not rehired until aggregate productivity returns to its normal level. Thus, in this case the unemployment pool is characterized by a distribution of skills that is skewed to the left. It is this change in the distribution of skills of the unemployment pool over the cycle that generates asymmetries in the aggregate job-finding rate.

In principle, worker heterogeneity aside, endogenous job destruction alone can give rise to "spiky" dynamics in the job-separation rate leading to asymmetries in employment. For example, consider the Diamond-Mortensen-Pissarides (DMP) model augmented with shocks to the separation rate as in Shimer (2005) or the endogenous job separation model à la Mortensen and Pissarides (1994). While these models could (at least qualitatively) account for the asymmetries in the U.S. data, it is well known that this class of models generate a counterfactual Beveridge curve and fail to generate realistic volatility in vacancies and jobfinding rates. Furthermore, as discussed above, I document in the paper that the asymmetries in the U.S. data are due to both job-separation and job-finding rates. As such a model relying exclusively on endogenous job destruction would be counterfactual vis-à-vis this observation. Thus, while relying solely on endogenous job destruction would "match" the asymmetry facts it will be at odds with other key empirical facts. It is the interaction between the endogenous separation margin and the permanent heterogeneity that allows the model to account for the asymmetry facts jointly with (i) realistic volatility in unemployment and job-finding rates, as well as (ii) the correct relative contribution of job-separation and job-finding rates to the asymmetry properties of the data.

In Section 4, I calibrate the model and evaluate its quantitative implications. I argue the model is able to replicate the key asymmetry facts as well as generate realistic volatility in unemployment and job-finding rates while preserving a downward-sloping Beveridge curve (unemployment-vacancy locus). Specifically, it is well known that accounting for the 
volatility of the U.S. labor market is one of the puzzles in analysis based on DMP models. ${ }^{4}$ Crucially, the model does not rely on a high calibration of the worker's outside option. Precisely, worker heterogeneity jointly with a fixed outside option delivers a spectrum of replacement ratios (i.e., worker's outside option as percent of the wage). This leads to a disconnect between average and marginal workers. On the one hand, marginal workers are the least productive in the labor force and the ones laid off during recessions. These workers feature high replacement ratios but account for only 5 percent of the labor force. On the other hand, high-skilled workers have low replacement ratios and account for the bulk of the workforce. As such the economy features on average a low replacement ratio.

As a by-product, the model provides stark predictions for the time series of skill-specific unemployment rates. In Section 5, I use CPS micro data for the period 1976:M1- 2013:M2 to test these predictions. Specifically, the model predicts that less productive workers account for the bulk of the average and variation over time of the unemployment rate. Since age and education are natural proxies for skills, I analyze their unemployment behavior and indeed find that (i) young and least-educated workers experience average unemployment rates that are up to nine times that of prime-aged workers and (ii) they account for approximately 70 percent of the time series variation in the U.S. unemployment rate. These facts provide strong support for the main prediction of the model: understanding cyclical movements of low-skilled workers is critical to explain the large fluctuations of the U.S. labor market.

The model has a wide range of implications for the design of macroeconomic policies. A general prediction of the analysis is that the effectiveness of stimulus policies varies over the business cycle. In Section 6, I show that the effects of policies that restore the profitability of low-productivity matches are time varying: these policies are much more effective during economic downturns than expansions. That is, the economy features impulse responses that vary with the state of the economy.

This paper relates to the literature on asymmetric cycles. Most of this literature consists of papers focusing on output and/or investment. ${ }^{5}$ Two exceptions are the studies on the labor market of Andolfatto (1997) and McKay and Reis (2008). However, this paper is the first attempt to provide a unified and quantitatively successful explanation for the volatility and asymmetry of the U.S. labor market. Importantly, I also show how cyclical asymmetries connect with nonlinearities in the amplification and propagation of shocks and argue about

\footnotetext{
${ }^{4}$ See Andolfatto (1996), Shimer (2005), and Costain and Reiter (2008).

${ }^{5}$ See Ball and Mankiw (1994), Acemoglu and Scott (1997), Kocherlakota (2000), Hansen and Prescott (2005), Jovanovic (2006), Van Nieuwerburgh and Veldkamp (2006), Devereux and Siu (2007), Cheremukhin and Tutino (2013), and Görtz and Tsoukalas (2013).
} 
their relevance for policy analysis.

\section{Asymmetry Facts}

This section details the basic facts on hours, unemployment and output that motivate the paper and discusses new facts on their asymmetry properties. I consider the employment rate (fraction of the labor force working in a given month, one minus the unemployment rate) as the main cyclical indicator of the U.S. labor market. Following Sichel (1993), I measure deepness and steepness asymmetry in an economic time series with the skewness coefficient of respectively its detrended counterpart-asymmetry in levels - and log-first-differencesasymmetry in growth rates. To test for asymmetry against the null hypothesis of symmetry, I use the test developed by Bai and Ng (2005). To isolate fluctuations at business cycle frequencies, I detrend the data with the Hodrick-Prescott (HP) filter. Figure 1 summarizes the main asymmetry facts for employment and output.

\subsection{Hours, unemployment, and output}

In Figure 2, I report percent deviations from the HP trend for the U.S. employment rate for the period 1948:Q1-2012:Q2. This figure illustrates that the largest deviations below trend (in absolute value) exceed the largest deviations above trend, i.e., troughs are deeper than peaks are tall. For example, there are six NBER-dated recessions during which the U.S. employment rate falls 2 percent below trend or more. On the other hand, the employment rate barely reaches as high as 2 percent above trend over the same period. This asymmetry between peaks and troughs indicates deepness in employment cycles. Moreover, the rate at which the employment rate falls during downturns exceeds the rate at which it raises during upturns. This asymmetry in rates of change over the contraction and expansion phases indicates steepness in employment.

Fact 1. Employment rates display negative skewness in levels and growth rates.

Fact 1 is well-known in the empirical literature on asymmetric cycles. Since Sichel (1993), this fact has been confirmed by many authors. ${ }^{6}$ Panel A and B in Figure 1 show that the empirical distributions of respectively detrended and first-difference employment rates

\footnotetext{
${ }^{6}$ See Verbrugge (1997) and Bai and Ng (2005) among others.
} 
A. HP-Filtered Employment Rate

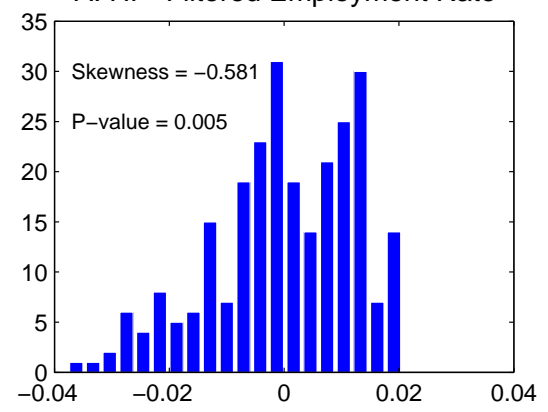

C. HP-Filtered Industrial Production

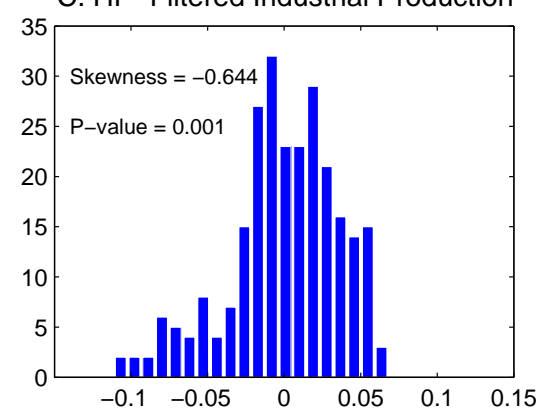

B. First-Difference Employment Rate
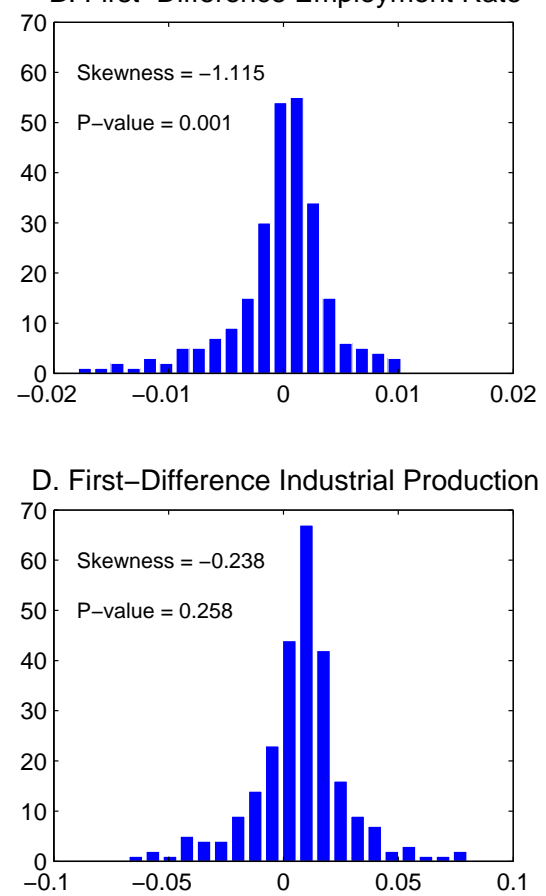

Figure 1: Asymmetry in Quarterly U.S. Data, 1948:Q1-2012:Q2

Notes: Panel A and B show the empirical distribution for respectively employment rate as deviations from the HP trend with smoothing parameter $10^{5}$ and log-first-differences. Employment rate is the fraction of the labor force working in a given month, one minus the unemployment rate. The seasonally-adjusted unemployment rate is from the CPS survey of the BLS. Survey home page http://www.bls.gov/cps/. Panel C and D show the empirical distribution for respectively industrial production (IP) as deviations from the HP trend with smoothing parameter 1600 and log-first-differences. All data are logged quarterly averages of monthly series for the period 1948:Q1-2012:Q2. Data are downloaded from the FRED website at http://research.stlouisfed.org/fred2/. 
are left-skewed. For the detrended series, the skewness coefficient equals -0.581 and it is highly statistically significant with a p-value of 0.005 . Negative skewness in the detrended series is capturing the fact there are a relatively large number of small deviations above trend compared to a relatively small number of large deviations below trend. The tails of the distribution reflects the asymmetry between peaks and troughs. For the series in first differences, the skewness coefficient equals -1.115 with a p-value of 0.001 . The skewness coefficient of growth rates is a simple statistics apt to identify large and sudden changes in employment rates. Negative skewness captures the presence of a relatively large number of small positive changes compared to a small number of large negative changes. These large negative changes in the employment rate occur at the onset of U.S. recessions.

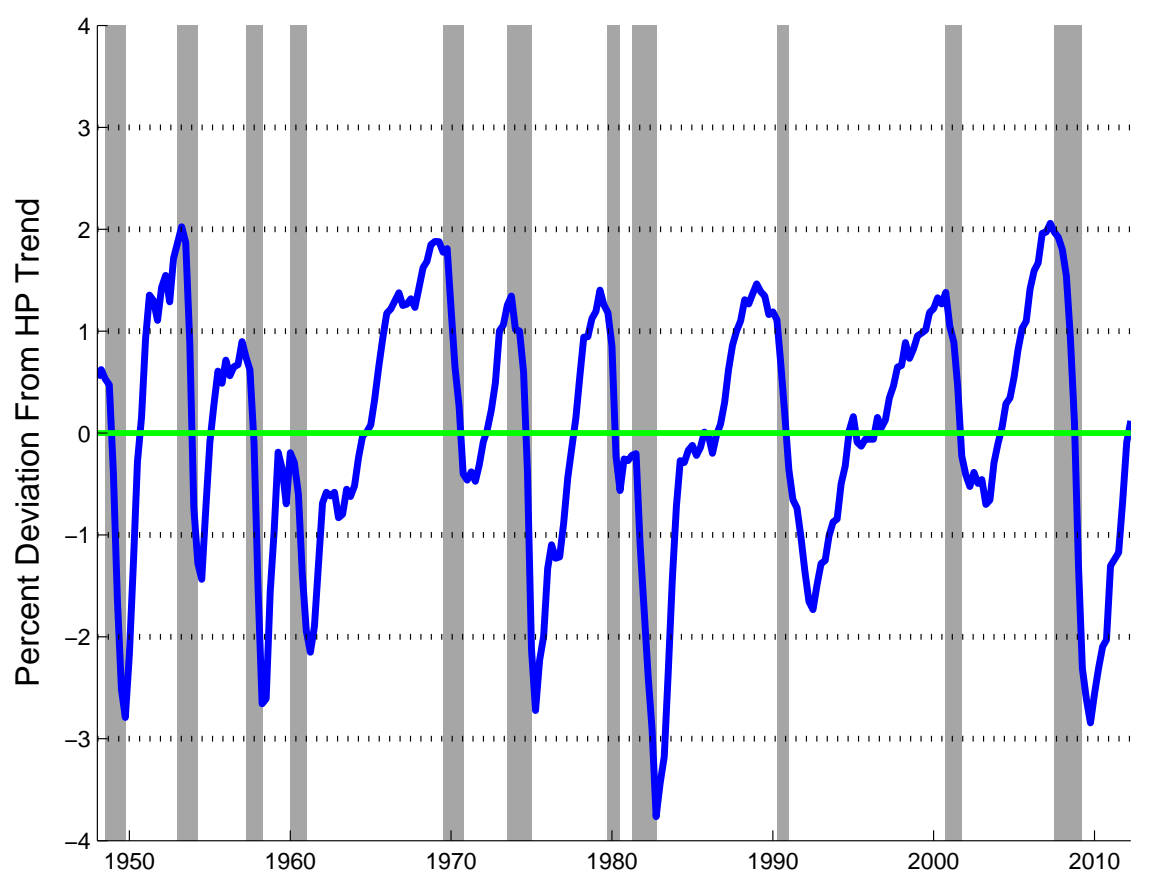

Figure 2: Detrended Quarterly U.S. Employment Rate, 1948:Q1-2012:Q2

Notes: Solid line shows a logged quarterly average of the U.S. employment rate (fraction of the labor force working in a given month, one minus the unemployment rate) as deviations from the HP trend with smoothing parameter $10^{5}$. Gray bands indicate NBER-dated recessions. The seasonally-adjusted unemployment rate is from the CPS survey of the BLS for the period 1948:Q1-2012:Q2. Survey home page http://www.bls.gov/cps/. Data are downloaded from the FRED website at http://research.stlouisfed.org/fred2/.

To strengthen Fact 1, I further document that cyclical asymmetries also characterize age-, gender- and education-specific employment rates and are a robust feature across U.S. states 
and different sectors of the U.S. economy. These findings prove that cyclical asymmetries characterize the entire labor market as such they can be meaningfully studied as an aggregate phenomenon (see Appendix B for further details).

Furthermore, I show that total hours worked feature cyclical asymmetries comparable to those of the U.S. employment rate. However, the asymmetric behavior is not present in hours per worker. These two facts suggest that the extensive margin of the labor market is critical to understand the asymmetries of the labor input. This observation is reminiscent of the well-known fact that most of the volatility of hours worked at business cycle frequencies is due to fluctuations in the number of employed as opposed to fluctuations in hours per employed worker. ${ }^{7}$ Table 1 shows results for hours and hours per worker.

Table 1: Asymmetry in Quarterly U.S. Hours, 1948:Q1-2012:Q2

\begin{tabular}{l|cc}
\hline \hline $\mathrm{x}$ & Hours & Hours per worker \\
\hline \multirow{3}{*}{$\operatorname{Skew}(\tilde{x})$} & $-0.329^{* *}$ & 0.303 \\
& $(0.028)$ & $(0.165)$ \\
& & \\
Skew $(\Delta x)$ & $-0.513^{* *}$ & 0.120 \\
& $(0.036)$ & $(0.225)$ \\
\hline \hline
\end{tabular}

Notes: Hours and hours per worker are respectively seasonally-adjusted quarterly hours worked and hours to employment ratio in the nonfarm business sector. Data are from the LPC release of the BLS for the period 1948:Q1-2012:Q2. Release home page http://www . bls.gov/lpc. Nonfarm business sector output (NBSO) excludes from the business sector the farm sector. Business sector output (BSO) is the annual-weighted index constructed by the BLS after excluding from gross domestic product (GDP) the following outputs: general government, nonprofit institutions, paid employees of private households, and the rental value of owner-occupied dwellings. Data are downloaded from the FRED website at http://research.stlouisfed.org/fred2/. Variables $\tilde{x}$ are in logs as deviations from the HP trend with smoothing parameter $10^{5}$. P-values (one-sided test) in parenthesis. ** denote statistical significance at $5 \%$ level.

There is some debate in the literature as whether the employment rate (as fraction of the labor force) or the employment-population ratio is a better indicator representing the state of the labor market. For example, Blanchard et al. (1990) argue that the number of workers moving directly into employment from out-of-the-labor force is as large as the

\footnotetext{
${ }^{7}$ See Rogerson and Shimer (2011) among others.
} 
number who move from unemployment to employment. ${ }^{8}$ To address this issue, I study the asymmetry properties of the U.S. participation rate, i.e., fraction of the population in the labor force (employed plus unemployed to population ratio). Figure 3 clearly shows that the null hypothesis of symmetry cannot be rejected in the data.

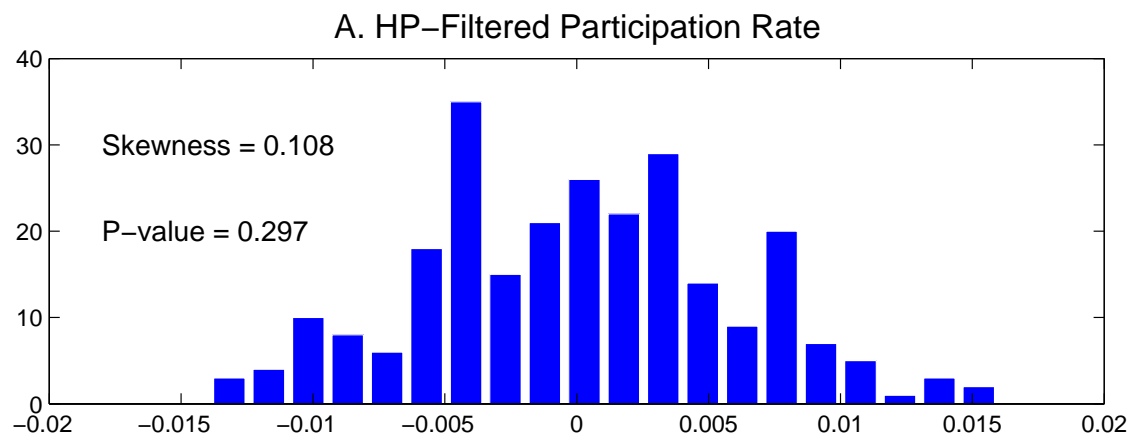

B. First-Difference Participation Rate

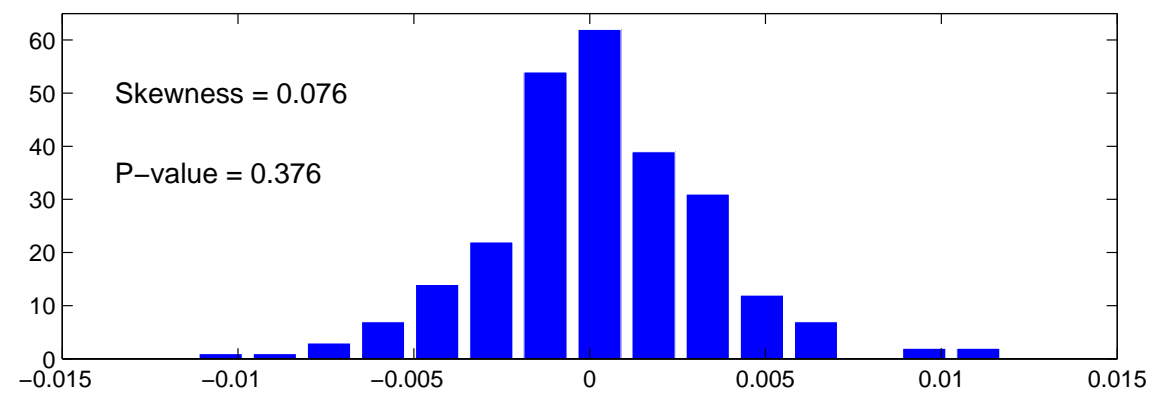

Figure 3: Asymmetry in Quarterly U.S. Participation Rate, 1948:Q1-2012:Q2

Notes: Panel A and B show the empirical distribution for respectively participation rate as deviations from the HP trend with smoothing parameter $10^{5}$ and log-first-differences. Participation rate is the fraction of the population in the labor force (employed plus unemployed to population ratio). Data are from the CPS survey of the BLS. Survey home page http://www.bls.gov/cps/. Data are logged quarterly averages of monthly series for the period 1948:Q1-2012:Q2. Data are downloaded from the FRED website at http://research.stlouisfed.org/fred2/.

The results in Figure 3 establish that fluctuations in the U.S. participation rate are symmetric. This fact suggests that to understand cyclical asymmetries in employment, I can abstract from movements in and out of the labor force.

In Figure 1, Panel $\mathrm{C}$ and $\mathrm{D}$ show the empirical distributions of detrended and firstdifference industrial production (IP). In Panel C, the skewness coefficient for the detrended

\footnotetext{
${ }^{8}$ See also Flinn and Heckman (1983), Juhn et al. (1991), Jones and Riddell (1999) and Cole and Rogerson (2001) for further discussions on whether the categories "unemployed" and "out-of-the-labor force" are different labor force states.
} 
series equals -0.644 and is highly statistically significant with a p-value of 0.001 . However, we cannot reject the null hypothesis of symmetry for the series in first differences. Panel D reports a skewness coefficient of -0.238 with a p-value of 0.258 .

Fact 2. Output displays negative skewness in levels but no skewness in growth rates.

Fact 2 is consistent with the evidence documented by Sichel (1993), Falk (1986), Long and Summers (1986) and more recently McKay and Reis (2008). Appendix B reports further results showing that steepness asymmetry is rejected in the data for several measure of real output as real GDP, business sector and nonfarm business sector output.

\subsection{Inflows and Outflows of Unemployment}

In this section, I document new facts about the asymmetric dynamics of the U.S. labor market. I compute counterfactual employment rate series based on Shimer (2012) and assess the relative contribution of job-finding and job-separation rates to the asymmetry properties of the U.S. employment rate.

\subsubsection{Job-Finding and Separation Rates}

In the standard DMP framework, the continuous time law of motion for employment is the following differential equation:

$$
\dot{e}(t)=u(t) f(t)-e(t) s(t)
$$

where a dot denotes a time derivative, $u(t)$ denotes the number of unemployed, $f(t)$ and $s(t)$ denote respectively job-finding rate (JFR) and job-separation rate (JSR). To estimate $f(t)$ and $s(t)$, I follow Shimer (2012). As such, I simply summarize here, and refer the reader to Shimer's work for further details. ${ }^{9}$ The approach uses monthly data on employment, unemployment and short-term unemployment from the CPS of BLS. All variables are in level (thousands of persons) and short-term unemployment refers to the number of unemployed persons for less than five weeks. The job-finding probability, $F_{t}$, between month $t$ and $t+1$ can be computed as:

\footnotetext{
${ }^{9}$ The job-finding and job-separation rates are derived under two assumptions: 1) workers do not transit in and out of the labor force; 2) workers are homogeneous with respect to job-finding and job-separation probabilities.
} 


$$
F_{t}=1-\frac{u_{t+1}-u_{t+1}^{s}}{u_{t}}
$$

where $u_{t}$ is the unemployment level in month $t$ and $u_{t+1}^{s}$, short-term unemployment level, is the number of persons unemployed for less than 5 weeks in month $t+1$. The job-finding rate is then $f_{t} \equiv-\log \left(1-F_{t}\right) \geq 0$. Shimer (2012) shows that one can solve the differential equation (1) forward to obtain an implicit nonlinear expression for the job-separation rate $s_{t}$. Given the job-finding rate $f_{t}$, data on employment and unemployment levels then the job-separation rate $s_{t}$ is uniquely determined. Finally, I calculate quarterly job-finding and job-separation rates by averaging over the corresponding monthly observations.

\subsubsection{Employment Counterfactuals}

To compute employment counterfactuals, I follow Shimer (2012) by approximating the U.S. employment rate series using its theoretical steady-state value from equation (1), associated with the contemporaneous job-separation and job-finding rate-Stochastic equilibrium:

$$
e_{t}^{\mathrm{se}}=\frac{f_{t}}{s_{t}+f_{t}}
$$

Hall (2005b) and Shimer (2012) show that the stochastic equilibrium is a strikingly good approximation for the actual U.S. employment rate (see Appendix B for a plot of actual and counterfactual employment). Given equation (2), I construct two counterfactual series. The first is an employment rate series that only allows for variation in the job-finding rate:

$$
e_{t}^{\mathrm{jfr}}=\frac{f_{t}}{\bar{s}+f_{t}}
$$

where $\bar{s}$ is the sample average of the job-separation rate $s_{t}$. The second counterfactual, instead, only allows for variation in the job-separation rate:

$$
e_{t}^{\mathrm{jsr}}=\frac{\bar{f}}{s_{t}+\bar{f}},
$$

where $\bar{f}$ is the sample average of the job-finding rate $f_{t}$.

Which counterfactual series better accounts for the asymmetric dynamics of the U.S. employment rate? To answer this question, I implement the asymmetry tests of Section 2.1 on the counterfactual employment rates $e_{t}^{\mathrm{jfr}}$ and $e_{t}^{\mathrm{jsr}} \cdot{ }^{\mathrm{j}}$

\footnotetext{
${ }^{10}$ The counterfactual employment series (3) and (4) are constructed under the assumption that job-finding
} 
Table 2: Asymmetry in Employment Rate Counterfactuals

\begin{tabular}{l|cccc}
\hline \hline $\mathrm{x}$ & $e^{u s}$ & $e^{\mathrm{se}}$ & $e^{\mathrm{jfr}}$ & $e^{\mathrm{jsr}}$ \\
\hline \multirow{3}{*}{$\operatorname{Skew}(\tilde{x})$} & $-0.581^{* * *}$ & $-0.682^{* * *}$ & $-0.792^{*}$ & $-0.330^{* * *}$ \\
& $(0.005)$ & $(0.001)$ & $(0.061)$ & $(0.009)$ \\
& & & & \\
\multirow{3}{*}{$\operatorname{Skew}(\Delta x)$} & $-1.115^{* * *}$ & $-0.999^{* *}$ & $0.328^{*}$ & $-0.409^{* * *}$ \\
& $(0.001)$ & $(0.010)$ & $(0.078)$ & $(0.000)$ \\
\hline \hline
\end{tabular}

Notes: $e^{u s}$ is a logged quarterly average of the U.S. employment rate (fraction of the labor force working in a given month, one minus the unemployment rate). The seasonally-adjusted unemployment rate is from the CPS survey of the BLS for the period 1948:Q1-2012:Q2. Survey home page http://www.bls.gov/cps/. Data are downloaded from the FRED website at http://research.stlouisfed. org/fred2/. $e^{\text {se }}=f /(s+f)$ is the counterfactual employment series under stochastic equilibrium. $e^{\mathrm{jfr}}=f /(\bar{s}+f)$ is the counterfactual employment series with job-separation rate fixed at the sample average. $e^{\text {jsr }}=\bar{f} /(s+\bar{f})$ is the counterfactual employment series with the job-finding rate fixed at the sample average. $\tilde{x}$ 's are in logs as deviations from the HP trend with smoothing parameter $10^{5}$. Pvalues (one-sided test) in parenthesis. ${ }^{* * *},{ }^{* *},{ }^{*}$ denote statistical significance respectively at $1 \%, 5 \%$ and $10 \%$ level. 
In Table 2, the first row shows that both counterfactual employment series, $e^{\mathrm{jfr}}$ and $e^{\mathrm{jsr}}$, display significant negative skewness as in the U.S. data. I conclude that both job-finding and job-separation rates are critical in accounting for the depth of fluctuations in the U.S. employment rate.

Fact 3. Job-finding and job-separation rates are jointly responsible for the negative skewness in levels in the employment rate.

In Table 2, the second row forcefully shows that negative steepness in the U.S. employment rate is entirely driven by the dynamics of job-separation rates.

Fact 4. Job-separation rates are the only responsible for the negative skewness in growth rates in the employment rate.

Barnichon (2012) reaches the same conclusion in Fact 4 using a different approach. Furthermore, notice that if the dynamics of the U.S. employment rate was only driven by jobfinding rates then we would observe positive skewness in the distributions of employment rate changes, i.e., positive instead of negative steepness as in the U.S. data.

Overall, this section suggests that both job-finding and job-separation rates are relevant to fully account for the asymmetric dynamics of the U.S. labor market. Specifically, jobseparation rates are the only responsible for the sharp reductions in the U.S. employment rate that occur at the onset of recessions. Job-finding rates are instead mostly responsible for why U.S. employment spends more time below trend. The combined of Fact 3 and 4 contribute to the ongoing debate on the proper treatment of the separation margin over which there is still little consensus in the literature. ${ }^{11}$

\section{Model}

In this section, I extend the textbook Pissarides (2000)'s model by introducing worker heterogeneity. Precisely, workers exhibit permanent differences in skill/productivity while em-

and job-separation rates are two independent sources of fluctuations in the employment rate. The independence assumption holds in all DMP models with exogenous and constant job-separation rate (trivially in this case) and in the Mortensen and Pissarides (1994)'s model with endogenous job separations.

${ }^{11}$ This debate has been recently revived by a series of papers with contrasting conclusions. On the one hand, Hall (2005a,b) and Shimer (2012) attribute most of the volatility in unemployment at business cycle frequencies to the dynamics of job-finding rates - "hiring-driven view." On the other hand, Fujita and Ramey (2009) and Elsby et al. (2009) resurrect the role played by the job-separation margin. While these papers focus on second-order moments of the data, I analyze their asymmetry properties. 
ployers are identical.

\subsection{Economic Environment}

Time is discrete and indexed by $t \in\{0,1, \ldots, \infty\}$. Workers are heterogeneous in their skills. Specifically, I consider an economy populated by $M$ types of workers indexed by $x \in\left\{x_{1}<\ldots<x_{M}\right\}$. The type $x$ is a permanent characteristic of the worker which is perfectly observable to employers. I ex-ante sort workers in submarkets based on their types. Therefore, the aggregate labor market is organized in $M$ submarkets indexed by worker's type $x$. In each submarket, there is a unit mass of infinitely lived workers of type $x$, either employed, $e_{t}(x) \in[0,1]$, or unemployed and searching for a job, $u_{t}(x) \in[0,1]$. The aggregate labor force is then $\sum_{x}\left(e_{t}(x)+u_{t}(x)\right)=M$. Each worker is endowed with an indivisible unit of labor. I adopt a 2-state representation of the labor market such that I abstract from movements in and out of the labor force. There is no on-the-job search, therefore only unemployed workers can search for a job. The economy is also populated by a continuum of identical and infinitely lived employers, either producing output, $y_{t}(x)$, or posting job vacancies, $v_{t}(x)$, to hire unemployed workers of type $x$. Workers and employers have riskneutral preferences and discount future payoffs at rate $\beta \in(0,1)$. I assume workers and employers can respectively search for jobs and post vacancies only in one submarket at the time. Specifically, employers are allowed to optimally choose how many vacancies to create and in which submarket to locate them. Workers instead do not move across submarkets. ${ }^{12}$

Matching and production technologies. I adopt the standard view of matching frictions in the labor market and postulate the exitence of a matching technology.

ASSUMPTION 1 (Matching function). In each submarket $x$, the matching function $m\left(v_{t}(x), u_{t}(x)\right)=\mu v_{t}(x)^{\alpha} u_{t}(x)^{1-\alpha}$ is strictly increasing and concave in both arguments and homogeneous of degree one in the number of unemployed workers, $u_{t}(x)$, and vacancies, $v_{t}(x)$. The scale parameter $\mu$ measures matching efficiency, and $\alpha \in(0,1)$ is the elasticity of new matches, or hires, $m\left(v_{t}(x), u_{t}(x)\right)$ with respect to the number of vacancies $v_{t}(x)$.

Each submarket is characterized by the tightness ratio $\theta_{t}(x) \equiv v_{t}(x) / u_{t}(x) .{ }^{13}$ An unemployed worker of type $x$ finds a job with probability $\phi\left(\theta_{t}(x)\right) \equiv m\left(v_{t}(x), u_{t}(x)\right) / u_{t}(x)=$

\footnotetext{
${ }^{12}$ This modelling choice is without loss of generality. One can show that in the equilibrium under directed search any active submarket is visited exclusively by one type of worker. Hence, the labor market is endogenously segmented by worker's type. See Menzio and Shi (2010) and Carrillo-Tudela and Visschers (2013) for a similar result.

${ }^{13}$ Petrongolo and Pissarides (2001) provide evidence supporting the constant-returns-to-scale assumption.
} 
$\mu \theta_{t}(x)^{\alpha}$ that is strictly increasing and concave in $\theta_{t}(x)$, i.e., $\phi^{\prime}(\cdot)>0$ and $\phi^{\prime \prime}(\cdot)<0$, and a vacancy posted in submarket $x$ is filled with probability $\rho\left(\theta_{t}(x)\right) \equiv m\left(v_{t}(x), u_{t}(x)\right) / v_{t}(x)=$ $\phi\left(\theta_{t}(x)\right) / \theta_{t}(x)=\mu \theta_{t}(x)^{\alpha-1}$ that is strictly decreasing and convex in $\theta_{t}(x)$, i.e., $\rho^{\prime}(\cdot)<0$ and $\rho^{\prime \prime}(\cdot)>0$. I assume workers and firms that are matched at time $t$ produce output at time $t+1$. A worker-employer match produces output via a linear technology.

ASSUMPTION 2 (Production function). In each submarket $x$, output is produced according to the linear production function, $y_{t}(x)=z_{t} x$, where $z_{t}$ is the aggregate stochastic component of labor productivity and $x$ is a time-invariant worker-specific component.

Shocks. Fluctuations are driven by exogenous variations in the aggegate component of labor productivity $\left\{z_{t}\right\}_{t=0}^{\infty} \cdot{ }^{14}$

ASSUMPTION 3 (Symmetric shocks). The stochastic process for the exogenous state $\left\{z_{t}\right\}$ is an asymptotically stationary $\mathcal{S}$-state Markov chain $\left(\mathcal{Z}, \Pi, \pi_{0}\right)$, with a unique, symmetric, and uni-modal stationary distribution $\pi_{\infty} \cdot{ }^{15}$

\subsection{Equilibrium Characterization}

I next characterize the equilibrium dynamics of a single submarket $x \in\left\{x_{1}, \ldots, x_{M}\right\}$. Abusing notation slightly, let $\phi_{s}(x) \equiv \phi\left(\theta_{s}(x)\right)$ and $\rho_{s}(x) \equiv \rho\left(\theta_{s}(x)\right)$ denote respectively the job-finding and job-filling rate in submarket $x$ when the random state of the model economy is $s \in\{1, \ldots, \mathcal{S}\}$.

Employer's problem. The employer decides either to remain in the match, and get the value $J_{s}^{c}(x)$, or to post a job vacancy, and get the value $V_{s}(x)$. Specifically, let $J_{s}(x)$ denote the value for an employer in submarket $x$ if the economy is in state $s$,

$$
J_{s}(x)=\max \left\{J_{s}^{c}(x), V_{s}(x)\right\}
$$

\footnotetext{
${ }^{14}$ Empirical evidence by Abraham and Katz (1986) and Blanchard et al. (1989) suggests that recessions are driven by aggregate activity shocks. In line with this evidence, I assume that fluctuations are driven by aggregate disturbances.

${ }^{15}$ The state space for $\left\{z_{t}\right\}$ is the finite set $\mathcal{Z}=\left\{z_{1}, \ldots, z_{\mathcal{S}}\right\}$. The states $z_{s} \in \mathcal{Z}$ take on $\mathcal{S}$ possible values, $z_{1}<\ldots<z_{s_{m}}<\ldots<z_{\mathcal{S}}$, that are symmetrically spaced around the median state $z_{s_{m}}$ which I normalize to one. The probability transition matrix is a $(\mathcal{S} \times \mathcal{S})$ matrix $\Pi=\left[\pi_{s, s^{\prime}}\right]$ with transition probabilities $\pi_{s, s^{\prime}}=\operatorname{Prob}\left\{z_{t+1}=z_{s^{\prime}} \mid z_{t}=z_{s}\right\}$, non-negative and stochastic, i.e., $\pi_{s, s^{\prime}} \geq 0$ and $\sum_{s^{\prime}} \pi_{s, s^{\prime}}=1$, for all $\left(s, s^{\prime}\right)$. The stationary distribution $\pi_{\infty}^{\prime}=\lim _{t \rightarrow \infty} \pi_{0}^{\prime} \Pi^{t}$ is symmetric and uni-modal, satisfying: $\pi_{\infty}^{s}=\pi_{\infty}^{\mathcal{S}-s+1}$ and $\pi_{\infty}^{s}<\pi_{\infty}^{s+1}$, for $s \in\left\{1, \ldots, s_{m}-1\right\}$, where $\pi_{\infty}^{s}$ denotes the $s$-th element of the probability vector $\pi_{\infty}$. The probability distribution at time $t=0$ is the $(\mathcal{S} \times 1)$ vector $\pi_{0}$.
} 
with

$$
J_{s}^{c}(x)=p_{s}(x)-\omega_{s}(x)+\beta \sum_{s^{\prime}} \pi_{s, s^{\prime}}\left\{\left[1-\delta_{s^{\prime}}(x)\right] J_{s^{\prime}}(x)+\delta_{s^{\prime}}(x) \max _{x}\left(V_{s^{\prime}}(x), 0\right)\right\}
$$

where $J_{s}^{c}(x)$ is the value of remaining in the match. $\Pi_{s}(x)=z_{s} x-\omega_{s}(x)$ are profits accruing to the employer, $p_{s}(x) \equiv z_{s} x$ denotes output, $\omega_{s}(x)$ is the wage payment to the worker, and $\delta_{s}(x)$ is the state-contingent job-separation rate. The price of output is normalized to one. The economy transits from state $s$ to the next period state $s^{\prime}$ according to the transition probability $\pi_{s, s^{\prime}}$. The value for the employer to post a vacancy in submarket $x$ if the economy is in state $s$ is,

$$
V_{s}(x)=-k(x)+\beta \sum_{s^{\prime}} \pi_{s, s^{\prime}}\left\{\rho_{s}(x) J_{s^{\prime}}(x)+\left[1-\rho_{s}(x)\right] \max _{x}\left(V_{s^{\prime}}(x), 0\right)\right\},
$$

where $k(x)$ is the unit cost to keep a job vacancy open for one period.

Worker's problem. The worker decides either to remain in the match, and get the value $W_{s}^{c}(x)$, or to be unemployed, and get the value $U_{s}(x)$. Specifically, let $W_{s}(x)$ denote the value for a worker in submarket $x$ if the economy is in state $s$,

$$
W_{s}(x)=\max \left\{W_{s}^{c}(x), U_{s}(x)\right\}
$$

with

$$
W_{s}^{c}(x)=\omega_{s}(x)+\beta \sum_{s^{\prime}} \pi_{s, s^{\prime}}\left\{\left[1-\delta_{s^{\prime}}(x)\right] W_{s^{\prime}}(x)+\delta_{s^{\prime}}(x) U_{s^{\prime}}(x)\right\},
$$

where $W_{s}^{c}(x)$ is the value of working in a continuing match. The value for the worker of being unemployed and searching for a job in submarket $x$ when the economy is in state $s$ is,

$$
U_{s}(x)=\lambda+\beta \sum_{s^{\prime}} \pi_{s, s^{\prime}}\left\{\phi_{s}(x) W_{s^{\prime}}(x)+\left[1-\phi_{s}(x)\right] U_{s^{\prime}}(x)\right\},
$$

where $\lambda$ is the worker's outside option, i.e., income earned when unemployed.

Timing. At time $t$, the aggregate shock $z_{t}$ realizes. Endogenous separations (layoffs) take place. The search and matching process follows: employers post job vacancies on one side and unemployed workers search for jobs on the other side. Unemployed workers matched 
with employers at time $t$ become productive at time $t+1$. Finally, production takes place.

Nash-bargaining equilibrium. Upon matching, the employer and worker enter Nash bargaining to determine the wage. The tightness ratio $\theta_{s}(x)$ is taken parametrically by agents and determined in equilibrium by the collection of all the individual optimal allocations.

DEFINITION 1 (Nash-bargaining equilibrium). A Nash-Bargaining Equilibrium is a collection of value functions $J_{s}(x)$ and $V_{s}(x)$ for the employers, $U_{s}(x)$ and $W_{s}(x)$ for the workers, wage payments $\omega_{s}(x)$, and tightness ratios $\theta_{s}(x)$, such that for each $s \in\{1, \ldots, \mathcal{S}\}$,

1. Employers are optimizing, taking as given the tightness ratios $\theta_{s}(x)$ and the wage payments $\omega_{s}(x)$. That is, employers with a filled job prefer to remain matched with the worker rather than posting a vacancy, $J_{s}(x)-V_{s}(x)>0$;

2. Workers are optimizing, taking as given the tightness ratios $\theta_{s}(x)$ and the wage payments $\omega_{s}(x)$. That is, workers in a job prefer to remain matched with an employer rather than being unemployed, $W_{s}(x)-U_{s}(x)>0$;

3. The free-entry condition is satisfied, $V_{s}(x)=0$;

4. Wage payments for newly formed and continuing matches solve the generalized Nashbargaining problem:

$$
\omega_{s}(x)=\arg \max \left[W_{s}(x)-U_{s}(x)\right]^{\eta} \cdot\left[J_{s}(x)-V_{s}(x)\right]^{1-\eta},
$$

where $\eta$ denotes the bargaining weight of workers.

The Nash-bargaining solution implies that worker and employer receive a constant and proportional share of the total surplus, $W_{s}(x)-U_{s}(x)=\eta S_{s}(x)$ and $J_{s}(x)=(1-\eta) S_{s}(x)$, where $S_{s}(x) \equiv W_{s}(x)+J_{s}(x)-U_{s}(x)$. The wage payment to the worker is,

$$
\omega_{s}(x)=(1-\eta) \lambda+\eta\left[z_{s} x+k(x) \theta_{s}(x)\right] .
$$

Under Nash-bargaining, the equilibrium dynamics of the model economy is fully characterized by the Bellman value equation for total match surplus,

$$
S_{s}(x)=\max \left\{S_{s}^{c}(x), 0\right\}
$$

with 


$$
S_{s}^{c}(x)=z_{s} x-\lambda+\beta \sum_{s^{\prime}} \pi_{s, s^{\prime}}\left[1-\delta_{s^{\prime}}(x)-\eta \phi_{s}(x)\right] S_{s^{\prime}}(x)
$$

where $S_{s}^{c}(x)$ is the continuation value of the total match surplus. After imposing $V_{s}(x)=$ 0 for all $s \in\{1, \ldots, \mathcal{S}\}$, equation (5) becomes,

$$
k(x)=\beta \rho_{s}(x) \sum_{s^{\prime}} \pi_{s, s^{\prime}}(1-\eta) S_{s^{\prime}}(x) .
$$

Equation (9) captures a central aspect of the model dynamics. Employers post vacancies up to the point where the expected surplus from making a match, $\beta \sum_{s^{\prime}} \pi_{s, s^{\prime}}(1-\eta) S_{s^{\prime}}(x)$, is exactly offset by the expected recruiting costs, $k(x) / \rho_{s}(x)$. As the employers post more vacancies, the tightness ratio $\theta_{s}(x)$ rises, the probability to fill the posted vacancy $\rho_{s}(x)$ decreases, and the point of zero net expected surplus is achieved. This mechanism pins down the key variable of the model, that is, the vacancy-unemployment ratio, $\theta_{s}(x)$. In a tight market with a relatively high ratio of vacancies to unemployment, it is easy for job seekers to find jobs - the job-finding rate $\phi\left(\theta_{s}(x)\right)$ is high - and difficult for firms to hire - the job-filling rate $\rho\left(\theta_{s}(x)\right)$ is low.

\subsection{Endogenous Job Destruction}

Equation (8) determines when jobs are endogenously destroyed-Job destruction margin. Since the continuation value of the total match surplus $S_{s}^{c}(x)$ is monotonically increasing in labor productivity, $p_{s}(x)=z_{s} x$, job destruction satisfies the reservation property. There exists a unique cutoff value for the aggregate state, $\bar{z}(x)$, such that all matches with workers of type $x$ are endogenously destroyed when hit by an adverse aggregate shock, $z_{s} \leq \bar{z}(x)$. Since employers and workers have the option to separate at no cost, a match continues in operation for as long as its value is above zero. Note that under Nash bargaining, separations are bilaterally efficient in that employers and workers agree on the decision to destroy existing matches. Hence, large negative shocks induce job destruction but the choice of when to destroy the job is optimally chosen by employers and workers, jointly. Therefore, the job destruction rate $\delta_{s}(x)$ is the following step function,

$$
\delta_{s}(x)=\left\{\begin{array}{cc}
\delta & \text { if } \quad z_{s}>\bar{z}(x) \Leftrightarrow S_{s}^{c}(x)>0 \\
1 \quad \text { if } \quad z_{s} \leq \bar{z}(x) \Leftrightarrow S_{s}^{c}(x) \leq 0
\end{array}\right.
$$


for each submarket $x \in\left\{x_{1}, \ldots, x_{M}\right\}$. Since total match surpluses are increasing in $x$, the cutoff on the aggregate state varies across workers' types, $\bar{z}\left(x_{1}\right)>\ldots>\bar{z}\left(x_{M}\right)$. This implies that matches with low-skilled workers are more likely to be destroyed, i.e., lowskilled workers face an higher probability to be laid off. Notice that the reservation property defines three regions in the productivity space: $(1) S_{\mathcal{S}}^{c}(\underline{x})=0$. Matches with workers of type $x \leq \underline{x}$ are never active in that total match surpluses are negative for any realization of the aggregate shock; $(2) S_{1}^{c}(\bar{x})=0$. Matches with workers of type $x>\bar{x}$ feature an exogenous constant rate of job destruction in that total match surpluses are always above zero; and (3) matches with workers of type $\underline{x}<x \leq \bar{x}$ feature both endogenous and exogenous rates of job destruction. This happens because exogenous variations in the aggregate state lead swings in total match surpluses that occasionally hit the non-negativity constraint, $S_{s}^{c}(x) \geq 0$. Hence, heterogeneous jobs respond differently to common shocks. Specifically, low-skilled workers experience more frequent and longer unemployment spells. Davis (2005) argues that layoffs are associated with greater unemployment incidence and longer unemployment spells than quits. To summarize, endogenous job destruction operates through a "selection mechanism." As the model economy is hit by an adverse aggregate shock, low-skilled workers are laid off. High-skilled workers instead enter unemployment spells at a constant exogenous rate. This implies that the aggregate separation rate spikes at the onset of economic downturns. Fujita and Ramey (2009) and Elsby et al. (2009) provide evidence supporting this prediction. The model also predicts that layoffs are countercyclical. As such, a disproportionate part of unemployment inflows during a downturns consists of laid-off workers. Davis et al. (1998) and Elsby et al. (2013) provide evidence supporting this view. Furthermore, since in the model laid-off workers are low-skilled, during downturns low-skill workers are over-represented in the group flowing into unemployment which in turn leads to a decrease in the average skill level of the unemployed pool, i.e., $\sum_{x} x u_{t}(x) / \sum_{x} u_{t}(x)$ falls during downturns.

To further sharpen intuition, I next focus on the labor market in steady state, i.e., $z_{t}=z_{s}$ for $s \in\{1, \ldots, \mathcal{S}\}$ and all $t$. This enables me to derive the cutoff value on the aggregate state analytically. To this aim, after manipulating equation (8), one gets

$$
\hat{p}(x) \equiv \hat{z} x=\lambda
$$

Equation (11) is a key condition of the model. The left hand side of the equation is the lowest productivity acceptable to employers with a filled job for remaining matched with workers of type $x$ rather than dissolve the match. The right hand side is instead the 
opportunity cost of employment for workers of type $x$, which consists of the worker's outside option $\lambda$. It is easy to verify that when $x$ decreases the cutoff on the aggregate state $\hat{z}$ needs to increase for (11) to hold, i.e., the cutoff value $\hat{z}(x)=\lambda / x$ is decreasing in worker's type $x$. In other words, high-skilled workers are laid off at lower realizations of the aggregate shock. Furthermore, for given $x$, an increase in $\lambda$ requires an equal increase in $\hat{z}(x)$ for (11) to hold. This implies that workers of type $x$ are more likely to be laid off and that a larger fraction of the labor force is now at risk of layoffs. The analysis suggests that workers' outside options are critical to understand the destruction margin of the labor market. This is particularly true for low-skilled workers who are always at the margin between participating the labor market and enjoying the value of non-market activities. A direct implication of this argument is that exogenous increases in workers' outside options, i.e., changes in the relative return to market versus non-market activity, lead to longer unemployment durations for low-skilled workers and extend the endogenous destruction region to workers with higher skills.

\subsection{Job Creation and Job Rationing}

In the model, endogenous job destruction and job creation are entwined by the reservation productivity in equation (11) that determines when (i) matches with low-skilled workers are endogenously destroyed and when (ii) low-skilled workers previously laid-off are viable for hiring (in the sense that they generate a positive surplus). This implies that the (permanent) heterogeneity in workers' skills that matters for the endogenous separation decision also affects hiring decisions. Specifically, it becomes profitable to hire low-skilled workers only when the aggregate state returns to a level that is high enough to guarantee positive surpluses. This is the essence of the selection mechanism that drives the dynamics of the model during downturns and recoveries. The model predicts that jobs are rationed during recessions.

DEFINITION 2 (Job rationing). Following Michaillat (2012), I define job rationing as the situation in which positive unemployment would persist even if the recruiting cost $k(x)$ was zero.

To understand how job rationing emerges in equilibrium, notice that the threshold $\hat{p}(x)$ in equation (11) is independent of the cost of posting a vacancy $k(x)$. Employers would find unprofitable to hire low-skilled workers with $p_{s}(x) \leq \hat{p}(x)$ even if the cost to post a vacancy was zero. This is intuitive since skills are a time-invariant characteristic of the labor force and low-skilled workers previously laid off remain low-skilled at the time of hiring. 
To further sharpen intuition, I focus on the labor market in steady state, i.e., $z_{t}=z_{s}$ for $s \in\{1, \ldots, \mathcal{S}\}$ and all $t$. This enables me to represent the equilibrium diagrammatically. To this aim, consider steady-state employment in submarket $x$,

$$
e_{s}(x)=\frac{\phi\left(\theta_{s}(x)\right)}{\delta_{s}(x)+\phi\left(\theta_{s}(x)\right)} .
$$

After manipulating equations (8) and (9), one gets

$$
\underbrace{z_{s} x-\lambda}_{\begin{array}{c}
\text { Net marginal } \\
\text { profits }
\end{array}}=\underbrace{\frac{k(x)}{\beta(1-\eta)} \cdot\left[\frac{1-\beta\left(1-\delta_{s}(x)\right)}{\rho\left(\theta_{s}(x)\right)}+\eta \beta \theta_{s}(x)\right]}_{\begin{array}{c}
\text { Marginal } \\
\text { recruiting expenses }
\end{array}} .
$$

Equations (12) and (13) fully characterize the steady-state equilibrium. Figure 4 represents the equilibrium diagrammatically.

In Figure 4, Panel A shows the equilibrium in the submarket for high-skilled workers, i.e., workers of type $x_{\text {high }}>\bar{x}$. As discussed in Section 3.3, these workers never experience endogenous separations in equilibrium, i.e., $S_{s}\left(x_{\text {high }}\right)>0$ for all realization of the aggregate shock. Equilibrium employment is obtained at the intersection of net marginal profits and recruiting expenses curves. Panel B depicts the equilibrim for high-skilled workers as I progressively decrease the cost of posting a job vacancy $k\left(x_{\text {high }}\right)$. A decrease in the cost of posting a vacancy makes the marginal recruiting expenses curve shift rightward which in turn leads to an increase in employment. This mechanism is the cornerstone of the frictional view of labor markets. As the recruting cost goes to zero, unemployment tends to vanish with high-skilled workers approaching full employment. Panel $\mathrm{C}$ shows how equilibrium employment changes as the aggregate state falls. The fall in the aggregate state makes the net marginal profits curve shift downwards, which in turn leads to a decrease in employment. An adverse shock to profits curtails the incentives to vacancy posting which in turn leads a drop in the market tightness ratio, job-finding probabilities and employment. This is the core mechanism driving recessionary unemployment in search-and-matching models. For high-skilled workers all unemployment is frictional at any point of the business cycle. Panel D depicts instead the equilibrium for low-skilled workers, i.e., workers of type $\underline{x}<x_{\text {low }} \leq \bar{x}$, when the adverse aggregate shock makes their productivity hit the rationing threshold, i.e., $p_{s}\left(x_{\text {low }}\right) \leq \hat{p}(x)$. For these workers, employment goes to zero irrespective of the cost of 
A. High-Skilled

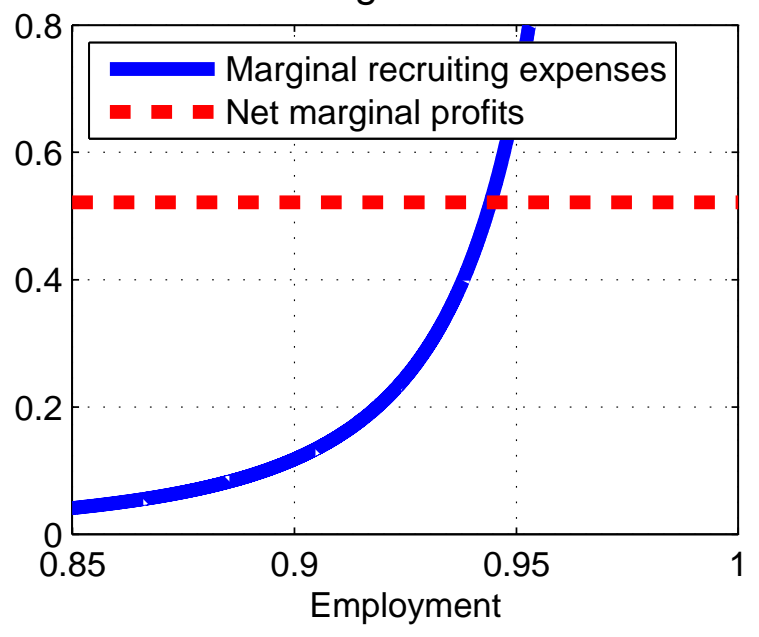

C. High-Skilled

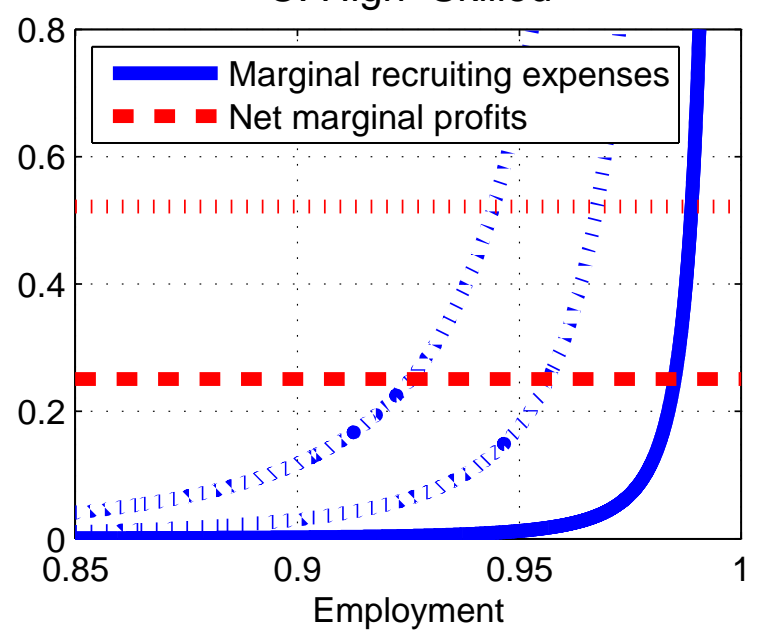

B. High-Skilled

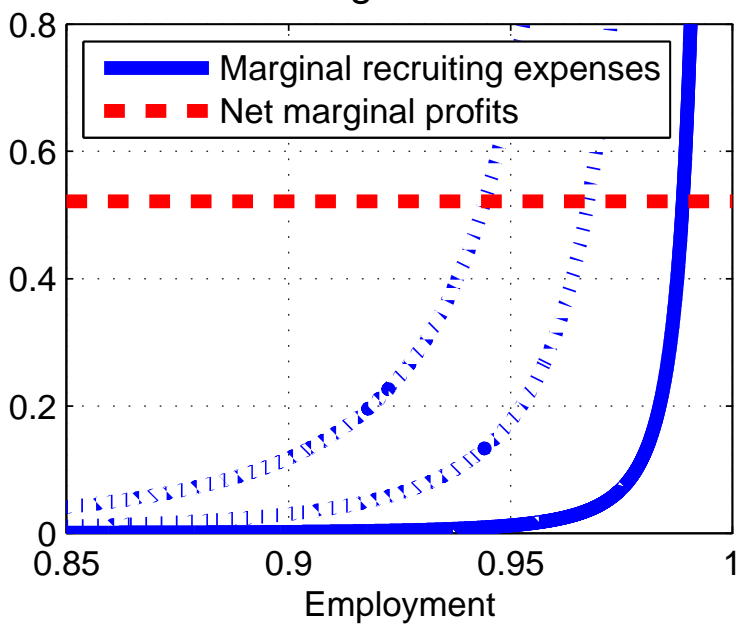

D. Low-Skilled

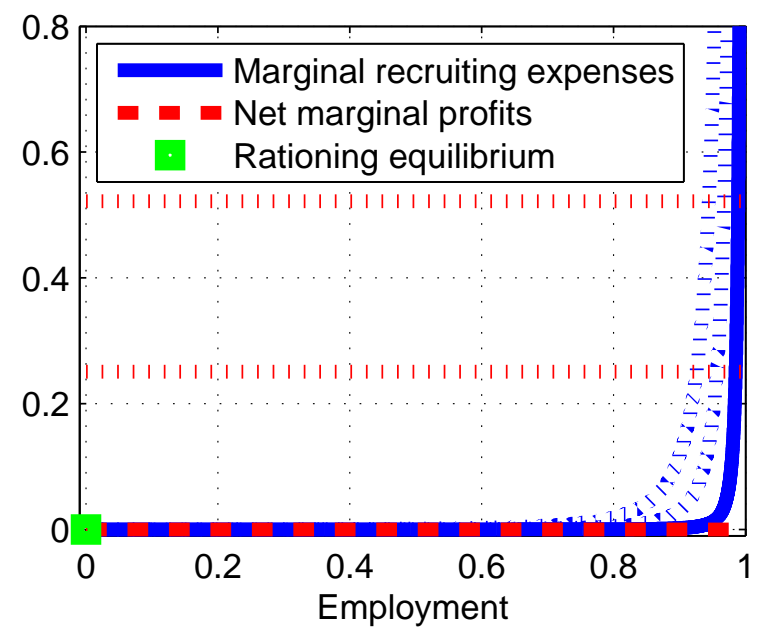

Figure 4: Frictional and Rationing Unemployment

Notes: On the $x$-axis, employment is steady-state employment as in equation (12). On the $y$-axis, net marginal profits and marginal recruiting expenses are respectively the left-hand and righthand side of equation (13). High-skilled workers have productivity $p\left(x_{\text {high }}\right)>\hat{p}(x)$ and low-skilled workers have productivity $p\left(x_{\text {low }}\right) \leq \hat{p}(x)$. The threshold $\hat{p}(x)$ is determined by equation $(11)$. 
posting a vacancy.

The model predicts that during downturns job-finding probabilities endogenously fall for all workers, though disproportionally more for low-skilled workers previously laid-off. This happens because jobs are rationed. At each point in time, aggregate unemployment consists of frictional $\left(U_{t}^{F}\right)$ and rationing $\left(U_{t}^{R}\right)$ unemployment,

$$
U_{t}=\underbrace{\sum_{p_{t}(x) \leq \hat{p}(x)} u_{t}(x)}_{\begin{array}{c}
\text { Rationing } \\
\text { unemployment }
\end{array}}+\underbrace{\sum_{p_{t}(x)>\hat{p}(x)} u_{t}(x)}_{\begin{array}{c}
\text { Frictional } \\
\text { unemployment }
\end{array}}=U_{t}^{R}+U_{t}^{F} .
$$

Furthermore, the relative importance of each component depends on the magnitude of the adverse aggregate shock. Specifically, deeper dowturns are characterized by larger shares of rationing unemployment, i.e., $u_{t}^{R} \equiv U_{t}^{R} /\left(U_{t}^{R}+U_{t}^{F}\right)$ is decreasing in the aggregate shock. This happens because a bigger fraction of the aggregate labor force hits the rationing threshold, $\hat{p}(x)$, in equation (11).

\subsubsection{Absence of Job Rationing in Existing Search-and-Matching Models with Endogenous Separations}

Michaillat (2012) discusses the absence of job rationing in standard search-and-matching models with a constant exogenous rate of job destruction. As such, I refer the reader to Michaillat's work for further details. In this section, I show that job rationing is also absent in models with endogenous separations à la Mortensen and Pissarides (1994). To this aim, I focus on a discrete time version of Mortensen and Pissarides's model as discussed in Fujita and Ramey (2012). In this setting, workers are identical. Heterogeneity arises ex-post due to match-specific idiosyncratic shocks to productivity. The match-specific component of productivity, $x \in\left\{x_{1}, \ldots, x_{M}\right\}$, switches to a new value with probability $\xi$. In this latter event, the value of $x$ is drawn randomly according to the c.d.f. $G(x)$. Matches are exogenously destroyed at the constant rate $\delta$ and those whose productivity is below a cutoff are endogenously destroyed. All new matches start at $x=x_{M}$. Hence, workers are homogeneous at the time of hiring. I refer the reader to Fujita and Ramey's work for further details on the model's structure.

To study the equilibrium theoretically, I focus on steady states (i.e., $z_{t}=z$ for all $t$ ). 
PROPOSITION 1 (Job rationing in models à la Mortensen and Pissarides). Under assumptions in Mortensen and Pissarides (1994), $\lim _{k \searrow_{0}} \theta(k)=+\infty$ and $\lim _{k \searrow_{0}} e(k)=1$, i.e., full employment, or $\lim _{k \searrow_{0}} \theta(k)=0$ and $\lim _{k \searrow_{0}} e(k)=0$, i.e., the entire labor market shuts down.

Proof. See Appendix C.

Hence, in models with endogenous separations à la Mortensen and Pissarides, as the cost to post a job vacancy goes to zero, either the economy converges to full employment or it features a 100\% unemployment rate, i.e., labor-market shutdown. The full employment case is a standard property of the texbook DMP model in that frictional unemployment vanishes in the absence of recruiting costs. In the case of market shutdown, the $100 \%$ unemployment rate is due to rationing (in the sense that all matches would generate negative surplus). Obviously, this latter case is unrealistic. As such I conclude that models in the extended Mortensen-Pissarides class are unable to generate job rationing.

\subsection{Aggregate Job-Finding Rate}

In this section, I focus on the labor market in steady state, i.e., $z_{t}=z_{s}$ for $s \in\{1, \ldots, \mathcal{S}\}$ and all $t$. This allows me to discuss the key properties of the aggregate job-finding rate in a transparent manner. The main goal of this section is to show that permanent heterogeneity in workers' skill/productivity is the critical ingredient that enables the model to account for the volatility and asymmetry of actual job-finding rates. To this aim, in Section 3.5.2 below, I analyze a version of the model in which the labor market is integrated instead of (endogenously) segmented as presented in Section 3.1. This allows me to make a clear assessment of which margin, permanent heterogeneity versus segmentation, is the key for the qualitative and quantitative properties of aggregate job-finding rates. In fact, I argue that permanent heterogeneity, instead of segmentation, is the most relevant margin at work.

\subsubsection{Segmented Labor Market}

In this section, I study the steady-state properties of the aggregate job-finding rate in the segmented labor market as presented in Section 3. Let $\Phi\left(z_{s}\right)$ denote the aggregate job-finding rate which is a weighted average of job-finding probabilities specific to each submarket with weights equal to unemployment shares $\pi_{s}(x) \equiv u_{s}(x) / U_{s}$ where $U_{s}=\sum_{x} u_{s}(x)$ denotes aggregate unemployment: 


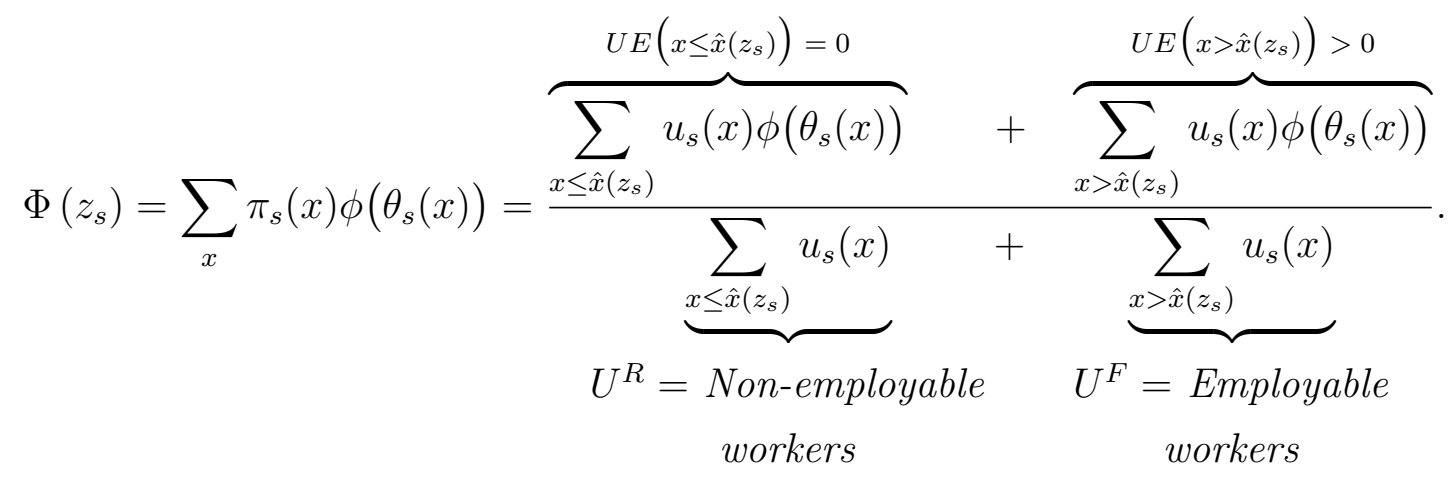

At the numerator of equation (15), $U E\left(z_{s}\right)=U E\left(x \leq \hat{x}\left(z_{s}\right)\right)+U E\left(x>\hat{x}\left(z_{s}\right)\right)$ are unemployment-to-employment (UE, hereafter) worker flows when the aggregate state of the economy is $s \in\{1, \ldots, \mathcal{S}\}$. Note that $U E\left(x \leq \hat{x}\left(z_{s}\right)\right)=0$ since low-skilled workers below the rationing threshold $\hat{x}\left(z_{s}\right)$ in (11) are non-employable workers (in the sense that they generate negative surplus), i.e., $\phi\left(\theta_{s}(x)\right)=0$ for all $x \leq \hat{x}\left(z_{s}\right)$. However, low-skilled, non-employable workers are in the unemployed pool, as such they count in the denominator of equation (15). This is the direct outcome of the selection mechanism that drives the endogenous separation decision. Low-skilled workers that are not viable for hiring are exactly the ones that have been laid off. This mechanism ties endogenous job destruction and job creation all together. Importantly, this is also the main point of departure from models of endogenous separations à la Mortensen and Pissarides (1994).

In Mortensen-Pissarides class of models, workers are identical, and heterogeneity across matches comes ex-post due to match-specific idiosyncratic shocks. Once matches are endogenously destroyed, workers flowing into the unemployment pool become viable for hiring. To make a closer analogy with the model of this paper, a Mortensen-Pissarides economy behaves as if laid-off workers become employable as soon as they enter the unemployment pool. As such the incentives to vacancy posting are larger and job-finding rates fall by less during downturns. In fact, the selection effect at work in the model of this paper is entirely due to the permanent nature of skills and it is also the only responsible for the large and deep falls of the aggregate job-finding rate during recessions.

Figure 5 shows the aggregate job-finding rate $\Phi\left(z_{s}\right)$ (see Panel A), UE worker flows $U E\left(z_{s}\right)$ (see Panel B), share of rationing unemployment, $u_{s}^{R} \equiv U_{s}^{R} /\left(U_{s}^{R}+U_{s}^{F}\right.$ ) (see Panel $\mathrm{C}$ ), and share of frictional unemployment, $u_{s}^{F} \equiv U_{s}^{F} /\left(U_{s}^{R}+U_{s}^{F}\right)$ (see Panel D). The steadystate values are computed numerically with the same parameter values used for the quanti- 

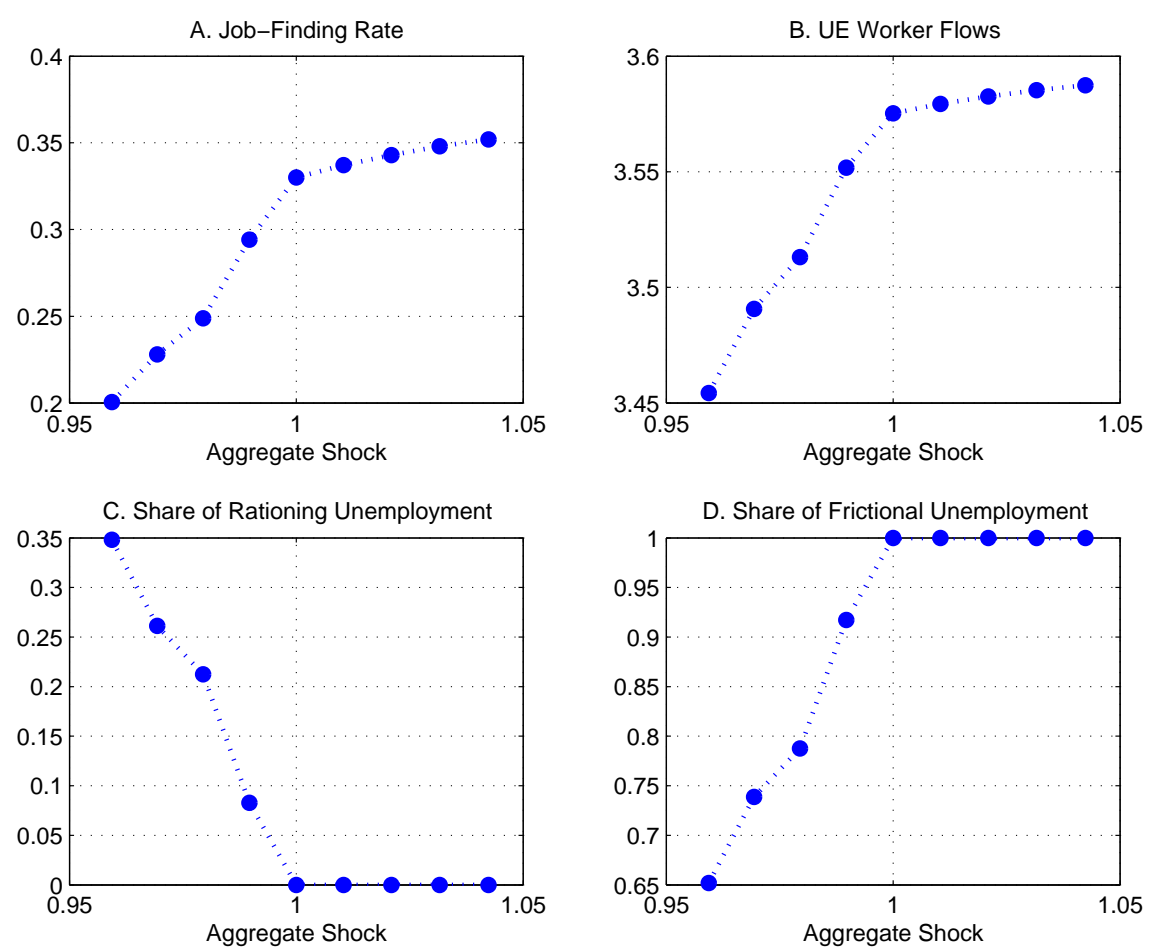

Figure 5: Aggregate Job-Finding Rate in the Segmented Labor Market

Notes: Panels A-D refer to the (segmented) labor market in steady state, i.e., $z_{t}=z_{s}$ for $s \in$ $\{1, \ldots, \mathcal{S}\}$ and all $t$. The $x$-axis is the support of the aggregate shock, $z_{s}$ with $s \in\{1,2, \ldots, 9\}$. I compute the steady-state values of the endogenous variables numerically with the same parameter values used for the quantitative analysis of Section 4. Details of the calibration are in Section 4.1, Table 3. 
tative analysis of Section 4. Panel A shows that aggregate job-finding rates are asymmetric. Same asymmetric behavior holds for UE worker flows in Panel B. These asymmetries derive from the fact that the number of non-employable workers in the unemployed pool (i.e., share of rationing unemployment to total unemployment) sharply increases in response to a negative aggregate shock (see Panel C). The share of frictional unemployment instead decreases in recessions (see Panel D). Consistently with Michaillat (2012), the model suggests that the unemployment problem during recessions is caused by insufficient economic activity rather than matching frictions. However, differently from Michaillat's work, I argue that an increasing share of recessionary unemployment involves workers in the left tail of the skill/productivity distributon.

To further clarify the main point of this section, I rewrite the aggregate job-finding rate in (15) as follows:

$$
\Phi\left(z_{s}\right)=\sum_{x>\hat{x}\left(z_{s}\right)} \pi_{s}(x) \phi\left(\theta_{s}(x)\right) \quad \text { with } \quad \pi_{s}(x) \equiv \frac{u_{s}(x)}{U_{s}} .
$$

In principle, fluctuations in the aggregate job-finding rate $\Phi\left(z_{s}\right)$ come from movements in worker-specific shares of employable workers in the unemployed pool, $\pi_{s}(x)$, and workerspecific job-finding probabilities of employable workers, $\phi\left(\theta_{s}(x)\right)$. To assess which margin is the most relevant, in the quantitative analysis of Section 4, I contrast two versions of the model: (i) endogenous job destruction (EJD) model which features endogenous separations and job rationing; and (ii) constant job destruction (CJD) model in which I calibrate the distribution of skills such that endogenous separations never occur in equilibrium. In this latter case, all workers in the unemployed pool are employable at any point of the business cycle. The quantitative results show that, different from the EJD model, the CJD model is unable to replicate the large and asymmetric fluctuations of the U.S. labor market. Thus, I conclude that fluctuations in the fraction of employable workers are of first-order importance for the quantitative success of the model.

As a final remark, note that during recessions the unemployment pool is characterized by a distribution of skills that is skewed to the left. This affects the aggregate job-finding rate only through changes in the share of employable workers. Job-finding probabilities in each submarket are instead independent of the distribution of skills of the unemployed pool and only depend on the aggregate state of the economy. This latter result comes from the assumption that workers' types are observable to the employers at the time of vacancy posting such that the labor market is segmented. 


\subsubsection{Integrated Labor Market}

In this section, I study the steady-state properties of the aggregate job-finding rate in the integrated labor market version of the model presented in Section 3. In this version of the model, the worker's type is known to the worker but it is unobservable by vacancy posting employers. Hence, an employer posting a vacancy to hire an unemployed worker internalize that it may come in contact with a worker of any type $x \in\left\{x_{1}, \ldots, x_{M}\right\}$. The contact probability is taken parametrically by the employer and determined in equilibrium by the distribution of unemployment across worker types, $\pi_{s}=\left\{\pi_{s}\left(x_{1}\right), \ldots, \pi_{s}\left(x_{M}\right)\right\}$ with $\pi_{s}(x)=u_{s}(x) / \sum_{x} u_{s}(x)$. Upon contact, the worker's type is revealed. At this stage, workers and employers decide whether to form a match and create a job or to continue their search process. The structure of the matching process implies that all unemployed workers face the same job-contact probability, $\phi\left(\theta_{s}\left(\pi_{s}\right)\right)$, but different job-finding and separation rates. Notice that I explicitly denote the dependence of the tightness ratio $\theta_{s}\left(\pi_{s}\right)$ on the entire distribution of contact probabilities, $\pi_{s}$. I refer the reader to Appendix D for further details on the model structure. Let $\Phi^{I n t}\left(z_{s}\right)$ denote the aggregate job-finding rate in the integrated labor market:

$$
\Phi^{\text {Int }}\left(z_{s}\right)=\frac{\phi\left(\theta_{s}\left(\pi_{s}\right)\right) \sum_{x>\hat{x}\left(z_{s}\right)} u_{s}(x)}{\sum_{x} u_{s}(x)}=\underbrace{\phi\left(\theta_{s}\left(\pi_{s}\right)\right)}_{\begin{array}{c}
\text { Job-contact } \\
\text { rate }
\end{array}} \times \underbrace{\sum_{x>\hat{x}\left(z_{s}\right)} \pi_{s}(x)}_{\begin{array}{c}
\text { Employable share } \\
\text { of unemployed }
\end{array}} .
$$

In principle, fluctuations in the aggregate job-finding rate $\Phi^{\text {Int }}\left(z_{s}\right)$ come from cyclical movements in job-contact probabilities, $\phi\left(\theta_{s}\left(\pi_{s}\right)\right)$, and the share of employable workers in the unemployed pool, $\sum_{x>\hat{x}\left(z_{s}\right)} \pi_{s}(x)$. Notice that in the integrated labor market, workerspecific shares of the unemployed pool $\pi_{s}(x)$ affect the aggregate job-finding rate through two channels: (1) the distribution of worker-specific shares $\pi_{s}=\left\{\pi_{s}\left(x_{1}\right), \ldots, \pi_{s}\left(x_{M}\right)\right\}$ directly affects market tightness $\theta_{s}\left(\pi_{s}\right)$. This channel is absent in the model with a segmented labor market. (2) The share of employable workers $\sum_{x>\hat{x}\left(z_{s}\right)} \pi_{s}(x)$ determines the fraction of workers in the unemployment pool that generate positive surplus once they come in contact with an employer. This channel is the only one at work in the model with a segmented labor market.

Figure 6 shows the aggregate job-finding, $\Phi^{\operatorname{Int}}\left(z_{s}\right)$, and job-contact rate, $\phi\left(\theta_{s}\left(\pi_{s}\right)\right.$ ) (see Panel A), UE worker flows (see Panel B), and the shares of rationing and frictional unem- 
ployment (see Panels C-D). Panel A shows that the aggregate job-finding rate (dotted line) displays a noticeable asymmetry. As such the job-finding rate in the economy with an integrated labor market shares the same asymmetric behavior of the economy with segmented labor markets (see Table 5, Panel A). Furthermore, as for the segmented labor-market case I discuss above, most of the asymmetry in the aggregate job-finding rate comes from the marked asymmetry in the share of non-employable workers in the unemployed pool (see Table 6, Panel C). Note that also the job-contact rate is asymmetric. However, its asymmetry is much less pronounced if compared to that of the job-finding rate. This result is important for two reasons: (1) the direct effect from the composition of the unemployed pool to market tighteness is not of first-order importance; and (2) the key mechanism driving asymmetry in the aggregate job-finding rate is the share of non-employable workers in the unemployed pool. Importantly, this is the key force at work in the model with segmented labor markets.
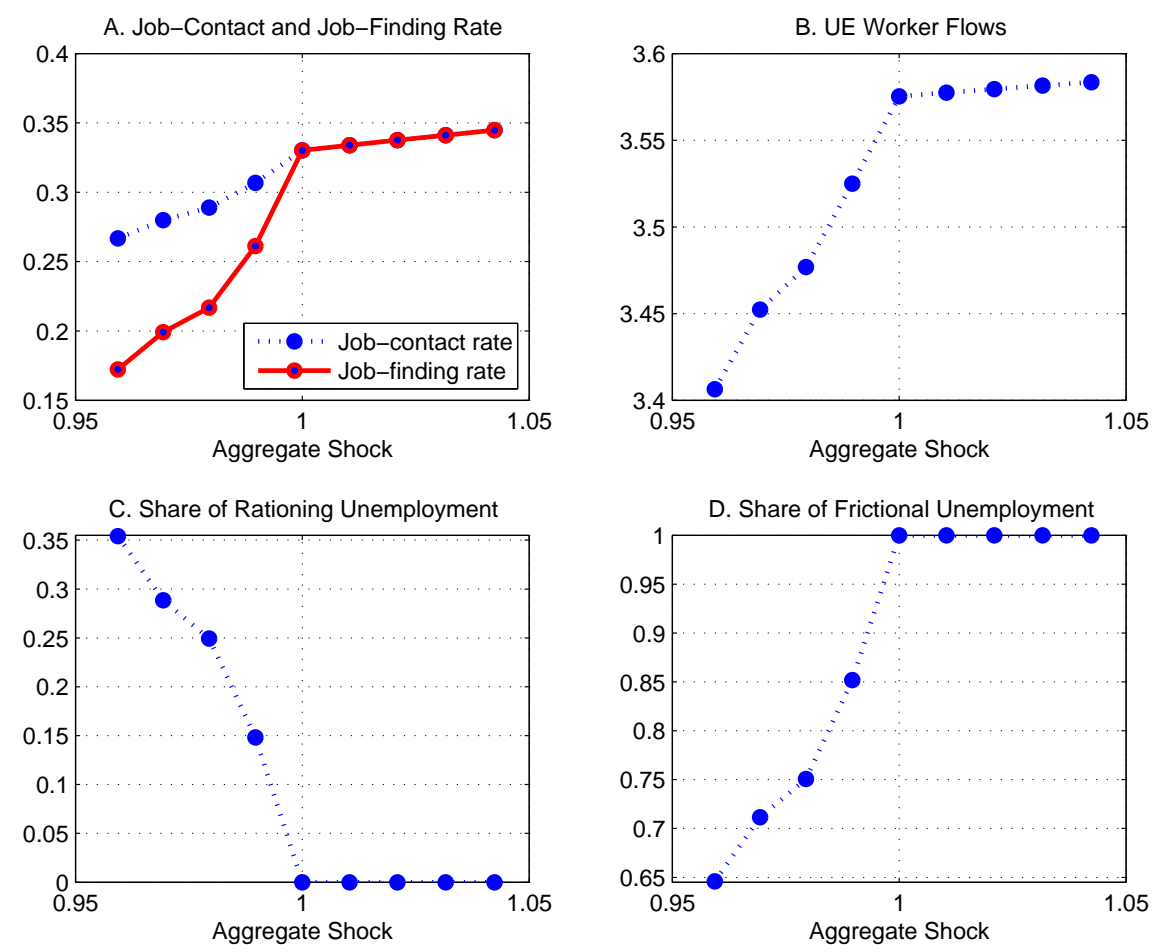

Figure 6: Aggregate Job-Finding Rate in the Integrated Labor Market

Notes: Panels A-D refer to the (integrated) labor market in steady state, i.e., $z_{t}=z_{s}$ for $s \in$ $\{1, \ldots, \mathcal{S}\}$ and all $t$. The $x$-axis is the support of the aggregate shock, $z_{s}$ with $s \in\{1,2, \ldots, 9\}$. I compute the steady-state values of the endogenous variables numerically with calibrated parameter values. I set the vacancy cost to $k=0.168$ such that $\theta_{s_{m}}\left(\pi_{s_{m}}\right)=1\left(z_{s_{m}}=1\right.$ in my normalization). The rest of the parameters are set as in Section 4.1, Table 3. 


\subsection{Aggregate Variables}

Unemployment in submarket $x \in\left\{x_{1}, \ldots, x_{M}\right\}$ follows the process

$$
u_{t+1}(x)= \begin{cases}1 & \text { if } \quad S_{t}(x) \leq 0 \\ u_{t}(x)+\delta e_{t}(x)-\phi\left(\theta_{t}(x)\right) u_{t}(x) & \text { if } \quad S_{t}(x)>0 .\end{cases}
$$

Aggregate labor force is $\sum_{x}\left(e_{t}(x)+u_{t}(x)\right)=E_{t}+U_{t}=M$, where $E_{t}=\sum_{x} e_{t}(x)$ and $U_{t}=\sum_{x} u_{t}(x)$ denote respectively aggregate employment and unemployment. The aggregate employment and unemployment rates are respectively $e_{t}=E_{t} / M$ and $u_{t}=U_{t} / M$. The aggregate job-finding and job-separation rates are respectively,

$$
\Phi_{t+1}=\frac{1}{U_{t}} \sum_{x} \phi\left(\theta_{t}(x)\right) u_{t}(x) \quad \text { and } \quad \Delta_{t+1}=\frac{1}{E_{t}} \sum_{x} \delta_{t+1}(x) e_{t}(x),
$$

where $\phi\left(\theta_{t}(x)\right)$ and $\delta_{t}(x)$ are respectively job-finding and job-separation probabilities for workers of type $x$. Aggregate vacancies are $v_{t}=\sum_{x} v_{t}(x)$, where $v_{t}(x)$ is the number of vacancies posted in submarket $x$. Total output and aggregate labor productivity are respectively,

$$
Y_{t}=\sum_{x} y_{t}(x)=z_{t} \sum_{x} x e_{t}(x) \quad \text { and } \quad p_{t}=\frac{Y_{t}}{E_{t}}=z_{t} \cdot \frac{\sum_{x} x e_{t}(x)}{\sum_{x} e_{t}(x)} .
$$

Notice that aggregate labor productivity $p_{t}$ consists of an exogenous component, $z_{t}$, and an endogenous component, $\sum_{x} x e_{t}(x) / \sum_{x} e_{t}(x)$, which is a skill-adjusted measure of the employed pool.

\subsection{Cross-Sectional Dispersion in Labor-Market Conditions and Matching Efficiency}

The model features cross-sectional dispersion in labor-market conditions. Dispersion comes from the fact that different types of workers respond differently to aggregate shocks. This is a fundamental property of the model which endogenosuly arises since workers are permanently heterogenous in skill/productivity. I next show that if an econometrician wrongly assumes the existence of an aggregate matching function then she would infer cyclical movements in matching efficiency. This would be misleading since in the model the technology parameter governing the efficiency of the market-specific matching function, $\mu$, is constant. Recall that 
for each submarket the number of hires is $m_{t}(x)=\mu v_{t}(x)^{\alpha} u_{t}(x)^{1-\alpha}$. In the aggregate instead, total hires are $M_{t}=\sum_{x} m_{t}(x)$,

$$
M_{t}=\mu \sum_{x} v_{t}(x)^{\alpha} u_{t}(x)^{1-\alpha}
$$

which is the true data generating process (DGP). Now, if an econometrician assumes the existence of an aggregate matching function then she would expect the following relationships to hold,

$$
\tilde{M}_{t}=\tilde{A}_{t}\left(\sum_{x} v_{t}(x)\right)^{\alpha}\left(\sum_{x} u_{t}(x)\right)^{1-\alpha}=\tilde{A}_{t} V_{t}^{\alpha} U_{t}^{1-\alpha}
$$

where $\tilde{M}_{t}$ are the number of hires implied by an aggregate matching function, $V_{t}=$ $\sum_{x} v_{t}(x)$ and $U_{t}=\sum_{x} u_{t}(x)$ are respectively aggregate vacancies and unemployment, and $\tilde{A}_{t}$ is measured matching efficiency. Suppose the econometrician is endowed with a dataset of artifical data generated by the model, $\left\{M_{t}, V_{t}, U_{t}\right\}_{t=0}^{T}$, and the value of the parameter $\alpha$. I ask now the fictional econometrician to estimate matching efficiency $\tilde{A}_{t}$ without providing her the true DGP in equation (19). She would calculate efficiency in a residual way as

$$
\ln \tilde{A}_{t}=\ln M_{t}-\alpha \ln V_{t}-(1-\alpha) \ln U_{t}
$$

Concavity of the matching function and Jensen's inequality imply that $M_{t} \leq \tilde{M}_{t}$ such that $\ln \tilde{A}_{t} \leq 0$ for all $t \geq 0$. Therefore, cross-sectional dispersion in tightness ratios induces a negative level effect on measured matching efficiency as compared to the benchmark economy with homogenous workers. Table 7 shows that, in addition to a level effect, measured matching efficiency would also display cyclical properties.

However, these infered variations are the artifact of neglecting heterogeneity. If the econometrican is endowed with the DGP in equation (19) and market-specific data on job vacancies and unemployment, $\left\{v_{t}(x), u_{t}(x)\right\}_{t=0}^{T}$, then she would estimate $\ln \tilde{A}_{t}=\mu$ for all $t \geq 0$.

The model suggests that recessions would look like periods of extremely low matching efficiency. The model generates an high correlation between measured matching efficiency and the aggregate shock, i.e., $\operatorname{corr}\left(\ln \tilde{A}_{t}, \ln z_{t}\right)=0.792$. Elsby et al. (2010) and Barnichon and Figura (2011) provide empirical support for this prediction. Using CPS micro data for 1976-2010, Barnichon and Figura (2011) show that the composition of the pool of unemployed 


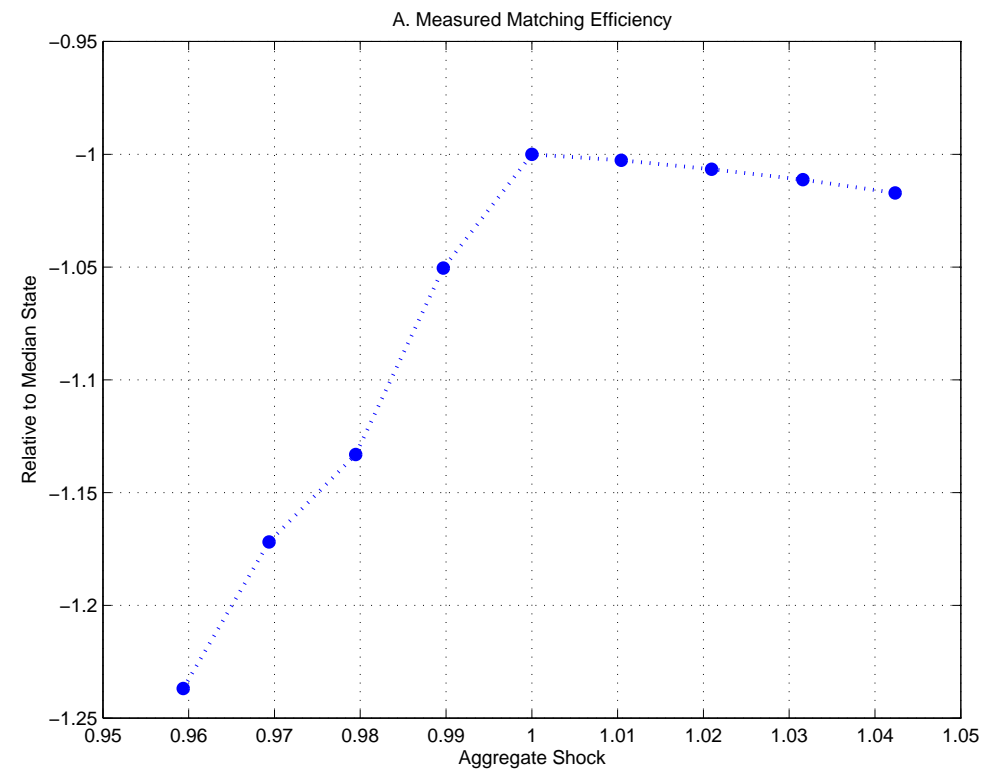

Figure 7: Time-Varying Matching Efficiency

Notes: Panel A refers to the labor market in steady state. The $x$-axis is the support of the aggregate shock, $z_{s}$ with $s=\{1,2, \ldots, 9\}$. The $y$-axis is measured matching efficiency relative to the median state $\left(z_{s_{m}}=1\right.$ in my normalization), i.e., $\ln \tilde{A}_{s} /\left|\ln \tilde{A}_{s_{m}}\right|$. I compute the steady-state values of the endogenous variables numerically with the same parameter values used for the quantitative analysis of Section 4. Details of the calibration are in Section 4.1, Table 3. 
accounts for most of the cyclical variation in matching efficiency up to 2006, and forty-five percent of the decline in matching efficiency for the 2007-2010 period. Note that in the model, dispersion in labor-market conditions across workers depends only on their different responses to aggregate shocks. Hence, there is no room for "mismatch." By mismatch I mean the sectoral misalignment between vacant jobs and unemployed workers, i.e., unemployed seeking employment in sectors (occupations, industries, locations) different from those where the available jobs are. Sahin et al. (2012) and Herz and van Rens (2012) argue that fluctuations in unemployment due to mismatch are small compared to the overall unemployment rate. As a final remark, the discussion of this section also suggests that interpreting cyclical movements in matching efficiency as "structural shocks" to the matching process can lead to erroneous explanations of unemployment dynamics during recessions.

\subsection{Textbook DMP Model}

In this section, I discuss the properties of the textbook DMP model which is a special case of the model with worker heterogeneity.

REMARK 1 (Textbook DMP model). When $x_{j}=1$ for all $j \in\{1, \ldots, M\}$, all workers are identical. In this case, the model nests a standard DMP model with a constant exogenous rate of job destruction.

The analysis focuses on the stochastic equilibrium of the economy. This allows me to study the equilibrium analytically.

DEFINITION 3 (Stochastic equilibrium). A stochastic equilirium is any equilibrium in which the shock $\left\{z_{t}\right\}$ repeats itself, i.e., $z_{t+1}=z_{t}=z_{s}$, for $s \in\{1, \ldots, \mathcal{S}\}$.

At the stochastic equilibrium, the employment rate is

$$
e_{s}=\frac{\phi\left(\theta_{s}\right)}{\delta+\phi\left(\theta_{s}\right)} .
$$

Employment rate, $e_{s}$, job-finding rate, $\phi\left(\theta_{s}\right)$, vacancies, $v_{s}=\theta_{s} u_{s}$, and log output, $\ln y_{s}$, are strictly increasing and concave functions of the tightness ratio, $\theta_{s}$.

\subsection{Three Propositions}

I next derive analytical results for the stochastic equilibrium of the standard DMP model. 
PROPOSITION 2 (Asymmetry bounds). Any stochastic equilibrium consistent with a constant exogenous rate of job destruction features asymmetry bounds on the unconditional distributions of the endogenous variables: for market tightness, (i) $\Delta \theta_{M M D} \equiv \mathbb{E}[\theta]-\theta_{s_{m}}>0$; and for any strictly increasing and concave function $\xi(\theta)$ (i.e., employment rate, job-finding rate, vacancies, and log of output), (ii) $\Delta \xi_{M M D} \equiv \mathbb{E}[\xi(\theta)]-\xi\left(\theta_{s_{m}}\right)<\xi(\mathbb{E}[\theta])-\xi\left(\theta_{s_{m}}\right)<$ $\xi^{\prime}\left(\theta_{s_{m}}\right) \Delta \theta_{M M D}$.

Proof. See Appendix C.

Proposition 2 formally states that the asymmetry properties of the endogenous variables are bounded by those of market tightness. Despite the theoretical convexity proved by Lemma 1 in Appendix C, the relationship between market tightness and aggregate shock turns out to be approximatively linear for all plausible calibrations of the model. This latter observation motivates the next corollary.

COROLLARY 1 (Mean-median asymmetry in levels). Consider the stochastic equilibrium for market tightness. If the support of the distribution of $\theta$ is symmetric around the median value then any equilibrium consistent with a constant exogenous rate of job destruction features negative skewness in the unconditional distribution of employment rate, job-finding rate, vacancies and log of output.

Proof. See Appendix C.

The results in Corollary 1 derive from a key property of the search-and-matching framework, i.e., matching displays decreasing returns to unemployment and vacancy posting. When the labor market is tight - $\theta$ is high - increasingly more vacancies are needed to generate a given redution in unemployment. This is the essence of the congestion externality which drives fluctuations in DMP models.

PROPOSITION 3 (Volatility and mean-median asymmetry in levels). Consider a mean-median-preserving spread $\Delta$ in the distribution of market tightness with stochastic equilibrium, $\theta_{s}=\theta_{s_{m}}+\frac{\left(s-s_{m}\right)}{\left(\mathcal{S}-s_{m}\right)} \cdot \Delta$, for $s \in\{1, \ldots, \mathcal{S}\}$ and $\Delta>0$. In any stochastic equilibrium consistent with a constant exogenous rate of job destruction, as $\Delta$ increases, the unconditional distribution of employment rate, job-finding rate, vacancies and log of output become more negatively skewed.

Proof. See Appendix C. 
Notice that by construction $\Delta$ does not affect the symmetry of the distribution of the tightness ratio, but it controls its range of variation. Hence, Proposition 3 characterizes a tight link between volatility and asymmetry in levels. Notice also that the proposition is built on the properties of the key endogenous variable of the model, i.e., market tightness, implying that any mechanism, be it exogenous or endogenous, raising the volatility of the tightness ratio also affects the asymmetry properties of the model. Specifically, more volatility induces more asymmetry in levels. Figure 8 shows a numerical example of the analytical results stated in Proposition 3.
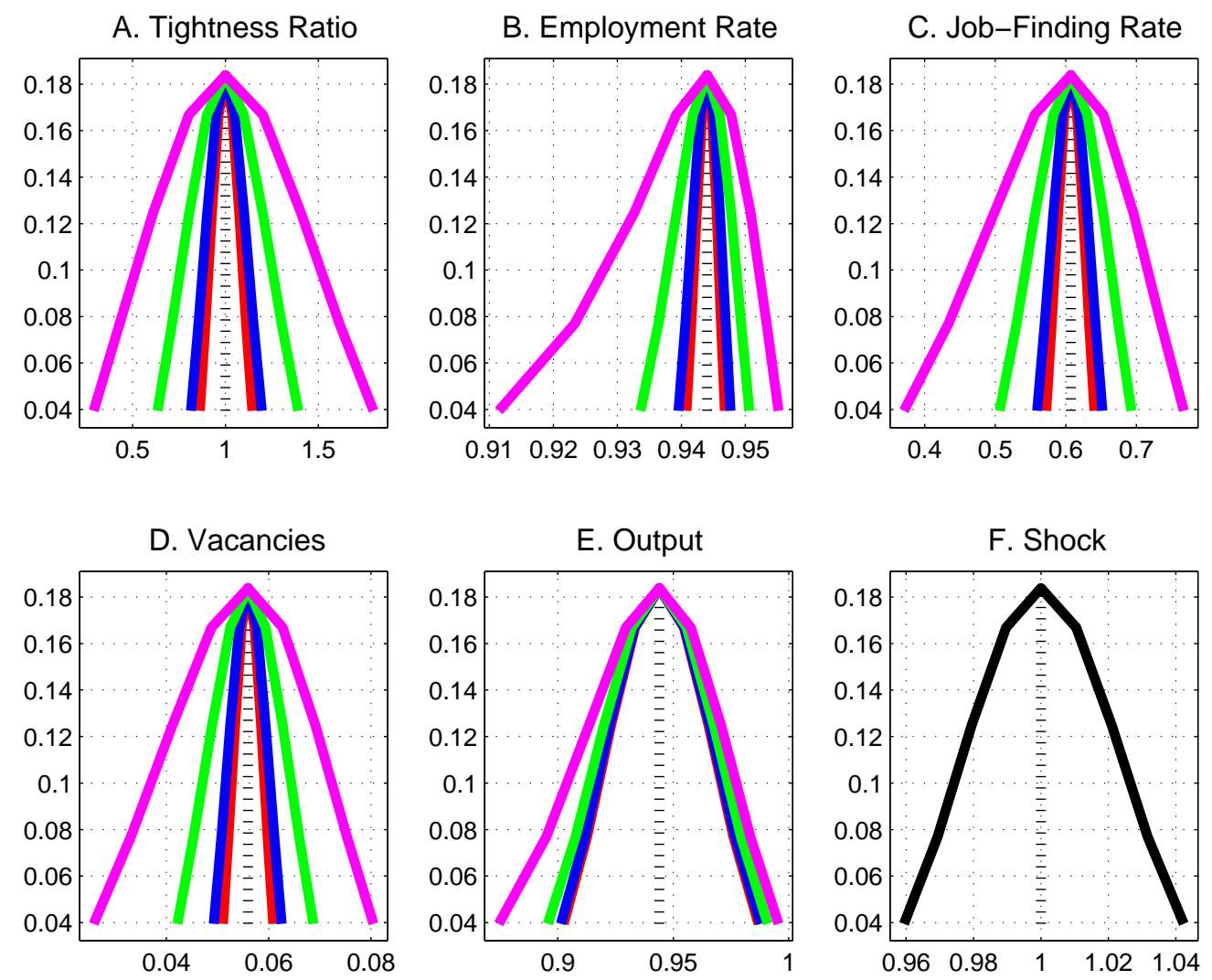

Figure 8: Probability Distributions under Stochastic Equilibrium

Notes: The unconditional probability distributions are computed numerically. Details of the calibration are in Table B.5 in Appendix B. Given the calibrated volatility of aggregate shocks, to induce greater dispersion in the distribution of the tightness ratio, I progressively increase the value of the worker's outside option, $\lambda$. Specifically, I use $\lambda=73 \%$ of mean wage (red line), $\lambda=80 \%$ of mean wage (blu line), $\lambda=90 \%$ of mean wage (green line), and $\lambda=95 \%$ of mean wage (purple line). In each case, I calibrate the cost of posting a vacancy to match the same median value of the variable over all $\lambda$ 's calibration. The vertical dashed line denotes the median value of the variable. 
In Figure 8, the inner distributions (red lines) are associated to the least volatile tightness ratio. The outer distributions (purple lines) are associated instead to the most volatile tightness ratio. Two features of the theoretical distributions are worth further explanation. First, in Panel A, notice that despite an evident increase in volatility, the distributions of tightness ratios preserve a substantial symmetry. This happens because the tightness ratio is approximately linear in the shock, see Panel A in Figure 9. Second, as the dispersion in the distribution of the tightness ratio increases, the distributions of the endogenous variables become increasingly left-skewed. This happens because employment rate, job-finding rate, vacancies and output are concave functions of the tightness ratio, see Figure 9. Notice that asymmetries arise with perfectly symmetric shocks, see Panel F in Figure 8.

I next characterize the properties of the endogenous variables in first-differences.

PROPOSITION 4 (Mean-median asymmetry in first-differences). Consider the stochastic equilibrium of a generic variable of the model $\tilde{x}_{s}$, for $s \in\{1, \ldots, \mathcal{S}\}$. At any equilibrium of the model consistent with a constant exogenous rate of job destruction: (i) if the support of the distribution of $\tilde{x}_{s}$ is symmetric around the median, $\tilde{x}_{s_{m}}$, then the unconditional distribution of $\Delta \tilde{x}_{s, s \prime}$ is symmetric; (ii) if the support of the distribution of $\tilde{x}_{s}$ has a longer left tail, then the unconditional distribution of $\Delta \tilde{x}_{s, s}$ is right-skewed; and (iii) if the support of the distribution of $\tilde{x}_{s}$ has a longer right tail, then the unconditional distribution of $\Delta \tilde{x}_{s, s}$ is left-skewed.

Proof. See Appendix C.

Tables B.6 and B.7 show numerical results which further strengthen the theoretical predictions of this section. The numerical analysis is based on two alternative calibrations of the worker's outside option. In the first calibration, which I refer to as Hall and Milgrom (2008)-type calibration, the worker's outside option amounts to $73 \%$ of steady-state wage. In the second calibration, which I refer to as Hagedorn and Manovskii (2008)-type calibration, I set the worker's outside option to $95 \%$ of steady-state wage. It is well-known that a textbook DMP model with a Hall-Milgrom-type calibration fails to generate realistic amplification in response to exogenous impulses. On the other hand, Hagedorn-Manovskii-type calibrations greatly help the standard model to generate realistic unemployment fluctuations. The numerical results in Appendix B suggest that a textbook DMP model with a constant exogenous rate of job destruction cannot account for the asymmetry properties of the data irrespective of its ability to generate realistic volatility. 
A. Tightness Ratio

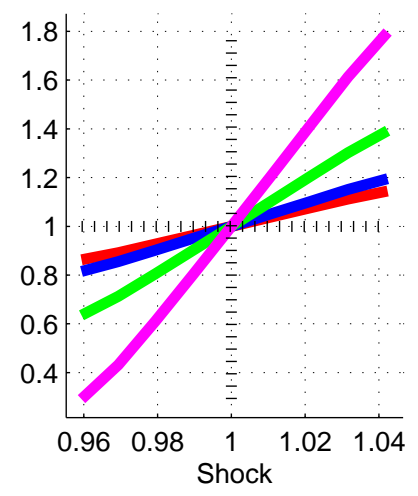

D. Vacancies

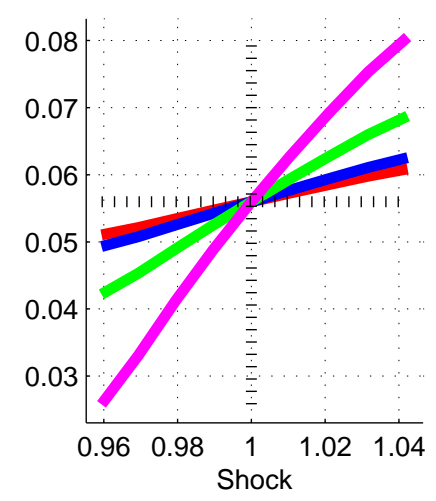

B. Employment Rate

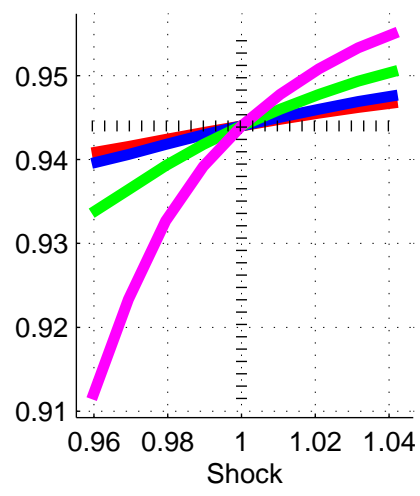

E. Output

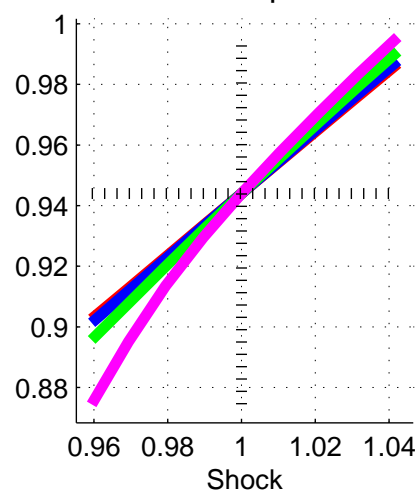

C. Job-Finding Rate

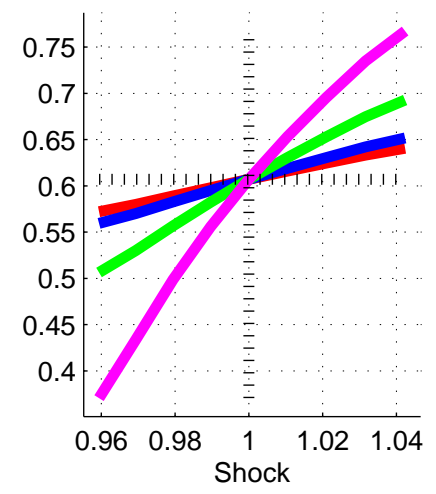

\section{Figure 9: Policy Rules under Stochastic Equilibrium}

Notes: Policy rules are computed numerically. Details of the calibration are in Table B.5 in Appendix B. Given the calibrated volatility of aggregate shocks, to induce greater dispersion in the distribution of the tightness ratio, I progressively increase the value of the worker's outside option, $\lambda$. Specifically, I use $\lambda=73 \%$ of mean wage (red line), $\lambda=80 \%$ of mean wage (blu line), $\lambda=90 \%$ of mean wage (green line), and $\lambda=95 \%$ of mean wage (purple line). In each case, I calibrate the cost of posting a vacancy to match the same median value of the variable over all $\lambda$ 's calibration. The vertical dashed line denotes the median value of the aggregate shock. 


\section{Quantitative Analysis}

In this section, I assess the quantitative properties of the model.

\subsection{Calibration}

The model is calibrated at the monthly frequency, as summarized in Table 3. The discount rate is set to $\beta=0.9959$ to accord with an annual risk-free interest rate of $5 \%$. I next discuss calibration of the labor-market parameters: $\alpha$ and $\mu$ for the matching function, worker's Nash-bargaining weight, $\eta$, vacancy costs, $k(x)$, exogenous and constant job destruction rate, $\delta$, and worker's outside option, $\lambda$. Relative to the standard DMP model, the model adds a number of new parameters: $x_{j}$, for $j=1, \ldots, M$.

Table 3: Calibration

\begin{tabular}{llcc}
\hline \hline & Interpretation & Value & Source/Target \\
\hline$\beta$ & Discount factor & 0.9959 & $5 \%$ annual interest rate \\
$\delta$ & Separation rate & 0.0189 & JOLTS, 2001:M1-2011:M9 \\
$k(x)$ & Vacancy cost & {$[0.0005, \ldots, 0.3359]$} & $\theta(x)=1$ when $z=1$ \\
$\alpha$ & Matching function: $m(v, u)=\mu v^{\alpha} u^{1-\alpha}$ & 0.4 & Brügemann (2008) \\
$\mu$ & Matching function scale & 0.33 & Median unemployment rate of 5.6\% \\
$\eta$ & Worker Nash-bargaining weight & 0.6 & Hosios (1990)'s condition \\
$\lambda$ & Flow value of unemployment & 0.44 & $62 \%$ of mean wage rate \\
$\ln \left(x_{180} / x_{20}\right)$ & Productivity dispersion, $90-10$ pctl range & 0.651 & Syverson (2011) \\
$\rho_{z}$ & Autocorrelation of exogenous state & 0.9642 & LPC, 1948:Q1-2011:Q3 \\
$\sigma_{\epsilon}$ & Standard deviation of shocks & 0.0055 & LPC, 1948:Q1-2011:Q3 \\
\hline \hline
\end{tabular}

I assume a Cobb-Douglas matching function, such that the job-finding rate, $\phi(\theta)$, and job-filling rate, $\rho(\theta)$, are in the following relation, $\phi(\theta)=\theta \rho(\theta)=\mu \theta^{\alpha}$. A large literature that directly estimates the aggregate matching function, provides a range of estimates for the parameter $\alpha$. Petrongolo and Pissarides (2001) establish a plausable range of 0.3-0.5. Brügemann (2008) obtains a refined range of 0.37-0.46. I specify $\alpha=0.4$ at the mid point of these ranges. For comparability with previous work, I specify the parameter of the Nashbargaining problem as $\eta=1-\alpha$ such that the Hosios (1990)'s condition is met and the decentralized equilibrium is efficient. I refer to Shimer (2005) for further details. 
I set the matching function scale to $\mu=0.33$ such that the model-implied median unemployment rate equals $5.6 \%$, which matches the median unemployment rate in the U.S. data for 1948:Q1-2011:Q3. The seasonally-adjusted monthly U.S. unemployment rate series is constructed by the BLS from the CPS. I set the constant exogenous rate of job destruction to $\delta=0.0189$, which is the average quit rate in the U.S. data for 2001:M1-2011:M9. The seasonally-adjusted monthly series for total quits to employment in the nonfarm business sector is constructed by the BLS from JOLTS.

I choose to target a $\mathrm{v}-\mathrm{u}$ ratio of 1 in each submarket, which requires setting vacancy costs to $k(x) \in[0.0005, \ldots, 0.3359]$. This calibration strategy implies that the cost to post a vacancy is (approximately) linearly increasing in skills, i.e., $k(x)=k x$. This is broadly consistent with the empirical evidence reported by Hamermesh and Pfann (1996).

I assume that workers' productivity distribution is uniform, satisfying $x_{1}=\underline{x}, x_{M}=\bar{x}$, and $x_{j}-x_{j-1}=(\bar{x}-\underline{x}) / M$. Thus, $j=M$ is the most productive, and $j=1$ is the least productive submarket. I choose $M=200$ and normalize $\bar{x}=1$. For the lower bound, I set $\underline{x}=0.44$, such that the submarket at the 90 th percentile of the distribution is twice as productive as the submarket at the 10th percentile, $\ln \left(x_{180} / x_{20}\right)=0.651$. Syverson $(2011)$ finds productivity differences of this order of magnitude within four-digit SIC industries in the U.S. manufacturing sector.

I set the flow value of unemployment to $\lambda=0.44$ such that all submarkets feature positive match surpluses in steady-state $\left(z_{s_{m}}=1\right.$ in my normalization), as such steadystate unemployment is all frictional. This calibration implies an average replacement ratio of $62 \%$, which is a value smaller than those used in Hall and Milgrom (2008), Mortensen and Nagypal (2007) and Pissarides (2000), and much smaller than Hagedorn and Manovskii (2008)'s calibration. In this regard, this paper's calibration is a conservative one.

Calibration of the worker's outside option, $\lambda$, deserves further explanation. The assumption that $\lambda$ is the same across workers of different skills implies that replacement ratios, i.e., $\lambda$ as percent of the wage, greatly differ across workers' types. This happens because low-skilled workers earn lower wages. Hence, while on average $\lambda$ amounts to $62 \%$ of aggregate wage compensation, there is a spectrum of replacement ratios. In Figure 10, Panel A shows the CDF of replacement ratios. Notice that approximately $5 \%$ of the aggregate labor force features a Hagedorn-Manovskii-type calibration, and approximately $70 \%$ of the labor force have replacement ratios smaller than those implied by a Hall-Milgrom-type calibration. Panel B shows that replacement ratios are decreasing in workers' productivity. Specifically, the 5\% 

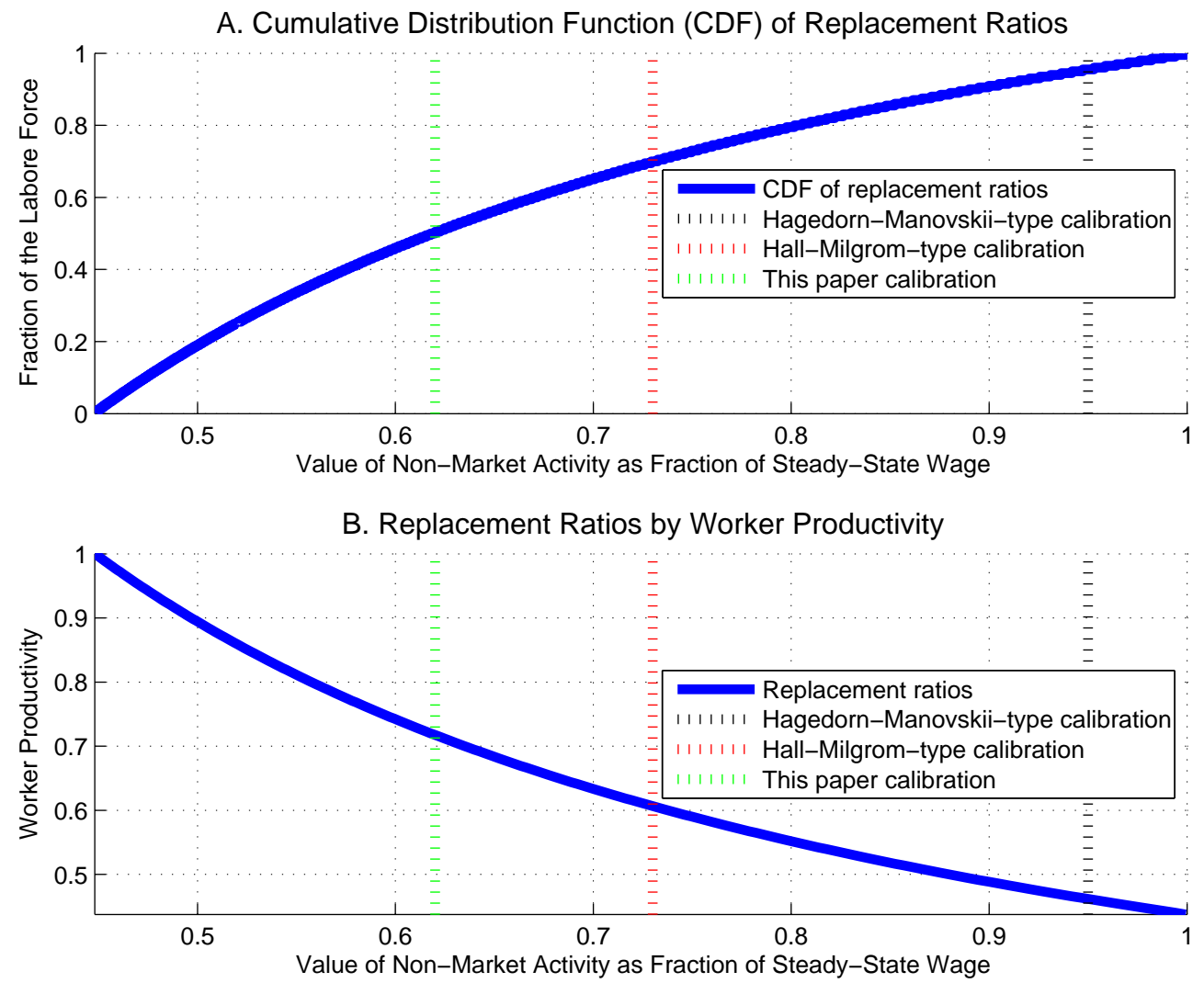

Figure 10: Replacement Ratios

Notes: In Hall-Milgrom-type calibration, the worker's outside option is set to $73 \%$ of steadystate wage. In Hagedorn-Manovskii-type calibration, the worker's outside option is set to $95 \%$ of steady-state wage. In this paper calibration, the worker's outside option is set to $62 \%$ of steady-state wage. See Table 3 for further details on calibration. 
of Hagedorn-Manovskii-type of workers are the least productive in the labor force. These low-skilled workers are the ones benefiting relatively less from being employed and always at risk of layoff. They are necessarily marginal workers in that they are almost indifferent to work in the labor market and enjoy the value of non-market activities.

Finally, I calibrate the exogenous stochastic process for labor productivity, which is the only driving force of fluctuations. I estimate an AR(1) process for the HP-filtered seasonallyadjusted quarterly real output per worker in the nonfarm business sector constructed by the BLS from the LPC release, for 1948:Q1-2011:Q3: $\ln \left(z_{t+1}\right)=\rho_{z} \ln \left(z_{t}\right)+\sigma_{\epsilon} \epsilon_{t+1}$ with

$\epsilon_{t} \stackrel{\text { iid }}{\sim} \mathcal{N}(0,1)$. The HP-filter smoothing parameter is $10^{5}$. With quarterly data, we obtain an autocorrelation of $\hat{\rho}_{z}=0.8963$ and a residual standard deviation of $\hat{\sigma}_{\epsilon}=0.0091$, which yields $\hat{\rho}_{z}=0.8963^{1 / 3}=0.9642$ and $\hat{\sigma}_{\epsilon}=0.0055$ at monthly frequency. Following Tauchen (1986), I approximate the continuous-valued $\mathrm{AR}(1)$ process for $\ln \left(z_{t}\right)$ through a $\mathcal{S}$-state Markov chain, having a discrete state space $\left\{z_{1}, \ldots, z_{\mathcal{S}}\right\}$ and transition probabilities $\pi_{s, s^{\prime}}=$ $\operatorname{Pr}\left\{z_{t+1}=z_{s^{\prime}} \mid z_{t}=z_{s}\right\}$. I set the number of grid points for the state space to $\mathcal{S}=9$.

\subsection{Simulated Moments}

In this section, I assess the quantitative performance of the model by comparing important simulated moments to their empirical counterparts in the U.S. data. I contrast two versions of the model which differ for the calibration of the lower bound of the workers' productivity distribution: (1) endogenous job destruction (EJD) model. In this case, $\underline{x}=0.438$, and the model features an endogenous rate of job destruction as in (10); (2) constant job destruction (CJD) model. In this case, $\underline{x}=0.455$, and endogenous job separations never occur in equilibrium. Notice that the CJD model can be seen as a collection of standard DMP models with constant exogenous rates of job destruction and cross-sectional dispersion of total match surpluses, i.e., $S_{s}(\underline{x})<S_{s}\left(x_{2}\right)<\ldots<S_{s}(\bar{x})$. Comparing these two versions of the model highlights the key ingredients for the quantitative success of the model.

\subsubsection{Volatility and Comovement in U.S. Data and Model}

Table 4 shows standard deviations (relative to labor productivity) and correlations for labormarket variables in the model and U.S. data. Panel A forcefully shows that the EJD model generates fluctuations in the unemployment rate, vacancies and job-finding rates that are comparable to those in the U.S. data. The EJD model outperforms the CJD model in any dimension. In this regard, the results for the CJD model confirm the previous negative findings 
on the inability of the standard DMP model to amplify exogenous impulses. The findings suggest that key for the amplification properties of the model is the selection mechanism which drives endogenous job destruction and job creation.

In Table 4, Panel B shows comovements between labor-market variables. Except for the correlation between vacancies and unemployment (Beveridge curve), the EJD model outperfomrs the CJD model. However, it still produces correlations of unemployment, jobfinding rates and vacancies with labor productivity that are too high (in absolute value) compared to the data. The success of the CJD model in replicating the empirical Beveridge curve is not surprising given its resemblance to a textbook DMP model. Shimer (2005) shows that the Berveridge curve is the only quantitative success of a textbook DMP model.

To understand the comovement between vacancies and unemployment, Figure 11 shows lead-lag correlations, where the current period unemployment rate is associated with future and lagged values of vacancies up to four quarters. First observe that a large value of contemporaneous correlation between unemployment and vacancies observed in the U.S. data, -0.858 , is reasonably close to the value generated by the model of -0.561 . The model preserves a downward-sloping Beveridge curve. A well-known criticism to models with endogenous job separations à la Mortensen and Pissarides (1994), is their counterfactual implications for the Beveridge curve. These models produce a strong positive correlation of unemployment with vacancies, whereas in the U.S. data this correlation is strongly negative at business cycle frequencies. With respect to the lead-lag relationship, the data suggest some tendency for vacancies to lead unemployment. ${ }^{16}$ Qualitatively, this pattern is captured well in the model. This reflects the mechanics of the model, wherein the search friction produces some lagged response in unemployment after the response in vacancy posting. In Mortensen and Pissarides's type of models, in contrast, the feedback from the movement of the separation rate into vacancy posting erases this feature, generating the tendency that unemployment leads vacancies.

\subsubsection{Asymmetry in U.S. Data and Model}

Table 5 contrasts the model with the asymmetry properties of the data. The EJD model generates asymmetries in employment, output and job-finding rates comparable to those observed in the data. Not surprisingly, given the results in Section 3.8, the CJD model completely fails to do so. Remarkably, the EJD model is also able to replicate the disconnect

\footnotetext{
${ }^{16}$ Correlations between lagged values of vacancies and current unemployment tend to be larger (in absolute value) than those between future values of vacancies and current unemployment.
} 
Table 4: Volatility and Comovement in U.S. Data and Model

\begin{tabular}{lccc}
\hline \hline & Data & EJD Model & CJD Model \\
\hline A. Volatility & & & \\
$s d(u) / s d(p)$ & 9.851 & 9.051 & 1.327 \\
$s d(\phi) / s d(p)$ & 7.213 & 9.232 & 1.491 \\
$s d(v) / s d(p)$ & 8.131 & 5.464 & 2.484 \\
B. Comovement & & & \\
$\operatorname{corr}(u, v)$ & -0.858 & -0.561 & -0.812 \\
$\operatorname{corr}(u, p)$ & -0.412 & -0.773 & -0.912 \\
$\operatorname{corr}(\phi, p)$ & 0.383 & 0.824 & 0.996 \\
$\operatorname{corr}(v, p)$ & 0.433 & 0.830 & 0.978 \\
\hline \hline
\end{tabular}

Notes: The seasonally-adjusted unemployment rate, $u$, is from the CPS survey of the BLS. Survey home page http://www.bls.gov/cps/. Labor productivity, $p$, is seasonally-adjusted quarterly real output per worker in the nonfarm business sector constructed by the BLS from the LPC release. Release home page http://www.bls.gov/lpc. The series are downloaded from the FRED website at http://research.stlouisfed.org/fred2/. Job-finding rates, $\phi$, are calculated based on Shimer (2012). Vacancies, $v$, are the composite HelpWanted Index constructed by Barnichon (2010). The variables $u, \phi$, and $v$ are quarterly averages of monthly series. All series cover the period 1948:Q12011:Q3. EJD model refers to the version of the model with endogenous job destruction. CJD model refer to the version of the model with constant and exogenous job destruction. Model simulated data are quarterly averages of 765 observations at the monthly frequency. The statistics reported are averages across 500 replications. All variables are reported in logs as deviations from the HP trend with smoothing parameter $10^{5}$. 


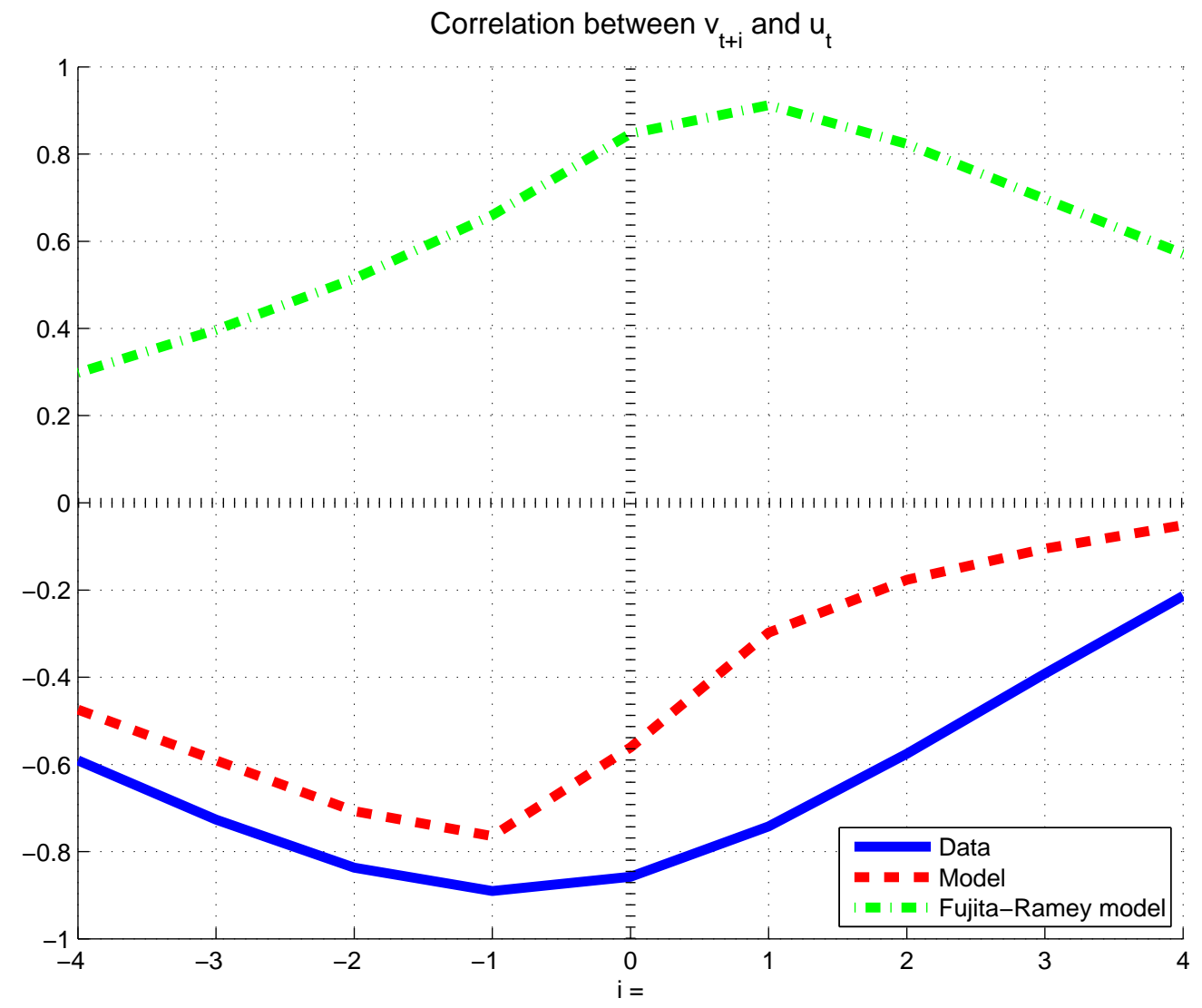

Figure 11: Dynamic Beveridge Curve

Notes: The seasonally-adjusted unemployment rate, $u$, is from the CPS survey of the BLS. Survey home page http://www.bls.gov/cps/. The series is downloaded from the FRED website at http://research.stlouisfed.org/fred2/. Vacancies, $v$, are the composite Help-Wanted Index constructed by Barnichon (2010). Model refers to the EJD model. Fujita-Ramey model refers to a stochastic discrete-time version of Mortensen and Pissarides (1994)'s model as presented in Fujita and Ramey (2012). 
between the asymmetry properties of employment and output, i.e., it generates deep and steep cycles in employment, and deep cycles in output with no steepness.

The model produces counterfactual implications for the asymmetry properties of vacancies, i.e., positive instead of negative skeweness in level and growth rates. These counterfactual predictions are due to the "echo effect" that characterizes the dynamics of vacancies in models with endogenous job separations. After a adverse aggregate shock that induces endogenous destruction of jobs, the pool of unemployed raises, the probability to fill a vacancy increases such that for the employer the expected recruiting cost decreases. This gives to employers strong incentives to post vacancies right at the end of a downturn since it is relatively cheaper to do so. Because in the model vacancies are a jump variable, they react "too much and too fast" to positive changes in the aggregate state coming from a recession causing positive skewness in levels and growth rates.

\subsubsection{What drives asymmetric employment dynamics?}

In this section, I assess the relative contribution of job-finding and job-separation rates to the skewness asymmetry of the employment rate series generated by the model. To this aim, I construct two counterfactual series for the employment rate in the EJD model. Recall that aggregate employment and employment rate are respectively $E_{t}=\sum_{x} e_{t}(x)$ and $e_{t}=E_{t} / M$. The first counterfactual is an employment rate series that only allows for variation in jobfinding rates, $e_{t+1}^{\mathrm{jfr}}=E_{t+1}^{\mathrm{jfr}} / M$, where

$$
E_{t+1}^{\mathrm{jfr}}=E_{t}^{\mathrm{jfr}}+\sum_{x} \phi\left(\theta_{t}(x)\right) u_{t}^{\mathrm{jfr}}(x)-\sum_{x} \delta_{s_{m}}(x) e_{t}^{\mathrm{jfr}}(x),
$$

and $\delta_{s_{m}}(x)=\delta$ are steady-state job-separation rates which are calibrated to be the same across submarkets. The second counterfactual series only allows for variation in jobseparation rates, $e_{t+1}^{\mathrm{jsr}}=E_{t+1}^{\mathrm{jsr}} / M$, where

$$
E_{t+1}^{\mathrm{jsr}}=E_{t}^{\mathrm{jsr}}+\sum_{x} \phi\left(\theta_{s_{m}}(x)\right) u_{t}^{\mathrm{jsr}}(x)-\sum_{x} \delta_{t+1}(x) e_{t}^{\mathrm{jsr}}(x)
$$

and $\phi\left(\theta_{s_{m}}(x)\right)=\mu$ are steady-state job-finding rates which are calibrated to be the same across submarkets. Which counterfactual series better accounts for the asymmetry properties of the employment rate? Recall I asked the same question in Section 2 for the actual U.S. employment rate. Answering this question allows us to disentangle the contribution of jobfinding and separation rates to the skewenss in levels and growth rates. In Table 6, Panel A 
Table 5: Asymmetry in U.S. Data and Model

\begin{tabular}{lccc}
\hline \hline & Data & EJD Model & CJD Model \\
\hline A. Skewness in levels & & & \\
Skew $(e)$ & $-0.591^{* * *}$ & -0.877 & -0.254 \\
$\operatorname{Skew}(y)$ & $-0.345^{* *}$ & -0.246 & -0.013 \\
$\operatorname{Skew}(\phi)$ & $-0.249^{* *}$ & -0.922 & -0.230 \\
$\operatorname{Skew}(v)$ & $-0.469^{* * *}$ & 0.542 & -0.130 \\
$\operatorname{B.Skewness}$ in growth rates & & & \\
$\operatorname{Skew}(\Delta e)$ & $-0.958^{* * *}$ & -0.794 & 0.044 \\
$\operatorname{Skew}(\Delta y)$ & -0.170 & -0.055 & 0.005 \\
$\operatorname{Skew}(\Delta \phi)$ & $0.235^{* * *}$ & 0.319 & 0.042 \\
$\operatorname{Skew}(\Delta v)$ & $-0.613^{* * *}$ & 0.670 & 0.044 \\
\hline \hline
\end{tabular}

Notes: The seasonally-adjusted unemployment rate, $u$, is from the CPS survey of the BLS. Survey home page http://www.bls.gov/cps/. Labor productivity, $p$, is seasonallyadjusted quarterly real output per worker in the nonfarm business sector constructed by the BLS from the LPC release. Release home page http://www.bls.gov/lpc. Output, $y$, is industrial production (IP). The series are downloaded from the FRED website at http://research.stlouisfed.org/fred2/. Job-finding rates, $\phi$, are calculated based on Shimer (2012). Vacancies, $v$, are the composite Help-Wanted Index constructed by Barnichon (2010). The variables $u, \phi$, and $v$ are quarterly averages of monthly series. All series cover the period 1948:Q1-2011:Q3. EJD model refers to the version of the model with endogenous job destruction. CJD model refers to the version of the model with constant and exogenous job destruction. Model simulated data are quarterly averages of 765 observations at the monthly frequency. The statistics reported are averages across 500 replications. In Panel A, all variables are reported in logs as deviations from the HP trend with smoothing parameter $10^{5}$. In Panel $\mathrm{B}$, all variables are reported as 3 -months log-differences. ${ }^{* * *}$, ** denote statistical significance at respectively $1 \%$ and $5 \%$ level. 
shows that both margins of the labor market, i.e., job-finding and job-separation rates, are jointly responsible for the skewness in levels of the employment rate. This prediction hold in U.S. data (see Fact 3 in Section 2).

Table 6: Asymmetry in Employment Rate Counterfactuals

\begin{tabular}{lll}
\hline $\mathrm{x}$ & $e^{\mathrm{jfr}}$ & $e^{\mathrm{jsr}}$ \\
\hline
\end{tabular}

A. Skewness in levels

$\operatorname{Skew}(x) \quad-0.877 \quad-0.937 \quad-1.068$

B. Skewness in growth rates

\begin{tabular}{llll}
$\operatorname{Skew}(\Delta x)$ & -0.794 & 1.691 & -1.075 \\
\hline \hline
\end{tabular}

Notes: EJD model simulations are 765 observations at the monthly frequency. The statistics reported are averages across 500 replications. $e$ is the employment rate (fraction of the labor force working in a given month, one minus the unemployment rate), $e^{\mathrm{jfr}}$ is the counterfactual employment rate series with job-separation rates fixed at steady-state values, and $e^{\text {jsr }}$ is the counterfactual employment rate series with job-finding rates fixed at steady-state values. In Panel A, all variables are quarterly averages reported in logs as deviations from the HP trend with smoothing parameter $10^{5}$. In Panel B, all variables are reported as 3 -months log-differences.

Panel B shows that in the model, job-separation rates are the only responsible for negative skewness in growth rates. Moreover, when the dynamics are only driven by job-finding rates, the model generates positive instead of negative skewness in growth rates. Importantly, these model predictions hold in the data (see Fact 4 in Section 2). To summarize, this section strengthens the results in Section 4.2.2 in that it shows the model is able to replicate not only the skewness asymmetry in employment but also the asymmetry properties implied by job-finding and separation rates.

\subsubsection{What drives asymmetric output dynamics?}

To understand what drives the disconnect between the asymmetry properties of employment and output, Table 7 shows statistics for the skewness in levels and growth rates for each output component simulated from the EJD model. In the model, aggregate output is 


$$
Y_{t}=\sum_{x} y_{t}(x)=z_{t} \cdot \sum_{x} x e_{t}(x)
$$

where $z_{t}$ is the exogenous aggregate shock, and $\sum_{x} x e_{t}(x)$ is a quality-adjusted measure of aggregate employment, which is a weighted average of worker-specific employment rates with weights equal to workers' types $x \in\left\{x_{1}<\ldots<x_{M}\right\}$. In Table 7 , the column labeled $Y$ reproduces the skewness statistics for aggregate output in Table 5. As discussed in Section 4.2 .2 , in the model as in the data, aggregate output displays negative skewness in levels with nearly no skewness in growth rates. Recall that the aggregate state $z_{t}$ is by assumption a symmetric Markov process, as such simulated shocks display (approximately) zero skewness both in levels and growth rates. Note that quality-adjusted employment, $\sum_{x} x e(x)$, displays negative skewness in levels and growth rates. Hence, it inherits the asymmetry properties of aggregate employment (see Table 5).

Table 7: Asymmetry in Output and its Components

\begin{tabular}{lccc}
\hline \hline & $Y$ & $z$ & $\sum_{x} x e(x)$ \\
\hline A. Skewness in levels & -0.246 & 0.000 & -0.858 \\
B. Skewness in growth rates & -0.055 & 0.000 & -0.761 \\
\hline \hline
\end{tabular}

Notes: EJD model simulated data are quarterly averages of 765 observations at the monthly frequency. The statistics reported are averages across 500 replications. In Panel A, all variables are reported in logs as deviations from the HP trend with smoothing parameter $10^{5}$. In Panel B, all variables are reported as 3-months log-differences.

The results in Table 7 suggest the reason why aggregate output behaves more symmetrically than employment is that aggregate shocks are symmetric and hit the production function directly.

\subsection{Impulse Response Functions}

In this section, I discuss key properties of the model by the means of impulse response functions (IRFs). I derive the dynamic response to a productivity shock by comparing the expected paths of two economies. The first economy starts with the level of the endogenous variable associated with the median state but is in the state below (above) the median state. 
The second economy starts with the same level of the endogenous variable and is in the median state. The difference between the two paths is the response over time to a negative (positive) impulse, which is the transition from the median to lower (higher) states that occured at time zero. I report the average response across 5,000 replications. Critically, the size of the positive and negative shock is the same. Figure 12 shows the responses of labor-market variables to a negative (solid line) and positive (dashed line) impulse. I flip the sign of the response to a positive impulse (dashed line) such that both responses lie in the same quadrant. Panel D shows the responses of the exogenous aggregate shock, which is by assumption a symmetric stochastic process.
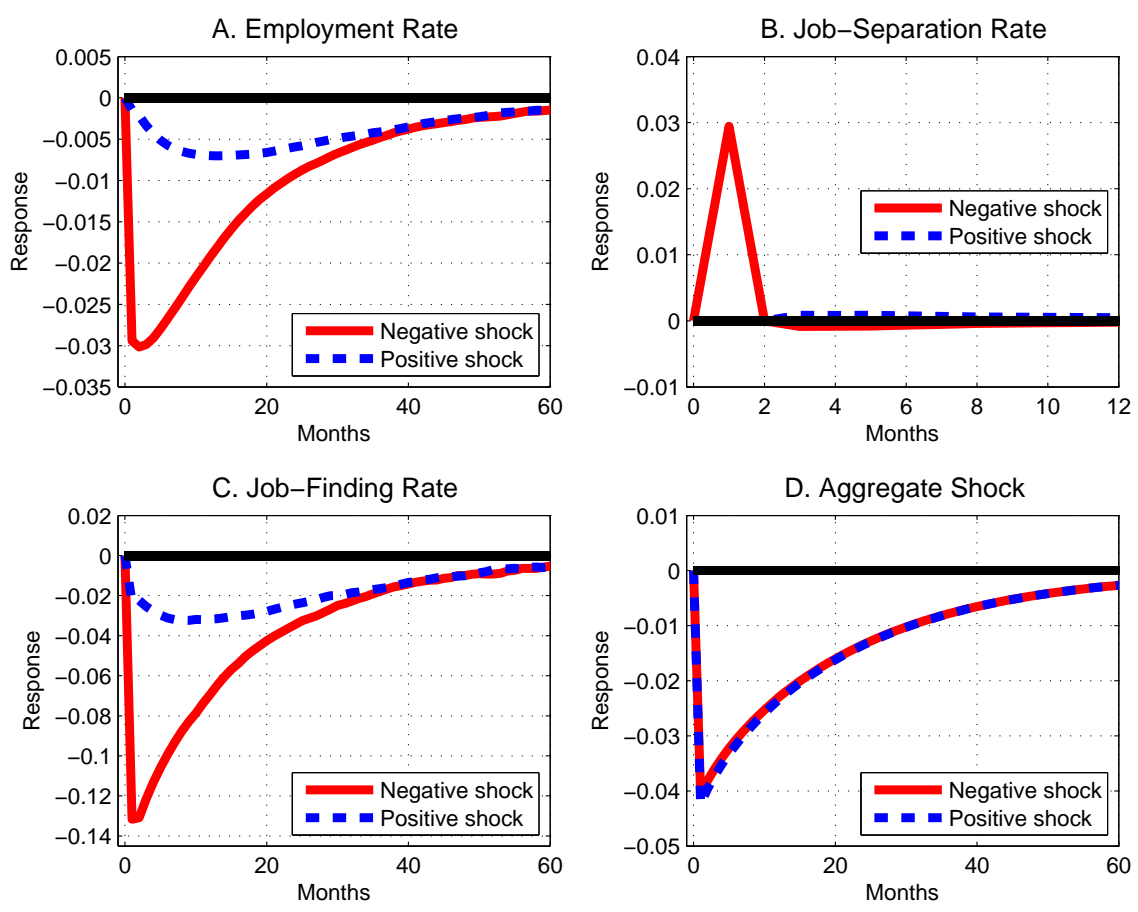

Figure 12: Impulse Responses for the Employment Rate

In Figure 12, Panel A shows that the employment rate's response to shocks is strongly asymmetric, with the response to a negative impulse being stronger than the response to a positive impulse. What is driving the asymmetric dynamics of the employment rate? Suppose at time $t=0$ the economy rests at the median state $\left(z_{s_{m}}=1\right.$ in my normalization), and a negative shock realizes. The immediate response of the model economy is a burst of job destruction which leads a spike in the aggregate separation rate, see Panel B. The endogenous job destruction margin is the one contributing more to the speed at which the employment rate reaches the trough of the response. At this stage, the aggregate job-finding rate plays 
a minor role in the dynamics. After the trough of the response is reached, the dynamics are governed by a low aggregate job-finding rate which determines the slow recovery towards the initial state. At this stage, job rationing is at work. The employment rate's response to a positive shock is driven only by a high aggregate job-finding rate. In this case, the forces driving the dynamics are the same as those of a standard DMP model with a constant job-separation rate. Panel $\mathrm{C}$ shows that the IRFs of the aggregate job-finding rate are also strongly asymmetric. The aggregate job-finding rate falls in response to a negative impulse much farther than it raises in response to a positive impulse. This asymmetric response comes from the direct effect that endogenous job destruction exerts on the aggregate jobfinding rate. After a negative shock, job-finding probabilities of all workers fall, however, they drop disproportionally more for low-skilled workers previously fired which are overrepresented in the group flowing into unemployment. Notice that the asymmetric behavior of the labor market comes entirely from the mechanics of the model. Panel D shows that the IRFs of the exogenous aggregate shock are fully symmetric. In the model, aggregate output is $Y_{t}=\sum_{x} y_{t}(x)=z_{t} \cdot \sum_{x} x e_{t}(x)$. Labor productivity, $Y_{t} / E_{t}$, consists of an exogenous and endogenous component,

$$
\frac{Y_{t}}{E_{t}}=\underbrace{z_{t}}_{\begin{array}{c}
\text { Aggregate } \\
\text { shock }
\end{array}} \cdot \underbrace{\frac{\sum_{x} x e_{t}(x)}{\sum_{x} e_{t}(x)}}_{\text {"Composition effect" }}
$$

The first term on the right hand side of equation (22) is the exogenous aggregate shock, $z_{t}$. The second term on the right hand side - "composition effect" - is a skill-adjusted measure of employment, which is an endogenous variable. Figure 13 shows the impulse responses for output, labor productivity, and the composition effect.

In Figure 13, Panel A shows that output contracts deeper after a negative impulse than it expands after a positive shock, i.e., the trough (in absolute value) exceeds the peak. However, besides the peak-trough asymmetry, the impulse responses are more symmetric if compared to those of the employment rate (see Panel A in Figure 12). Panel B shows the response of labor productivity. The sharp fall in employment after a negative impulse is muted by the endogenous response of labor productivity, which tends to fall by less because of the composition effect. Panel $\mathrm{C}$ shows that the composition effect's responses to shocks are strongly asymmetric. It reacts much stronger to a negative than to a postive impulse. Specifically, it raises more in response to a negative impulse than it falls after a positive 

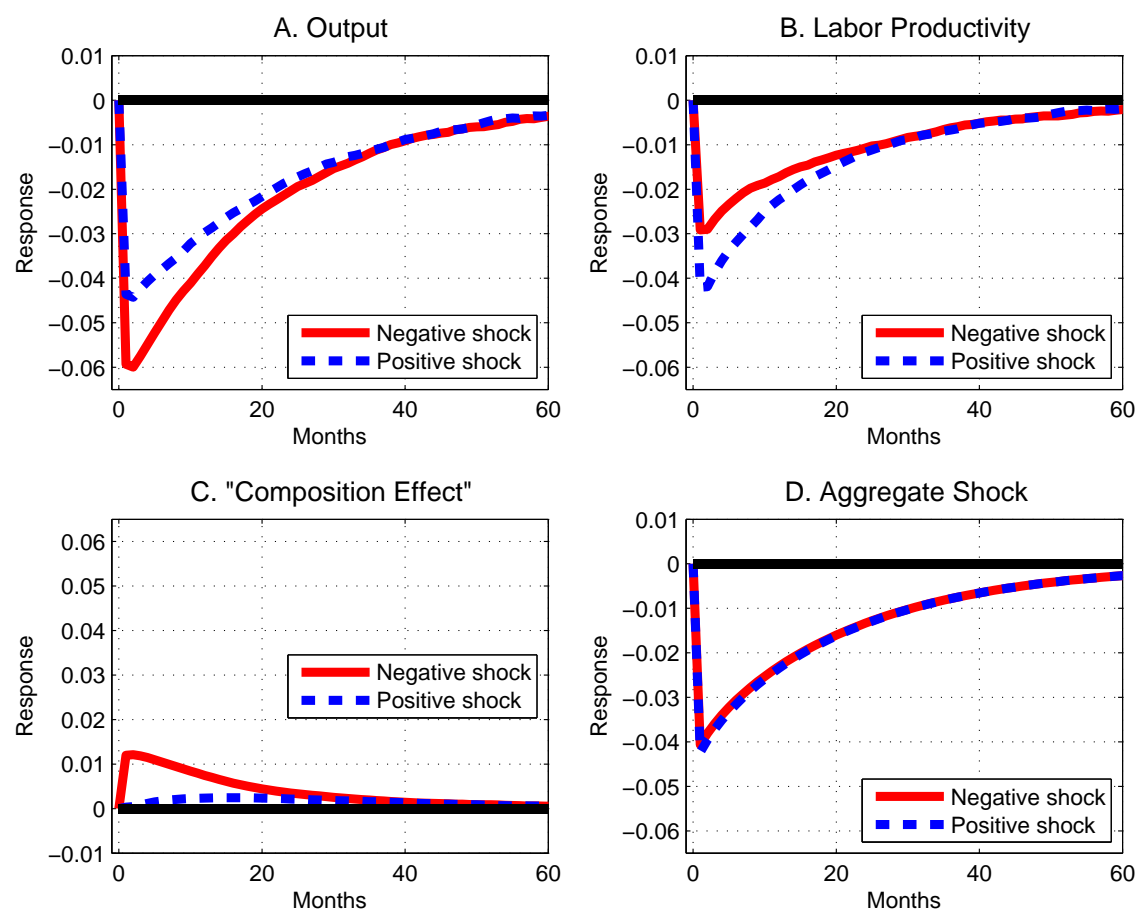

Figure 13: Impulse Responses for Output

impulse. After a negative impulse, low-skilled workers are laid off, a disproportionate part of the employed pool consists of high-skilled workers. This selection mechanism causes skilladjusted employment to raise sharply. After a positive impulse instead, no endogenous job destruction occurs, a disproportionate part of the employed pool consists of low-skilled workers. In this case, the composition effect causes skill-adjusted employment to smoothly decrease.

\section{Labor-Market Fluctuations at the Micro Level}

The model highlights the crucial role of low-skilled workers in shaping cyclical movements in aggregate unemployment. As a by-product, the model provides stark predictions for the time series of skill-specific unemployment rates. Precisely, low-skilled workers experience (i) higher average unemployment rates and (ii) they account for most of the variation in aggregate unemployment. In this section, I use CPS micro data for the period 1976:M12013:M2 and test this prediction. Specifically, the goal is to investigate whether there are relatively unskilled groups of workers that contribute disproportionately more to the large fluctuations of the U.S. labor market. 
Clearly, the identification of worker's abilities in the data is challenging. However, a large empirical literature in the tradition of Mincer (1974)'s work, has identified experience and education as important drivers of wage differentials. Hence, to the extent to which actual wages reflect workers' marginal product, one can arguably think of age and education as good proxies for worker-specific productivity on the job. Following the lead of this literature, I consider unemployment rates by age and education groups and investigate whether their time series properties accord with the predictions of the model. To this aim, I consider 6 age groups (16-24, 25-34, 35-44, 45-54, 55-64, 65 and over) and 3 education levels (High school dropouts, HSD, High school graduates joint with some college, HSG/SC, and College graduates and post-college degree holders, CGPC). As such there are 18 age/education groups. The first row of Table 8 reports average unemployment rates for different age groups.

Table 8: Average Unemployment Rates by Age Group

\begin{tabular}{lcccccc}
\hline \hline & $16-24$ & $25-34$ & $35-44$ & $45-54$ & $55-64$ & $65+$ \\
\hline Percent (\%) & 12.90 & 6.16 & 4.64 & 4.09 & 3.92 & 3.83 \\
Normalized & 3.16 & 1.51 & 1.14 & 1 & 0.96 & 0.94 \\
\hline \hline
\end{tabular}

Notes: Data are from the CPS micro files for 1976:M1-2013:M2 and downloaded from the NBER website at http://www.nber.org/data/cps_basic.html. Seasonal adjustment is implemented with a 13-term symmetric moving average. The first row shows sample averages of unemployment rates by age in percent. The second row reports average unemployment rates by age relative to that of $45-54$ years old.

Unemployment rates decrease monotonically with age. This fact is well-known, see Gervais et al. (2013). Specifically, the average unemployment rate for the 16-24 years old is $12.9 \%$ and sharply falls to $3.92 \%$ for the 55-64 years old. Note also that the age differences are large. The second row of Table 8 displays the average unemployment rate for each age group relative to that of the 45-54 years old. Over the period 1976:M1-2013:M2, the average unemployment rate for the 16-24 years old was 3.16 times that of the 45-54 years old.

Table 9 displays average unemployment rates for different education groups. Clearly, unemployment rates sharply decrease with education. The average unemployment rate for high-school dropouts is $12.72 \%$ and falls to $2.79 \%$ for workers with the highest educational attainments. Note that the average unemployment rate for HSD is 2 times that of the HSG/SC and as high as 4.56 times that of workers with a college or post-college degree.

Table 10 reports average unemployment rates for different age/education groups. The 
Table 9: Average Unemployment Rates by Education Group

\begin{tabular}{cccc}
\hline \hline & HSD & HSG/SC & CGPC \\
\hline Percent (\%) & 12.72 & 6.10 & 2.79 \\
Normalized & 4.56 & 2.19 & 1 \\
\hline \hline
\end{tabular}

Notes: Data are from the CPS micro files for 1976:M12013:M2 and downloaded from the NBER website at http: //www.nber.org/data/cps_basic.html. HSD, HSG, SC and CGPC denote respectively High School Dropouts, High School Graduates, Some College and College Graduates and Post-College Degree Holders. Seasonal adjustment is implemented with a 13-term symmetric moving average. The first row shows sample averages of unemployment rates by education in percent. The second row reports average unemployment rates by education relative to that of CGPC.

results show that unemployment rates are decreasing in age and education even within groups. Precisely, (i) average unemployment rates decrease monotonically with age after sorting on education levels and (ii) average unemployment rates decrease monotonically with education after sorting on age differences. These facts are important since confirm a tight monotonic link between unemployment rates and skill levels. Note also that age/education differences are large. High-school dropouts in the 16-24 years old group experience an average unemployment rate of $21 \%$ which is 9 times that of the CGPC workers in the $45-54$ years hold group.

Overall, the empirical findings suggest that the U.S. labor market features large differences in average unemployment rates once I sort workers by age and education. These facts are broadly consistent with the predictions of the model. Table 11 displays average unemployment rates by skill/productivity group for artificial data generated by the model. Recall that the index $x \in\left\{x_{1}, \ldots, x_{M}\right\}$ denotes the skill type of the worker which determines her productivity on the job. The model generates large dispersion in average unemployment rates across workers. Specifically, lowest-skilled workers experience an average unemployment rate 8.5 times larger than that of high-skilled workers in the right tail of the productivity distribution, i.e., $\left(x_{7}-x_{200}\right)$ group. Importantly, this dispersion in unemployment rates is the endogenous outcome of the model. I calibrated the unemployment rates to be the same across workers in the median state $\left(z_{s_{m}}=1\right.$ in my normalization). As such these large dif- 
ferences in average unemployment rates come exclusively from the different cyclical behavior of workers with different skills.

I next provide evidence that the young and least-educated workers not only experience higher average unemployment rates but they also contribute disproportionately more to the time series variation of the U.S. unemployment rate.

Table 10: Average Unemployment Rates by Age/Education Group

\begin{tabular}{lcccccc}
\hline \hline & $16-24$ & $25-34$ & $35-44$ & $45-54$ & $55-64$ & $65+$ \\
\hline HSD & 21.01 & 13.02 & 9.46 & 7.57 & 6.08 & 5.08 \\
HSG/SC & 10.45 & 6.60 & 4.87 & 4.09 & 3.82 & 3.77 \\
CGPC & 6.05 & 2.86 & 2.35 & 2.31 & 2.50 & 2.71 \\
& & & & & & \\
& & & & & & \\
HSD & 9.10 & 5.64 & 4.10 & 3.28 & 2.63 & 2.20 \\
HSG/SC & 4.52 & 2.86 & 2.11 & 1.77 & 1.65 & 1.63 \\
CGPC & 2.62 & 1.24 & 1.02 & 1 & 1.08 & 1.17 \\
\hline \hline
\end{tabular}

Notes: Data are from the CPS micro files for 1976:M1-2013:M2 and downloaded from the NBER website at http://www.nber.org/data/cps_basic.html. HSD, HSG, SC and CGPC denote respectively High School Dropouts, High School Graduates, Some College and College Graduates and Post-College Degree Holders. Seasonal adjustment is implemented with a 13-term symmetric moving average. Panel A shows sample averages of unemployment rates by age/education group. Panel B shows average unemployment rates by age/education relative to that of 45-54 years old with CGPC education level.

To this aim, let us decompose the actual U.S. unemployment rate as the sum of unemployed workers sorted in different groups indexed by $x$ divided by the aggregate labor force, $l f_{t} \equiv E_{t}+U_{t}$, such that

$$
u_{t}=\frac{U_{t}}{E_{t}+U_{t}}=\frac{u_{t}\left(x_{1}\right)}{E_{t}+U_{t}}+\frac{u_{t}\left(x_{2}\right)}{E_{t}+U_{t}}+\ldots+\frac{u_{t}\left(x_{M}\right)}{E_{t}+U_{t}}
$$


Table 11: Average Unemployment Rates by Skill/Productivity Group

\begin{tabular}{cccccccc}
\hline \hline & $x_{1}$ & $x_{2}$ & $x_{3}$ & $x_{4}$ & $x_{5}$ & $x_{6}$ & $\left(x_{7}-x_{200}\right)$ \\
\hline Percent (\%) & 46.35 & 34.15 & 32.94 & 21.17 & 12.92 & 12.13 & 5.43 \\
Normalized & 8.54 & 6.29 & 6.07 & 3.90 & 2.38 & 2.23 & 1 \\
\hline \hline
\end{tabular}

Notes: The statistics reported are average unemployment rates in the EJD model by skill/productivity group averaged across 500 replications. The second row reports average unemployment rates by skill/productivity relative to that of $\left(x_{7}-x_{200}\right)$ group.

where $U_{t}=\sum_{x} u_{t}(x)$ and $E_{t}=\sum_{x} e_{t}(x)$ are respectively the total number of unemployed and employed. The index $x \in\left\{x_{1}, \ldots, x_{M}\right\}$ denotes an observable worker-specific charecteristics, e.g., age and/or educational attainments. Let $\hat{u}_{t}(x) \equiv u_{t}(x) / l f_{t}$ denote the share of unemployed workers of characteristic $x$ in the labor force. Standard calculations yield

$$
\operatorname{Var}\left(u_{t}\right)=\sum_{x} \operatorname{Var}\left(\hat{u}_{t}(x)\right)+\sum_{x \neq x^{\prime}} \operatorname{Cov}\left(\hat{u}_{t}(x), \hat{u}_{t}\left(x^{\prime}\right)\right) .
$$

Tables 12-13 report percentage shares of U.S. unemployment rate variance attributed to a specific group of workers. Specifically, I group workers by age (see Table 12), education (see Table 13), and age/education (see Table B.8 in Appendix B).

Table 12: Volatility Shares by Age Group

\begin{tabular}{lcccccc}
\hline \hline & $16-24$ & $25-34$ & $35-44$ & $45-54$ & $55-64$ & $65+$ \\
\hline Cov. not incl. & 47.28 & 25.93 & 8.87 & 12.32 & 5.28 & 0.33 \\
Cov. incl. & 30.84 & 28.12 & 13.53 & 14.69 & 10.86 & 1.96 \\
\hline \hline
\end{tabular}

Notes: Data are from the CPS micro files for 1976:M1-2013:M2 and downloaded from the NBER website at http://www.nber.org/data/cps_basic.html. Seasonal adjustment is implemented with a 13-term symmetric moving average. The statistics reported are percentage shares of total U.S. unemployment rate variance attributed to each age group. "Cov. not incl." means covariance terms are ignored such that total variation is the sum of the variables' variances. "Cov. incl." means total variation includes covariance terms such that total variation is the sum of the variables' variances plus two times their covariance.

Table 12 shows that 2 age groups, i.e., 16-24 and 25-34, account for the bulk of the 
variation in the actual U.S. unemployment rate. A similar picture emerges from Table 13 in which HSD, HSG and SC are responsible for most of the time series variation of U.S. unemployment. Table B.8 in Appendix B further confirms that in the U.S. economy, unemployment volatility is clustered between the young and the least-educated workers.

Importantly, these findings are consistent with the predictions of the model. In Table 14, I report volatility shares for artificial data generated by the model. In the model, as in the data, few skill/productivity groups account for most of the variation of the unemployment rate. These are workers in the left tail of the skill/productivity distribution.

Table 13: Volatility Shares by Education Group

\begin{tabular}{lccc}
\hline \hline & HSD & HSG/SC & CGPC \\
\hline Cov. not incl. & 24.51 & 69.39 & 6.10 \\
Cov. incl. & 26.16 & 62.38 & 11.46 \\
\hline \hline
\end{tabular}

Notes: Data are from the CPS micro files for 1976:M12013:M2 and downloaded from the NBER website at http: //www.nber.org/data/cps_basic.html. HSD, HSG, SC and CGPC denote respectively High School Dropouts, High School Graduates, Some College and College Graduates and PostCollege Degree Holders. Seasonal adjustment is implemented with a 13-term symmetric moving average. The statistics reported are percentage shares of total U.S. unemployment rate variance attributed to each education group. "Cov. not incl." means covariance terms are ignored such that total variation is the sum of the variables' variances. "Cov. incl." means total variation includes covariance terms such that total variation is the sum of the variables' variances plus two times their covariance.

Note that changes in unemployment shares $\hat{u}_{t}(x) \equiv u_{t}(x) / l f_{t}$ are due to changes in either skill-specific unemployment rates, or skill-specific shares of the aggregate labor force:

$$
\hat{u}_{t}(x)=\underbrace{u_{t}(x)+u_{t}(x)}_{\begin{array}{c}
\text { Skill-specific } \\
\text { unemployment rate }
\end{array}} \times \underbrace{\frac{e_{t}(x)+u_{t}(x)}{E_{t}+U_{t}}}_{\begin{array}{c}
\text { Skill-specific } \\
\text { shares of the labor force }
\end{array}} .
$$

I refer to the first margin as the unemployment margin, and to the latter as the participa- 
Table 14: Volatility Shares by Skill/Productivity Group

\begin{tabular}{lccccccc}
\hline \hline & $x_{1}$ & $x_{2}$ & $x_{3}$ & $x_{4}$ & $x_{5}$ & $x_{6}$ & $x_{7}-x_{200}$ \\
\hline Cov. not incl. & 29.19 & 22.81 & 22.03 & 13.67 & 6.34 & 5.83 & 0.13 \\
Cov. incl. & 19.72 & 19.37 & 18.96 & 13.56 & 7.79 & 7.16 & 13.44 \\
\hline \hline
\end{tabular}

Notes: The statistics reported are percentage shares of total unemployment rate variance in the EJD model attributed to each skill/productivity group averaged across 500 replications. "Cov. not incl." means covariance terms are ignored such that total variation is the sum of the variables' variances. "Cov. incl." means total variation includes covariance terms such that total variation is the sum of the variables' variances plus two times their covariance.

tion margin. If the participation margin was the main driver of fluctuations in unemployment shares of young and/or least educated workers then modeling skill-specific differences in participation decisions would be of first-order importance. In this case, my modelling choice of constant labor force shares would be unappealing. If not, it would suggest that to a firstorder, the factor generating age/education group differences are variations in skill-specific unemployment rates. This would bring support to the main mechanism at work in the model. The variance of unemployment shares is decomposed as:

$$
\operatorname{Var}\left(\hat{u}_{t}\right)=\operatorname{Var}\left(u r_{t}(x)\right)+\operatorname{Var}\left(l f s_{t}(x)\right)+2 \operatorname{Cov}\left(u r_{t}(x), l f s_{t}(x)\right)
$$

where $u r_{t}(x)=u_{t}(x) /\left(e_{t}(x)+u_{t}(x)\right)$ and $l f s_{t}(x)=\left(e_{t}(x)+u_{t}(x)\right) /\left(E_{t}+U_{t}\right)$. Tables 15-16 show that almost all variation at business cycle frequencies in unemployment shares comes from fluctuations in skill-specific unemployment rates. Table B.9 in Appendix B shows the unemployment shares' variance decomposition by age/education group.

To summarize, the facts documented in this section state that: (i) most of the time series variation in the U.S. unemployment rate can be attributed to the young and least-educated workers. Since age and education are natural proxies for skills, the empirical findings suggest that understanding the cyclical behavior of low-skilled workers is critical to explain the large fluctuations of the U.S. labor market; (ii) at business cycle frequencies, most of the volatility in unemployment shares comes from changes in skill-specific unemployment rates and not from variation in skill-specific shares of the aggregate labor force. These facts are reminiscent of the well-known observation that volatility in labor market conditions greatly differs for workers of different age and education levels (see Clark and Summers (1981), 
Table 15: Unemployment versus Participation Margin by Age Group

\begin{tabular}{lcccccc}
\hline \hline & $16-24$ & $25-34$ & $35-44$ & $45-54$ & $55-64$ & $65+$ \\
\hline Unemployment margin & 98.95 & 99.81 & 99.81 & 99.82 & 99.67 & 97.12 \\
Participation margin & 1.05 & 0.19 & 0.19 & 0.18 & 0.33 & 2.88 \\
\hline \hline
\end{tabular}

Notes: Data are from the CPS micro files for 1976:M1-2013:M2 and downloaded from the NBER website at http://www.nber.org/data/cps_basic.html. Seasonal adjustment is implemented with a 13-term symmetric moving average. Data are logged and HP-filtered with smoothing parameter 129,000 at the monthly frequency. See Ravn and Uhlig (2002) for a thorough discussion on the choice of the HP smoothing parameter and the frequency of observations. The statistics reported are percentage shares of total unemployment shares variance attributed to the unemployment and participation margin by each age group. Covariance terms are not included such that total variation is the sum of the variables' variances.

Table 16: Unemployment versus Participation Margin by Education Group

\begin{tabular}{lccc}
\hline \hline & HSD & HSG/SC & CGPC \\
\hline Unemployment margin & 98.78 & 99.94 & 99.80 \\
Participation margin & 1.22 & 0.06 & 0.20 \\
\hline \hline
\end{tabular}

Notes: Data are from the CPS micro files for 1976:M1-2013:M2 and downloaded from the NBER website at http://www.nber.org/data/cps_ basic.html. HSD, HSG, SC and CGPC denote respectively High School Dropouts, High School Graduates, Some College and College Graduates and Post-College Degree Holders. Seasonal adjustment is implemented with a 13-term symmetric moving average. Data are logged and HP-filtered with smoothing parameter 129,000 at the monthly frequency. See Ravn and Uhlig (2002) for a thorough discussion on the choice of the HP smoothing parameter and the frequency of observations. The statistics reported are percentage shares of total unemployment shares variance attributed to the unemployment and participation margin by each education group. Covariance terms are not included such that total variation is the sum of the variables' variances. 
Gomme et al. (2005), and Jaimovich and Siu (2009) among others). Importantly, this latter result also suggests that modelling skill-specific differences in participation decisions is not of first-order importance. Overall, the emprical analysis provides strong support for the main prediction of the model: the left tail of the skill/productivity distribution is key to understand unemployment dynamics.

\section{Policy Analysis}

In this section, I show that in addition to matching key business cycle moments, the model also generates a wide range of implications for the design of macroeconomic policies. For instance, a general prediction of the analysis is that the effectiveness of macroeconomic policies varies over the business cycle. For instance, policies apt to decrease matching frictions in the labor market are less effective during recessions than during booms: programmes designed to give job search assistance to the unemployed (e.g., think of an exogenous increase in matching efficiency) and/or policies apt to decrease recruiting costs are far less effective in reducing unemployment during recessions than expansions. This happens because during recessions, jobs are rationed: matches with low-skilled workers would generate negative surpluses even if the cost to post a job vacancy was zero (i.e., no recruiting costs). Note that the ineffectiveness of these type of policies in a search-and-matching framework with rationing has been first discussed by Michaillat (2012). However, in Michaillat's model workers are identical and rationing arises in recessions because of decreasing returns to labor and wage stickiness. In this paper instead, rationing is a by-product of worker permanent heterogeneity. Hence, differently from Michaillat's work, I argue that low-skilled workers are the ones bearing the cost of this policy failure. The main insight of the analysis is that any policy that leaves un-changed the surplus after the match has occurred, it is then ineffective in reducing unemployment. This line of resoning suggests that key to tackle the unemployment problem during recessions is to restore the profitability of low-productivity firms, or in other words, subsidize matches with low-skilled workers. Policies restoring firms' profitability are the most effective in economic dowturns. Note that also the effectiveness of this latter type of policies is time varying. Specifically, subsidies to worker-employer low-productivity matches are much more effective during economic downturns than expansions. The time-varying effect of labor-market policies derives from the property that the impulse responses to aggregate shocks vary with the state of the economy. Since fiscal stimulus is tipically timed during recessions, assessing the response of the labor market and output to aggregate shocks 
during recessions is of particular relevance. I show that in the model unemployment is more responsive to changes in aggregate conditions during recessions than during normal times.
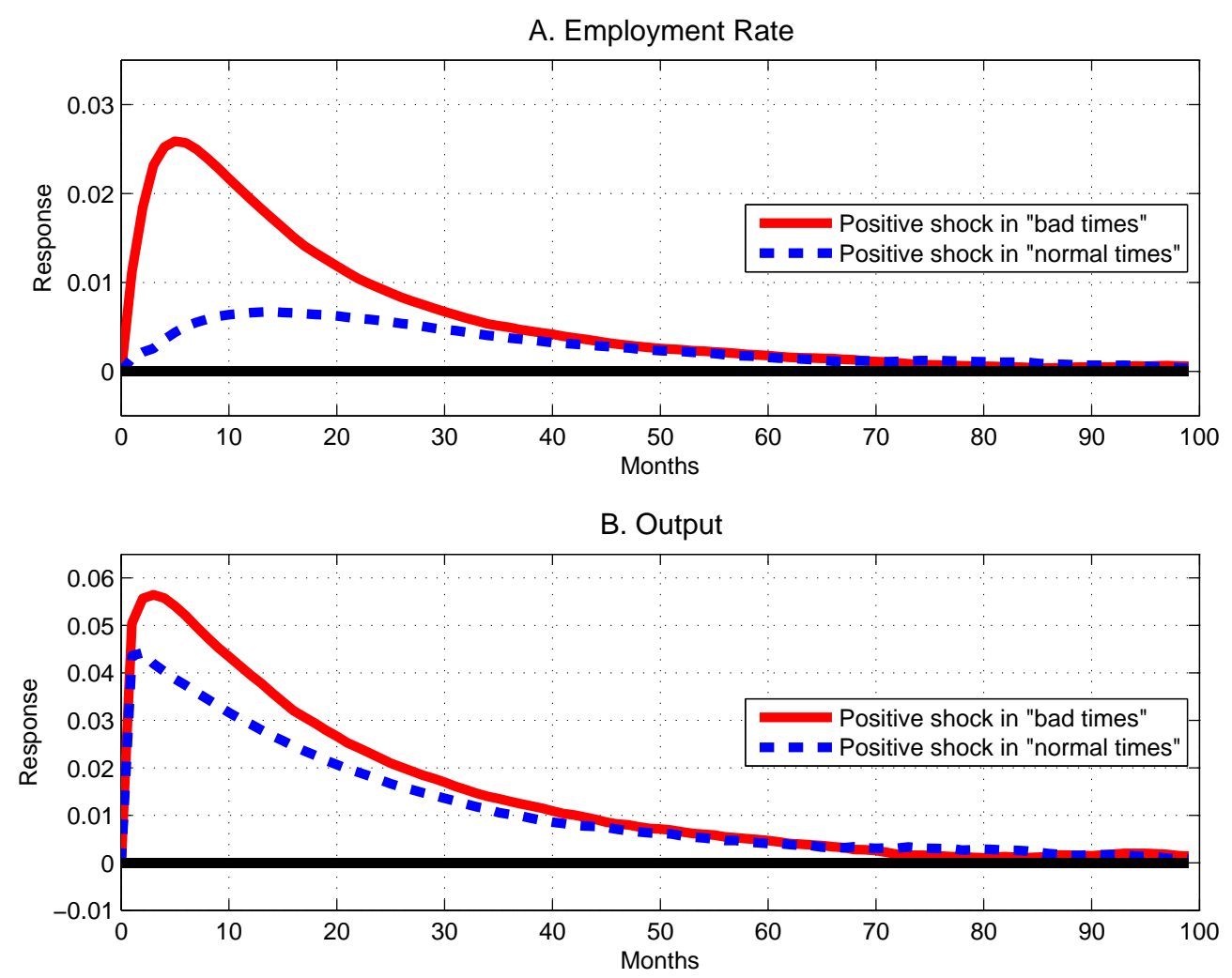

Figure 14: State-Dependent Impulse Responses

State-dependent effects of aggregate shocks. As in Section 4.3, I derive the dynamic response to a positive aggregate shock by comparing the expected paths of two simulated economies. For the IRF in "bad times," the first simulated economy starts with the level of the endogenous variable associated with the lowest aggregate state but is in the median state. The second simulated economy starts with the same level of the endogenous variable and is in the lowest aggregate state. The difference between the two paths is the response over time to a positive impulse during recessions. For the IRF in "normal times" instead, the first economy starts with the level of the endogenous variable associated with the median state but is in the highest state. The second simulated economy starts with the same level of the endogenous variable and is in the median state. The difference between the two paths is the response over time to a positive impulse during normal times. In both cases, I report the average response across 5,000 replications. Critically, the size of the shock is the same across scenarios. In Figure 14, Panel A shows that the employment rate is much more responsive 
to aggregate shocks in bad than in good times. The difference in responsiveness between bad and good times is instead far less pronounced for output (see Figure 14, Panel B). This latter result is perhaps not surprising given that the bahavior of output is far less asymmetric than that of the employment rate (see Sections 4.2 and 4.3). Overall, the analysis suggests that the model economy features counter-cyclical IRFs. This property comes entirely from the asymmetric amplification and propagation of symmetric shocks. In Appendix B, I document that the response of the actual U.S. unemployment rate to shocks is systematically stronger during recessions than during expansions. To this aim, I follow Bachmann et al. (2010) and estimate a two-stage time series model. In the first stage, I astimate an $\mathrm{AR}(2)$ process for the U.S. unemployment rate. Then in the second stage, I regress the absolute value of the first stage residuals on the average lagged unemployment rate to assess whether residual variance differs during recessions. The estimates show that the U.S. unemployment rate displays conditional heteroskedasticity. Specifically, the variance of the reduced-form innovations raise dramatically during times of high unemployment. However, this finding can be rationalized in two different ways: (1) the shocks driving fluctuations have constant variance but U.S. unemployment respond more to these shocks during recessions than during booms. Note that this is exactly what happens in the model. (2) Aggregate shocks are conditionally heteroskedastic with recessions initiated by shocks of larger size. However, Berger and Vavra (2012) show that there is no evidence of conditional heteroskedasticity for shocks commonly used in the business cycle literature. These facts seem to suggests that asymmetric responses, instead of asymmetric shocks, are responsible for heteroskedasticity in the U.S. unemployment rate.

State-dependent effects of fiscal stimulus. To understand the exact link between aggregate shocks and exogenous changes in policies, I introduce into the model four tax instruments: (1) sales tax, $\tau_{S}$; (2) labor income tax, $\tau_{W}$; (3) payroll tax, $\tau_{F}$; and (4) recruiting costs expensing, $\tau_{K}$. Equations (8) and (9) then become,

$$
S_{s}(x)=\max \left\{S_{s}^{c}(x), 0\right\}
$$

with

$$
S_{s}^{c}(x)=\left(1-\tau_{S}\right) z_{s} x-\left(\frac{1+\tau_{F}}{1-\tau_{W}}\right) \lambda+\beta \sum_{s^{\prime}} \pi_{s, s^{\prime}}\left[1-\delta_{s^{\prime}}(x)-\eta \phi_{s}(x)\right] S_{s^{\prime}}(x),
$$


where $\Pi_{s}\left(z_{s} x, \lambda, \tau_{S}, \tau_{F}, \tau_{W}\right) \equiv\left[\left(1-\tau_{S}\right) z_{s} x-\left(\frac{1+\tau_{F}}{1-\tau_{W}}\right) \lambda\right]$ denote "profits" accruing to the worker-employer relationship. The free-entry condition for each submarket is

$$
\left(1-\tau_{K}\right) k(x)=\beta \rho_{s}(x) \sum_{s^{\prime}} \pi_{s, s^{\prime}}(1-\eta) S_{s^{\prime}}(x) .
$$

Note that: (i) all tax rates affect $S_{s}(x)$ through the profit term $\Pi_{s}\left(z_{s} x, \lambda, \tau_{S}, \tau_{F}, \tau_{W}\right)$. As such cuts in either tax rate can be seen as "subsidies" to the worker-employer match. Moreover, since these subsidies act like changes in the aggregate shock, exogenous changes in tax rates can be interpreted as shocks to the aggregate state of the economy. Hence, the dynamics in Figure 14 can also be interpreted as responses to exogenous decreases in either tax rate. This observation implies that fiscal policy is more effective during recessions than expansions. These predictions are consistent with the empirical evidence produced by Auerbach and Gorodnichenko (2012); (ii) the expensing rate of vacancy posting costs only enters the free-entry condition (28). As discussed in Section 3.4, changes in the cost to post a job vacancy are irrelevant for rationing unemployment. As such policies working through that margin are ineffective in reducing unemployment during recessions.

\section{Conclusions}

The paper develops a search-and-matching model with permanently heterogeneous workers (in skill/productivity) that accounts for the asymmetric fluctuations of the U.S. labor market and output. The fundamental property of the model is that recessions are initiated by a burst of job losses and job-finding rates display asymmetries over the cycle. The model generates realistic volatility in unemployment and job vacancies preserving a downwardsloping Beveridge curve. As a by-product, the model provides stark predictions for the time series of skill-specific unemployment rates. These predictions hold in CPS micro data once I sort workers by age and education. The model predicts that the effectiveness of macroeconomic policies varies over the business cycle. For instance, the effects of policies that restore the profitability of low-productivity matches are time varying: these policies are much more effective during economic downturns than expansions. That is, the economy features impulse responses that vary with the state of the economy. 


\section{Appendix}

\section{A Data Sources}

The seasonally-adjusted monthly U.S. unemployment rate, participation rate (fraction of the population in the labor force), unemployment rates by age, gender, education, employment (thousands of persons), unemployment (thousands of persons), and short-term unemployment level (thousands of persons, number of unemployed persons for less than five weeks) are constructed by the Bureau of Labor Statistics (BLS) from the Current Population Survey (CPS). Survey home page http://www.bls.gov/cps/. Seasonally-adjusted monthly employment (thousands of persons) by major sectors is constructed by the BLS from the Current Employment Statistics (CES). Survey home page http://www.bls.gov/ces/. Following Yedid-Levi (2013), I classify natural resources and mining, construction, durable goods manufacturing, and a half of professional and business services as investment sector, and the rest as consumption sector. State-level employment rates are from the Local Area Unemployment Statistics (LAUS) survey of the BLS for the period 1976:Q1-2012:Q2. Survey home page http://www.bls.gov/lau/. CPS micro data for 1976:M1-2013:M2 are downloaded from the NBER website at http://www.nber.org/data/cps_basic.html. Seasonally-adjusted quarterly hours, hours per worker, and real output per worker in the nonfarm business sector is constructed by the BLS from the Labor and Productivity Costs (LPC) release. Release home page http://www.bls.gov/lpc. BLS definitions: Business sector output (BSO) is the annual-weighted index constructed by the BLS after excluding from gross domestic product (GDP) the following outputs: general government, nonprofit institutions, paid employees of private households, and the rental value of owner-occupied dwellings. Nonfarm business sector output (NBSO) excludes from the business sector the farm sector. The series are downloaded from the FRED website at http://research.stlouisfed.org/fred2/. Monthly

job-finding and job separation rates are calculated based on Shimer (2012). Vacancies are the monthly composite Help-Wanted Index constructed by Barnichon (2010). 


\section{B Tables and Figures}

\begin{tabular}{c|cccc} 
Table B.1: Asymmetry in Employment & Rates by Age A \\
\hline \hline & $25-34$ & $35-44$ & $45-54$ & $55+$ \\
\hline \multirow{2}{*}{ Skew $(\tilde{e})$} & $-0.728^{* * *}$ & $-0.690^{* * *}$ & $-0.610^{* * *}$ & $-0.407^{* * *}$ \\
& $(0.003)$ & $(0.004)$ & $(0.001)$ & $(0.009)$ \\
& & & & \\
Skew $(\Delta e)$ & $-1.033^{* * *}$ & $-0.866^{* * *}$ & $-0.775^{* *}$ & $-0.434^{*}$ \\
& $(0.001)$ & $(0.001)$ & $(0.010)$ & $(0.075)$ \\
\hline \hline
\end{tabular}

Notes: $e$ is a logged quarterly average of the seasonally-adjusted monthly U.S. employment rate (fraction of the labor force working in a given month, one minus the unemployment rate) by age group. $\tilde{e}$ is the HP-filtered counterpart of $e$ with smoothing parameter $10^{5}$. Data are from the CPS survey of the BLS for the period 1948:Q12013:Q1. Survey home page http://www.bls.gov/cps/. Data are downloaded from the FRED website at http://research.stlouisfed.org/fred2/. P-values (one-sided test) in parenthesis. ${ }^{* *}, * *, *$ denote statistical significance respectively at $1 \%, 5 \%$ and $10 \%$ level.

Table B.2: Asymmetry in Employment Rates by Education

\begin{tabular}{c|cccc}
\hline \hline & HSD & HSG & SC & CGPC \\
\hline \multirow{3}{*}{ Skew $(\tilde{e})$} & $-0.553^{* *}$ & $-0.675^{* *}$ & $-0.396^{*}$ & -0.140 \\
& $(0.032)$ & $(0.022)$ & $(0.073)$ & $(0.298)$ \\
& & & & \\
\multirow{2}{*}{ Skew $(\Delta e))$} & $-1.582^{*}$ & $-1.527^{*}$ & $-1.537^{*}$ & $-1.088^{*}$ \\
& $(0.090)$ & $(0.076)$ & $(0.082)$ & $(0.065)$ \\
\hline \hline
\end{tabular}

Notes: $e$ is a logged quarterly average of the seasonally-adjusted monthly U.S. employment rate (fraction of the labor force working in a given month, one minus the unemployment rate) by education gropus. $\tilde{e}$ is the HP-filtered counterpart of $e$ with smoothing parameter $10^{5}$. HSD, HSG, SC and CGPC denote respectively High School Dropouts, High School Graduates, Some College and College Graduates and Post-College Degree Holders. Data are from the CPS survey of the BLS for the period 1992:Q11-2013:Q1. Survey home page http://www.bls.gov/cps/. Data are downloaded from the FRED website at http://research.stlouisfed.org/fred2/. P-values (one-sided test) in parenthesis. ${ }^{* *},{ }^{*}$ denote statistical significance respectively at $5 \%$ and $10 \%$ level. 
Table B.3: Asymmetry in Employment Rates By Gender

\begin{tabular}{c|cc}
\hline \hline & Men & Women \\
\hline \multirow{3}{*}{$\operatorname{Skew}(\tilde{e})$} & $-0.690^{* * *}$ & $-0.417^{* *}$ \\
& $(0.004)$ & $(0.012)$ \\
& & \\
$\operatorname{Skew}(\Delta e)$ & $-0.938^{* * *}$ & $-1.372^{* * *}$ \\
& $(0.002)$ & $(0.009)$ \\
\hline \hline
\end{tabular}

Notes: $e$ is a logged quarterly average of the seasonally-adjusted monthly U.S. employment rate (fraction of the labor force working in a given month, one minus the unemployment rate) by gender. $\tilde{e}$ is the HP-filtered counterpart of $e$ with smoothing parameter $10^{5}$. Data are from the CPS survey of the BLS for the period 1948:Q12012:Q2. Survey home page http://www.bls.gov/cps/. Data are downloaded from the FRED website at http://research.stlouisfed.org/fred2/. P-values (one-sided test) in parenthesis. ${ }^{* *},{ }^{* *}$ denote statistical significance respectively at $1 \%$ and $5 \%$ level.

Table B.4: Asymmetry in Employment by Sector

\begin{tabular}{c|cc}
\hline \hline & Consumption & Investment \\
\hline \multirow{3}{*}{ Skew $(\tilde{e})$} & $-0.271^{*}$ & $-0.266^{*}$ \\
& $(0.055)$ & $(0.075)$ \\
& & \\
Skew $(\Delta \tilde{e})$ & $-0.820^{* * *}$ & $-0.530^{*}$ \\
& $(0.003)$ & $(0.065)$ \\
\hline \hline
\end{tabular}

Notes: $e$ is a logged quarterly average of seasonally-adjusted monthly employment (thousands of persons) as deviations from the HP trend with smoothing parameter $10^{5}$. Data are from the CES survey of the BLS for the period 1948:Q1-2012:Q2. Survey home page http://www.bls.gov/ces/. Following Yedid-Levi (2013), I classify natural resources and mining, construction, durable goods manufacturing, and a half of professional and business services as investment sector, and the rest as consumption sector. Data are downloaded from the FRED website at http://research.stlouisfed.org/ fred2/. P-values (one-sided test) in parenthesis. ***, * denote statistical significance respectively at $1 \%$ and $10 \%$ level. 
A. HP-Filtered Business Sector Output

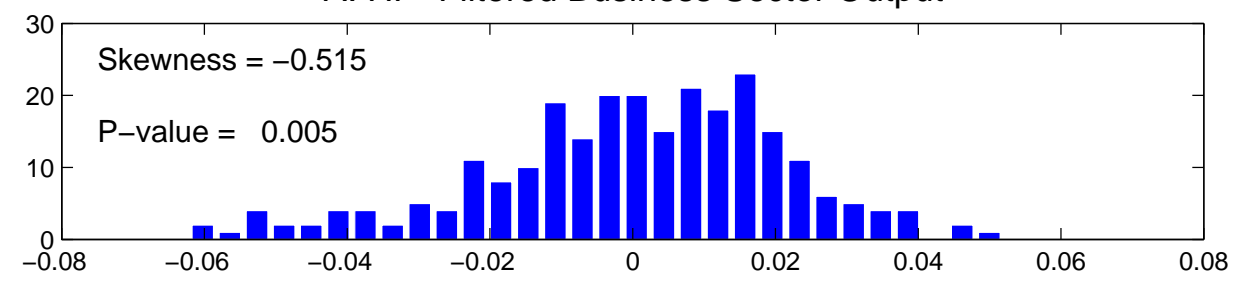

B. HP-Filtered Nonfarm Business Sector Output

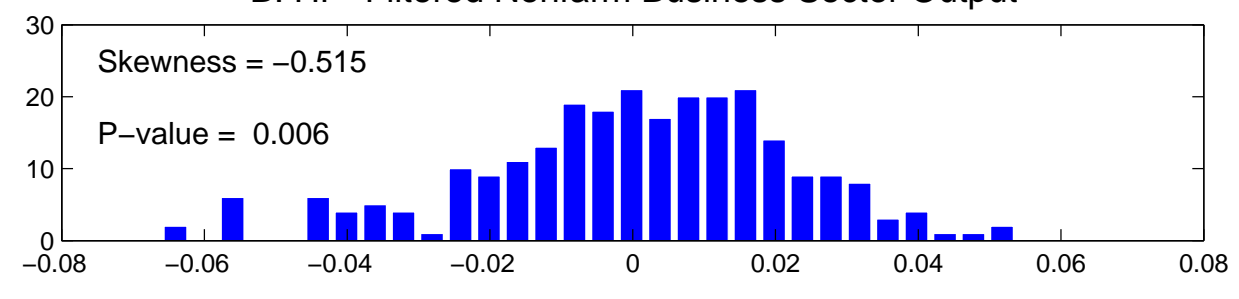

C. HP-Filtered Real GDP

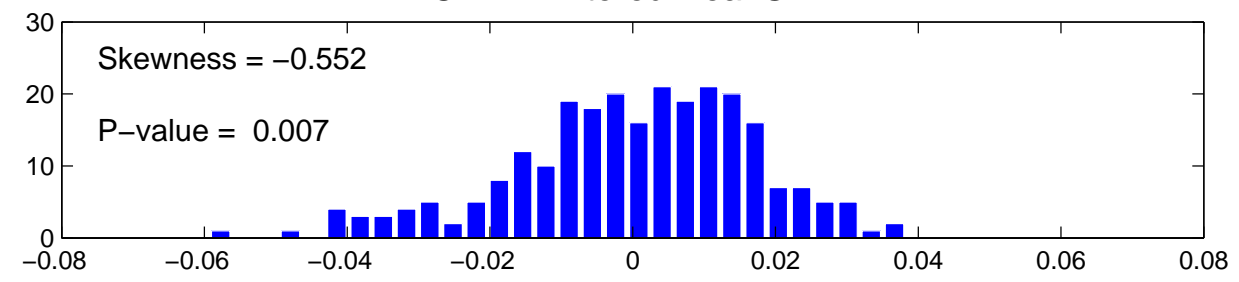

Figure B.1: Deepness Asymmetry in Quarterly U.S. Output, 1948:Q1-2012:Q2

Notes: All series are in logs as deviations from the HP trend with smoothing parameter 1600. In Panel A, business sector output (BSO) is the annual-weighted index constructed by the BLS after excluding from gross domestic product (GDP) the following outputs: general government, nonprofit institutions, paid employees of private households, and the rental value of owner-occupied dwellings. In Panel B, nonfarm business sector output (NBSO) excludes from the business sector the farm sector. In Panel C, real GDP is in billions of chained 2005 dollars. Data are seasonallyadjusted at the quarterly frequency for the period 1948:Q1-2012:Q2. BSO and NBSO data are from the LPC release of the BLS. Release home page http://www.bls.gov/lpc. BSO and NBSO data are downloaded from the FRED website at http://research.stlouisfed.org/fred2/. Real GDP data are from the NIPA Table 1.1.6. and downloaded from the BEA website at http: //www. bea.gov/index.htm. 
A. First-Difference Business Sector Output

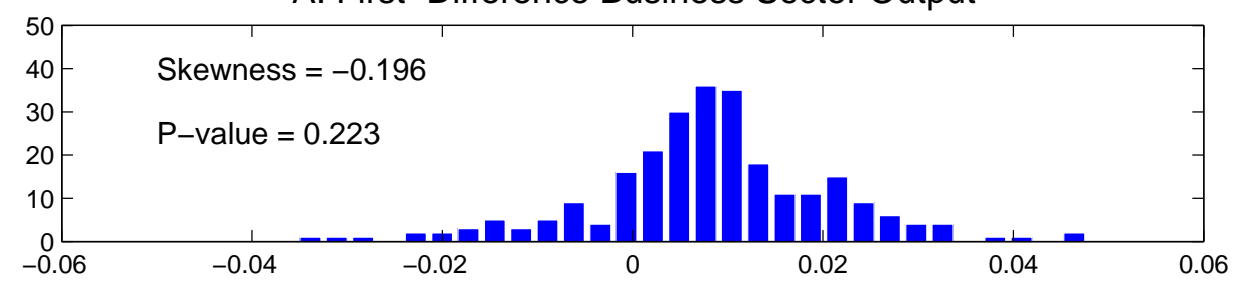

B. First-Difference Nonfarm Business Sector Output

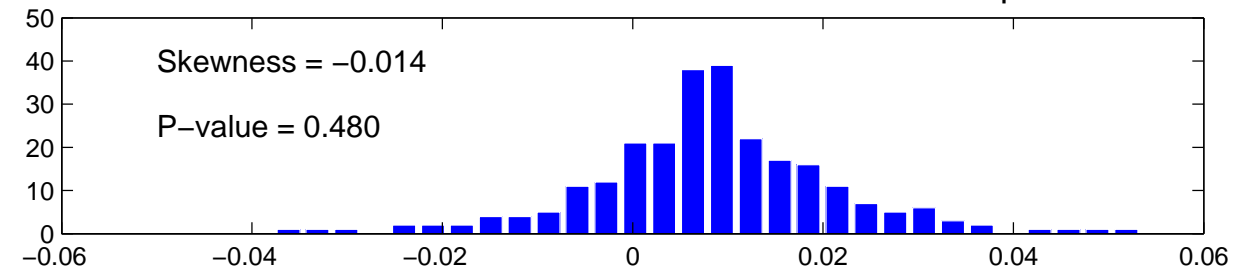

C. First-Difference Real GDP

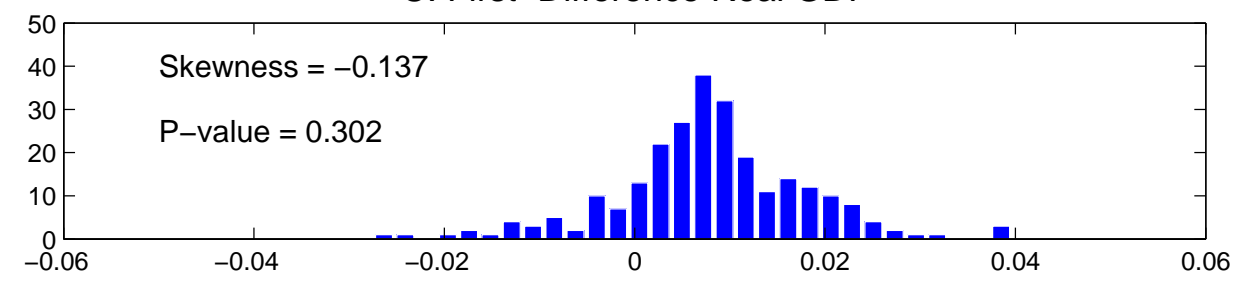

Figure B.2: Steepness Asymmetry in Quarterly U.S. Output, 1948:Q1-2012:Q2

Notes: All series are in log-first-differences. In Panel A, business sector output (BSO) is the annualweighted index constructed by the BLS after excluding from gross domestic product (GDP) the following outputs: general government, nonprofit institutions, paid employees of private households, and the rental value of owner-occupied dwellings. In Panel B, nonfarm business sector output (NBSO) excludes from the business sector the farm sector. In Panel C, real GDP is in billions of chained 2005 dollars. Data are seasonally-adjusted at the quarterly frequency for the period 1948:Q1-2012:Q2. BSO and NBSO data are from the LPC release of the BLS. Release home page http://www.bls.gov/lpc. BSO and NBSO data are downloaded from the FRED website at http://research.stlouisfed.org/fred2/. Real GDP data are from the NIPA Table 1.1.6. and downloaded from the BEA website at http://www.bea.gov/index.htm. 

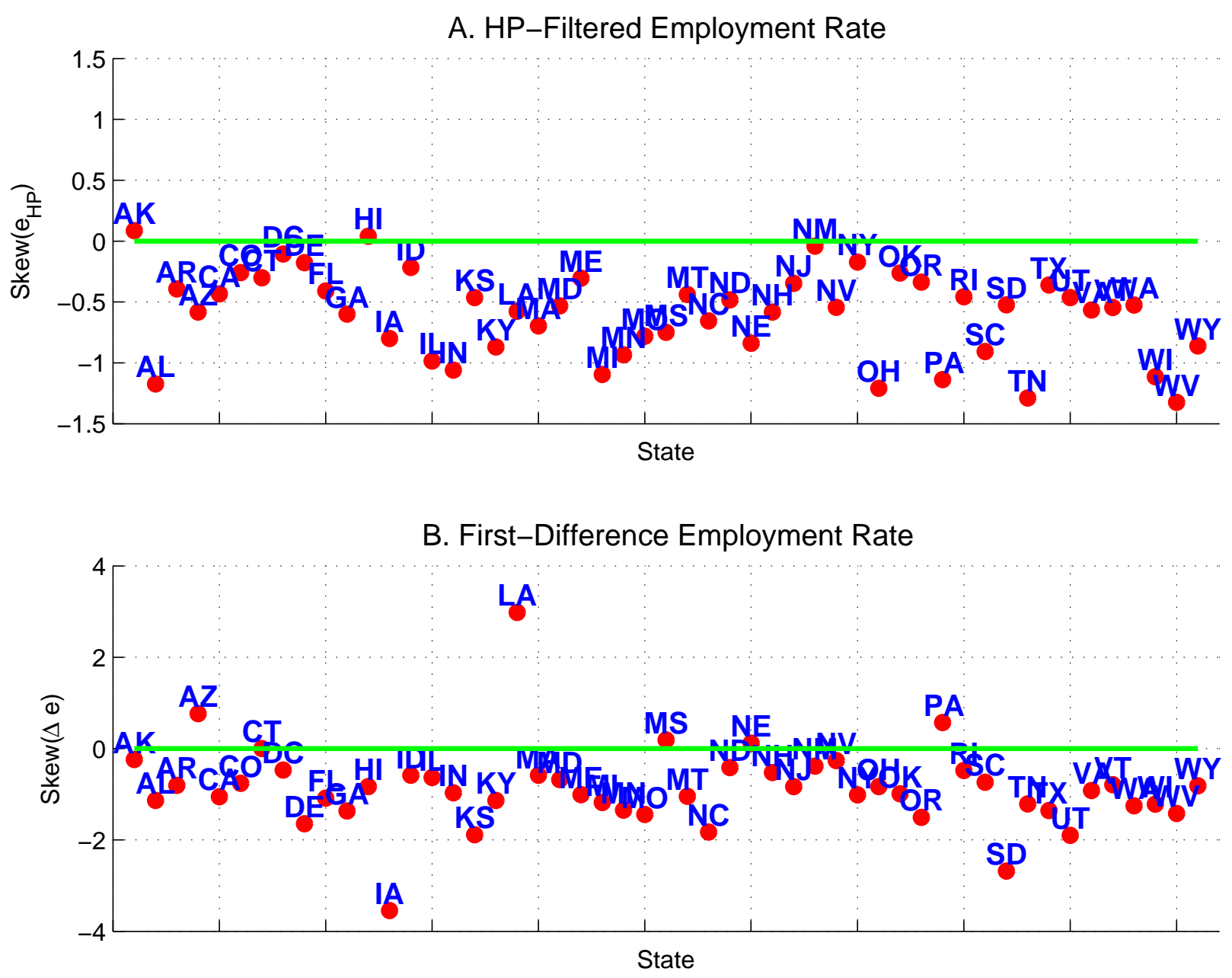

Figure B.3: Asymmetry in Employment Rates by State

Notes: In Panel A, red dot indicates the value of the skewness coefficient for the U.S. state-level employment rate (fraction of the labor force working in a given month, one minus the unemployment rate) as deviations from the HP trend with smoothing parameter $10^{5}$. In Panel B, red dot indicates the value of the skewness coefficient for the first-difference of the U.S. state-level employment rate. Employment rate is the logged quarterly average of the monthly series. On the $x$-axis, U.S. states are in alphabetical order. Data are from the LAUS survey of the BLS for the period 1976:Q12012:Q2. Survey home page http://www.bls.gov/lau/. Data are downloaded from the FRED website at http://research.stlouisfed.org/fred2/. 


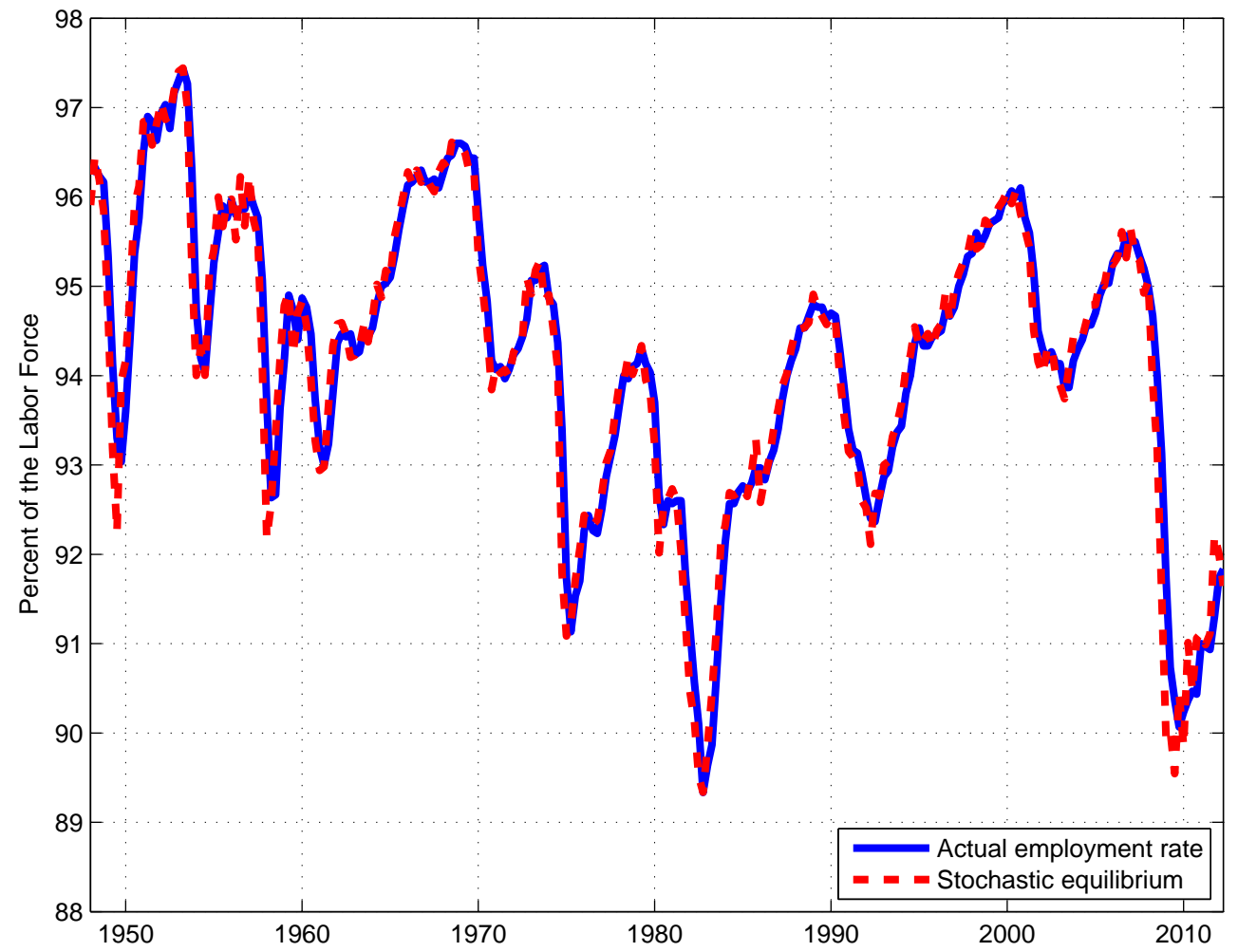

Figure B.4: Quarterly U.S. Employment Rate and Stochastic Equilibrium, 1948:Q1-2012:Q2

Notes: Solid line shows a quarterly average of the U.S. employment rate (fraction of the labor force working in a given month, one minus the unemployment rate) for the period 1948:Q1-2012:Q2. The seasonally-adjusted unemployment rate is from the CPS survey of the BLS for the period 1948:Q12012:Q2. Survey home page http://www.bls.gov/cps/. Data are downloaded from the FRED website at http://research.stlouisfed.org/fred2/. Dashed line shows the counterfactual employment rate series under stochastic equilibrium. See Section 2.2.2 for details. 
Table B.5: Calibration of the Standard DMP Model (Monthly Frequency)

\begin{tabular}{llcc}
\hline \hline & Interpretation & Value & Source/Target \\
\hline$\beta$ & Discount factor & 0.9959 & $5 \%$ annual interest rate \\
$\delta$ & Separation rate & 0.036 & JOLTS, 2001:M1-2011:M9 \\
$k$ & Vacancy cost & 0.1669 & $\theta=1$ when $z=1$ \\
$\alpha$ & Matching function: $m(v, u)=\mu v^{\alpha} u^{1-\alpha}$ & 0.4 & Brügemann (2008) \\
$\mu$ & Matching function scale & 0.607 & Median unemployment rate of 5.6\% \\
$\eta$ & Worker Nash-bargaining weight & 0.6 & Hosios (1990)'s condition \\
$\lambda$ & Flow value of unemployment & 0.7221 & 0.73\% of mean wage rate \\
$\rho_{z}$ & Autocorrelation of exogenous state & 0.9642 & LPC, 1948:Q1-2011:Q3 \\
$\sigma_{\epsilon}$ & Standard deviation of shocks & 0.0055 & LPC, 1948:Q1-2011:Q3 \\
\hline \hline
\end{tabular}

Notes: The separation rate, $\delta$, is the monthly average of seasonally-adjusted total separations to employment in the nonfarm business sector. Data are from the JOLTS survey of the BLS for the period 2001:M1-2011:M9. Survey home page http://www.bls.gov/jlt/. To calibrate the stochatic process for labor productivity, I estimate an $\operatorname{AR}(1)$ process for the HP-filtered seasonally-adjusted quarterly real output per worker in the nonfarm business sector constructed by the BLS from the LPC release, for 1948:Q1-2011:Q3: $\ln \left(z_{t+1}\right)=\rho_{z} \ln \left(z_{t}\right)+\sigma_{\epsilon} \epsilon_{t+1}$ with $\epsilon_{t} \stackrel{\text { iid }}{\sim} \mathcal{N}(0,1)$. The HP-filter smoothing parameter is $10^{5}$. With quarterly data, we obtain an autocorrelation of $\hat{\rho}_{z}=0.8963$ and a residual standard deviation of $\hat{\sigma}_{\epsilon}=0.0091$, which yields $\hat{\rho}_{z}=0.8963^{1 / 3}=0.9642$ and $\hat{\sigma}_{\epsilon}=0.0055$ at monthly frequency. Following Tauchen (1986), I approximate the continuous-valued $\mathrm{AR}(1)$ process for $\ln \left(z_{t}\right)$ through a $\mathcal{S}$-state Markov chain, having a discrete state space $\left\{z_{1}, \ldots, z_{\mathcal{S}}\right\}$ and transition probabilities $\pi_{s, s^{\prime}}=\operatorname{Pr}\left\{z_{t+1}=z_{s^{\prime}} \mid z_{t}=z_{s}\right\}$. I set the number of grid points for the state space to $\mathcal{S}=9$. Release home page http://www.bls.gov/lpc. Nonfarm business sector output (NBSO) excludes from the business sector the farm sector. Business sector output (BSO) is the annual-weighted index constructed by the BLS after excluding from gross domestic product (GDP) the following outputs: general government, nonprofit institutions, paid employees of private households, and the rental value of owner-occupied dwellings. Data are downloaded from the FRED website at http://research.stlouisfed.org/fred2/. 
Table B.6: Volatility and Comovement in U.S. Data and DMP Model

\begin{tabular}{lccc}
\hline \hline & Data & $\begin{array}{c}\text { DMP Model } \\
\lambda=0.73 \cdot \bar{\omega}\end{array}$ & $\begin{array}{c}\text { DMP Model } \\
\lambda=0.95 \cdot \bar{\omega}\end{array}$ \\
\hline A. Volatility & & & \\
$s d(u) / s d(p)$ & 9.851 & 1.303 & 7.864 \\
$\operatorname{sd}(\phi) / s d(p)$ & 7.213 & 1.401 & 8.599 \\
$\operatorname{sd}(v) / s d(p)$ & 8.131 & 2.284 & 14.167 \\
$\operatorname{B.} \operatorname{Comovement}$ & & & -0.880 \\
$\operatorname{corr}(u, v)$ & -0.858 & -0.900 & -0.934 \\
$\operatorname{corr}(u, p)$ & -0.412 & -0.958 & 0.974 \\
$\operatorname{corr}(\phi, p)$ & 0.383 & 0.999 & 0.954 \\
$\operatorname{corr}(v, p)$ & 0.433 & 0.986 & \\
\hline \hline
\end{tabular}

Notes: The seasonally-adjusted unemployment rate, $u$, is from the CPS survey of the BLS. Survey home page http://www.bls.gov/cps/. Labor productivity, $p$, is seasonally-adjusted quarterly real output per worker in the nonfarm business sector constructed by the BLS from the LPC release. Release home page http://www.bls.gov/lpc. Nonfarm business sector output (NBSO) excludes from the business sector the farm sector. Business sector output (BSO) is the annual-weighted index constructed by the BLS after excluding from gross domestic product (GDP) the following outputs: general government, nonprofit institutions, paid employees of private households, and the rental value of owner-occupied dwellings. The series are downloaded from the FRED website at http://research.stlouisfed.org/ fred2/. Job-finding rates, $\phi$, are calculated based on Shimer (2012). Vacancies, $v$, are the composite Help-Wanted Index constructed by Barnichon (2010). The variables $u, \phi$, and $v$ are quarterly averages of monthly series. All series cover the period 1948:Q1-2011:Q3. DMP model refers to the standard DMP model with Nash-Bargaining and a constant exogenous rate of job destruction. $\lambda$ and $\bar{\omega}$ denote respectively the flow value of unemployment and the mean wage rate. Model simulated data are quarterly averages of 765 observations at the monthly frequency. The statistics reported are averages across 500 replications. All variables are reported in logs as deviations from the HP trend with smoothing parameter $10^{5}$. 
Table B.7: Asymmetry in U.S. Data and DMP Model

\begin{tabular}{lccc}
\hline \hline & Data & $\begin{array}{c}\text { DMP Model } \\
\lambda=0.73 \cdot \bar{\omega}\end{array}$ & $\begin{array}{c}\text { DMP Model } \\
\lambda=0.95 \cdot \bar{\omega}\end{array}$ \\
\hline A. Skewness in levels & & & \\
Skew $(e)$ & $-0.591^{* * *}$ & -0.105 & -0.898 \\
Skew $(y)$ & $-0.345^{* *}$ & -0.000 & -0.267 \\
Skew $(\phi)$ & $-0.249^{* *}$ & -0.068 & -0.649 \\
Skew $(v)$ & $-0.469^{* * *}$ & -0.081 & -0.760 \\
B. Skewness in growth rates & & & 0.158 \\
$\operatorname{Skew}(\Delta e)$ & & & 0.089 \\
$\operatorname{Skew}(\Delta y)$ & $-0.958^{* * *}$ & 0.018 & 0.007 \\
$\operatorname{Skew}(\Delta \phi)$ & -0.170 & 0.002 & 0.110 \\
Skew $(\Delta v)$ & $0.235^{* * *}$ & 0.000 & \\
\hline \hline
\end{tabular}

Notes: Employment rate, $e$, is the fraction of the labor force working in a given month, one minus the unemployment rate. The seasonally-adjusted unemployment rate is from the CPS survey of the BLS. Survey home page http://www.bls.gov/cps/. Output, $y$, is industrial production (IP). The series are downloaded from the FRED website at http://research . stlouisfed.org/fred2/. Job-finding rates, $\phi$, are calculated based on Shimer (2012). Vacancies, $v$, are the composite Help-Wanted Index constructed by Barnichon (2010). The variables $e, y, \phi$, and $v$ are quarterly averages of monthly series. All series cover the period for period 1948:Q1-2011:Q3. DMP model refers to the standard DMP model with NashBargaining and a constant exogenous rate of job destruction. $\lambda$ and $\bar{\omega}$ denote respectively the flow value of unemployment and the mean wage rate. Model simulated data are quarterly averages of 765 observations at the monthly frequency. The statistics reported are averages across 500 replications. In Panel A, all variables are reported in logs as deviations from the HP trend with smoothing parameter $10^{5}$. In Panel B, all variables are reported as 3 -months log-differences. ${ }^{* * *},{ }^{* *}$ denote statistical significance respectively at $1 \%$ and $5 \%$ level. 
Table B.8: Volatility Shares by Age/Education Group

\begin{tabular}{|c|c|c|c|c|c|c|}
\hline & 16-24 & $25-34$ & $35-44$ & $45-54$ & $55-64$ & $65+$ \\
\hline \multicolumn{7}{|c|}{ A. Cov. not incl. } \\
\hline HSD & 17.90 & 2.56 & 1.03 & 1.31 & 0.92 & 0.04 \\
\hline $\mathrm{HSG} / \mathrm{SC}$ & 26.57 & 22.27 & 7.44 & 10.93 & 4.18 & 0.25 \\
\hline CGPC & 0.16 & 0.85 & 0.94 & 1.49 & 1.08 & 0.08 \\
\hline \multicolumn{7}{|c|}{ B. Cov. incl. } \\
\hline HSD & 9.43 & 5.18 & 3.79 & 4.38 & 2.96 & 0.42 \\
\hline $\mathrm{HSG} / \mathrm{SC}$ & 19.87 & 19.15 & 7.70 & 8.66 & 5.98 & 1.03 \\
\hline CGPC & 1.55 & 3.80 & 2.04 & 1.65 & 1.92 & 0.50 \\
\hline
\end{tabular}

Notes: Data are from the CPS micro files for 1976:M1-2013:M2 and downloaded from the NBER website at http://www.nber.org/data/cps_basic.html. HSD, HSG, SC and CGPC denote respectively High School Dropouts, High School Graduates, Some College and College Graduates and Post-College Degree Holders. Seasonal adjustment is implemented with a 13-term symmetric moving average. The statistics reported are percentage shares of total U.S. unemployment rate variance attributed to each age-education group. "Cov. not incl." means covariance terms are ignored such that total variation is the sum of the variables' variances. "Cov. incl." means total variation includes covariance terms such that total variation is the sum of the variables' variances plus two times their covariance. 
Table B.9: Unemployment versus Participation Margin by Age/Education Group

\begin{tabular}{lcccccc}
\hline \hline \multicolumn{7}{c}{ A. Unemployment margin } \\
\hline HSD & $16-24$ & $25-34$ & $35-44$ & $45-54$ & $55-64$ & $65+$ \\
HSG/SC & 93.36 & 97.41 & 98.23 & 97.72 & 98.92 & 93.75 \\
CGPC & 95.76 & 99.71 & 99.70 & 99.66 & 99.67 & 97.51 \\
& & 99.56 & 99.63 & 99.26 & 98.18 & 97.21 \\
HSD & 6.64 & 2.59 & 1.77 & 2.28 & 1.08 & 6.25 \\
HSG/SC & 1.24 & 0.29 & 0.30 & 0.34 & 0.33 & 2.49 \\
CGPC & 4.73 & 0.44 & 0.37 & 0.74 & 1.82 & 2.79 \\
\hline \hline
\end{tabular}

Notes: Data are from the CPS micro files for 1976:M1-2013:M2 and downloaded from the NBER website at http://www.nber.org/data/cps_basic.html. HSD, HSG, SC and CGPC denote respectively High School Dropouts, High School Graduates, Some College and College Graduates and Post-College Degree Holders. Seasonal adjustment is implemented with a 13-term symmetric moving average. Data are logged and HP-filtered with smoothing parameter 129,000 at the monthly frequency. See Ravn and Uhlig (2002) for a thorough discussion on the choice of the HP smoothing parameter and the frequency of observations. The statistics reported are percentage shares of total unemployment shares variance attributed to the unemployment and participation margin by each education group. Covariance terms are not included such that total variation is the sum of the variables' variances. 


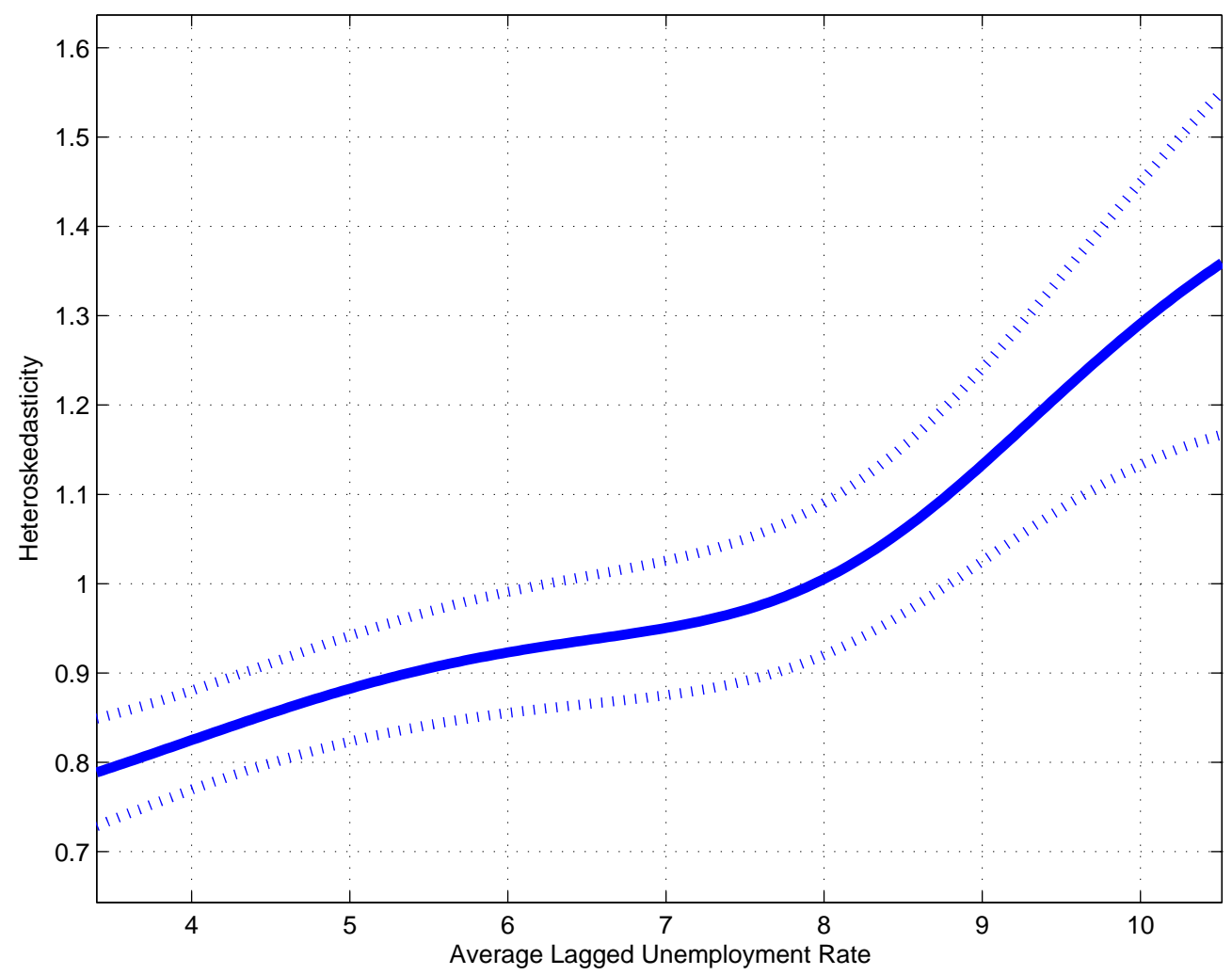

Figure B.5: Conditional Heteroskedasticity in Quarterly U.S. Unemployment Rate, 1959:Q12012:Q2 


\section{Proofs}

Proof of Proposition 1. Standard reasoning provides the reservation productivity,

$$
z x=\lambda+\frac{\eta k}{1-\eta} \cdot \theta-\xi \beta(1-\delta) \cdot \int_{x}^{x_{M}} S(y) d G(y) .
$$

Rearrange equation (C.1) to get,

$$
\theta=\frac{1-\eta}{\eta k} \cdot\left[z x-\lambda+\xi \beta(1-\delta) \cdot \int_{x}^{x_{M}} S(y) d G(y)\right] .
$$

In equation (C.2), as long as the term in square brackets is larger than zero, $\lim _{k \searrow 0} \theta(k)=$ $+\infty$ and $\lim _{k \searrow 0} e(k)=1$. On the other hand, as the term in square brackets falls below zero, $\lim _{k \searrow 0} \theta(k)=0$ and $\lim _{k \searrow 0} e(k)=0$.

LEMMA 1 (Convexity of market tightness). At any stochastic equilibrium consistent with a constant exogenous rate of job destruction, the tightness ratio, $\theta$, is a strictly increasing and convex function of the exogenous state, $z$, i.e., $\theta=\varphi(z)$ with $\varphi^{\prime}(\cdot)>0$ and $\varphi^{\prime \prime}(\cdot)>0$.

Proof of Lemma 1. At any stochastic equilibrium consistent with a constant exogenous rate of job destruction, the total match surplus $S_{s}$ is,

$$
S_{s}=\frac{z_{s}-\lambda}{1-\beta\left[1-\delta-\eta \phi\left(\theta_{s}\right)\right]}
$$

for $s=1, \ldots, \mathcal{S}$. After substituting $S_{s}$ into the free-entry condition, $k=\beta \rho\left(\theta_{s}\right)(1-\eta) S_{s}$, using $\phi(\theta)=\mu \theta^{\alpha}$, and rearranging terms,

$$
\underbrace{k[1-\beta(1-\delta)]}_{\mathcal{A}>0}=\underbrace{\beta \mu(1-\eta)}_{\mathcal{B}>0}(z-\lambda) \theta^{\alpha-1}-\underbrace{k \beta \mu \eta}_{\mathcal{C}>0} \theta^{\alpha},
$$

where we omit the state subscript, $s$, for notational convenience. I can further rearrange the equation above to get $\theta$ as an implicit function $F(\theta, z)$ of $z$,

$$
F(\theta, z) \equiv \mathcal{A} \theta^{1-\alpha}+\mathcal{C} \theta-\mathcal{B} z=-\mathcal{B} \lambda .
$$

By applying the implicit function theorem,

$$
\frac{d \theta}{d z}=-\frac{\partial F(\theta, z) / \partial z}{\partial F(\theta, z) / \partial \theta}=\frac{\mathcal{B}}{\mathcal{A}(1-\alpha) \theta^{-\alpha}+\mathcal{C}}>0
$$


implying that $\theta$ is strictly increasing in $z$. To further characterize the shape of the relationship between the market-tightness ratio and the exogenous state, I compute $d^{2} \theta / d z d \theta$,

$$
\frac{d^{2} \theta}{d z d \theta}=\frac{\alpha(1-\alpha) \mathcal{A} \theta^{-(1+\alpha)}}{\left[\mathcal{A}(1-\alpha) \theta^{-\alpha}+\mathcal{C}\right]^{2}}>0
$$

such that $\theta$ is strictly convex in $z$, and this proves the lemma.

Proof of Proposition 2. Part (i). From Lemma 1, the tightness ratio is a strictly increasing and convex function of the exogenous state $z$, i.e., $\theta=\varphi(z)$ with $\varphi^{\prime}(\cdot)>0$ and $\varphi^{\prime \prime}(\cdot)>0$. By Jensen's inequality,

$$
\mathbb{E}[\theta] \equiv \mathbb{E}[\varphi(z)]>\varphi(\mathbb{E}[z])
$$

By Assumption 3, $\mathbb{E}[z]=z_{s_{m}}$ such that $\varphi(\mathbb{E}[z])=\varphi\left(z_{s_{m}}\right)$ and $\mathbb{E}[\varphi(z)]>\varphi\left(z_{s_{m}}\right)$. Hence,

$$
\Delta \theta_{M M D} \equiv \mathbb{E}[\theta]-\theta_{s_{m}}>0
$$

and this proves part (i) of the proposition. Part (ii). At any stochastic equilibrium consistent with a constant exogenous rate of job destruction, the employment rate, jobfinding rate, vacancies, and log output are strictly increasing and concave functions of the tightness ratio $\theta$. Consider a generic increasing and concave function $\xi(\theta)$, with $\xi^{\prime}(\cdot)>0$ and $\xi^{\prime \prime}(\cdot)<0$. By Jensen's inequality, we know that $\mathbb{E}[\xi(\theta)]<\xi(\mathbb{E}[\theta])$, and by adding and subtracting $\xi\left(\theta_{s_{m}}\right)$ on the right hand side of the inequality, we get

$$
\Delta \xi_{M M D} \equiv \mathbb{E}[\xi(\theta)]-\xi\left(\theta_{s_{m}}\right)<\xi(\mathbb{E}[\theta])-\xi\left(\theta_{s_{m}}\right)<\xi^{\prime}\left(\theta_{s_{m}}\right) \Delta \theta_{M M D}>0
$$

The second term on the right hand side, $\xi(\mathbb{E}[\theta])-\xi\left(\theta_{s_{m}}\right)$, is larger than zero given that $\Delta \theta_{M M D} \equiv \mathbb{E}[\theta]-\theta_{s_{m}}>0$ and $\xi^{\prime}(\cdot)>0$. The second inequality on the right hand side is a fundamental property of concave functions. Finally, the third term on the right hand side, $\xi^{\prime}\left(\theta_{s_{m}}\right) \Delta \theta_{M M D}$, is larger than zero given $\xi^{\prime}(\cdot)>0$ and $\Delta \theta_{M M D}>0$ from part $(i)$, and this completes the proof of the proposition.

Proof of Corollary 1. The symmetry and uni-modality of the stationary distribution of the exogenous state, $z$, (Assumption 3), and the linear support of the distribution of the tightness ratio $\theta$, 


$$
\theta_{s}=\theta_{s_{m}}+\frac{\left(s-s_{m}\right)}{\left(\mathcal{S}-s_{m}\right)} \cdot \Delta,
$$

imply that $\Delta \theta_{M M D} \equiv \mathbb{E}[\theta]-\theta_{s_{m}}=0$. From Proposition 2, it follows that for any incrasing and concave function of the tightness ratio $\xi(\theta)$ (i.e., employment rate, job-finding rate, vacancies, $\log$ output), $\Delta \xi_{M M D} \equiv \mathbb{E}[\xi(\theta)]-\xi\left(\theta_{s_{m}}\right)<0$, and this proves the corollary.

Proof of Proposition 3. Part (i). The state space of the tightness ratio $\theta$ is the finite set $\Theta=\left\{\theta_{1}, \ldots, \theta_{\mathcal{S}}\right\}$. In order to isolate the effects of an increase in volatility, let's assume that $\theta_{s} \in \Theta$ takes on values, $\theta_{1}<\ldots<\theta_{s_{m}}<\ldots<\theta_{\mathcal{S}}$, that are symmetrically spaced around the median $\theta_{s_{m}}$, satisfying the condition:

$$
\theta_{s}=\theta_{s_{m}}+\frac{\left(s-s_{m}\right)}{\left(\mathcal{S}-s_{m}\right)} \cdot \Delta
$$

for $s \in\{1, \ldots, \mathcal{S}\}$ and $\Delta>0$. The parameter $\Delta$ controls the range of variation of the support of the distribution of $\theta$. Notice that by construction, changes in $\Delta$ have no effect on the median value $\theta_{s_{m}}$. Given the symmetry assumption $\pi_{\infty}^{s}=\pi_{\infty}^{\mathcal{S}-s+1}$ for $s=1, \ldots, s_{m}$ (Assumption 3), also the expected value of $\theta$ under the stationary distribution $\pi_{\infty}$ is invariant to changes in $\Delta$ and equal to the median value $\theta_{s_{m}}$, i.e., $\mathbb{E}[\theta]=\sum_{s=1}^{\mathcal{S}} \pi_{\infty}^{s} \theta_{s}=\theta_{s_{m}}$ for all $\Delta \geq 0$. Hence, the parameter $\Delta$ acts like a mean-median-preserving spread in the distribution of $\theta$.

In any equilibrium of the model consistent with a constant exogenous rate of job destruction $\delta$, the unemployment rate follows a $\mathcal{S}$-state Markov chain with stochastic equilibrium

$$
u_{s}=\frac{\delta}{\delta+\phi\left(\theta_{s}\right)}
$$

for $s \in\{1, \ldots, \mathcal{S}\}$. The function $f(\theta)=\frac{\delta}{\delta+\phi(\theta)}$ is differentiable, decreasing, $f^{\prime}(\cdot)<0$, and convex, $f^{\prime \prime}(\cdot)>0$, with $f(0)=1$ and $\lim _{\theta \rightarrow \infty} f(\theta)=0$.

Let $\Delta u_{M M D} \equiv \mathbb{E}[u]-u_{s_{m}}$ denote the difference between the expected and the median value of unemployment, and use $u=f(\theta)$ to write $\Delta u_{M M D}$ as:

$$
\begin{gathered}
\Delta u_{M M D}=\sum_{s=1}^{\mathcal{S}} \pi_{\infty}^{s} f\left(\theta_{s}\right)-f\left(\theta_{s_{m}}\right)=\left(\pi_{\infty}^{s_{m}}-1\right) f\left(\theta_{s_{m}}\right)+\pi_{\infty}^{1} f\left(\theta_{s_{m}}-\Delta\right)+\ldots \\
\ldots+\pi_{\infty}^{s_{m}-1} f\left(\theta_{s_{m}}-\frac{\Delta}{\mathcal{S}-s_{m}}\right)+\ldots+\pi_{\infty}^{s_{m}+1} f\left(\theta_{s_{m}}+\frac{\Delta}{\mathcal{S}-s_{m}}\right)+\ldots+\pi_{\infty}^{\mathcal{S}} f\left(\theta_{s_{m}}+\Delta\right) .
\end{gathered}
$$


By using the symmetry assumption $\pi_{\infty}^{s}=\pi_{\infty}^{\mathcal{S}-s+1}$ for $s=1, \ldots, s_{m}$ (Assumption 3), we can rewrite the expression above as,

$$
\begin{aligned}
\Delta u_{M M D}= & \left(\pi_{\infty}^{s_{m}}-1\right) f\left(\theta_{s_{m}}\right)+\pi_{\infty}^{1}\left[f\left(\theta_{s_{m}}-\Delta\right)+f\left(\theta_{s_{m}}+\Delta\right)\right]+\ldots \\
& \ldots+\pi_{\infty}^{s_{m}-1}\left[f\left(\theta_{s_{m}}-\frac{\Delta}{\mathcal{S}-s_{m}}\right)+f\left(\theta_{s_{m}}+\frac{\Delta}{\mathcal{S}-s_{m}}\right)\right] .
\end{aligned}
$$

We are interested in how $\Delta u_{M M D}$ changes as $\Delta$ increases:

$$
\begin{aligned}
\frac{\partial \Delta u_{M M D}}{\partial \Delta}= & \pi_{\infty}^{1}\left[f^{\prime}\left(\theta_{s_{m}}+\Delta\right)-f^{\prime}\left(\theta_{s_{m}}-\Delta\right)\right]+\ldots \\
& \ldots+\frac{\pi_{\infty}^{s_{m}-1}}{\mathcal{S}-s_{m}}\left[f^{\prime}\left(\theta_{s_{m}}+\frac{\Delta}{\mathcal{S}-s_{m}}\right)-f^{\prime}\left(\theta_{s_{m}}-\frac{\Delta}{\mathcal{S}-s_{m}}\right)\right] .
\end{aligned}
$$

Using $f^{\prime}(\cdot)<0$, we rewrite $(\mathrm{C} .5)$ is a slightly different way,

$$
\begin{aligned}
\frac{\partial \Delta u_{M M D}}{\partial \Delta}= & \pi_{\infty}^{1}\left[\left|f^{\prime}\left(\theta_{s_{m}}-\Delta\right)\right|-\left|f^{\prime}\left(\theta_{s_{m}}+\Delta\right)\right|\right]+\ldots \\
& \ldots+\frac{\pi_{\infty}^{s_{m}-1}}{\mathcal{S}-s_{m}}\left[\left|f^{\prime}\left(\theta_{s_{m}}-\frac{\Delta}{\mathcal{S}-s_{m}}\right)\right|-\left|f^{\prime}\left(\theta_{s_{m}}+\frac{\Delta}{\mathcal{S}-s_{m}}\right)\right|\right] .
\end{aligned}
$$

Since $f^{\prime}(\cdot)<0$ and $f^{\prime \prime}(\cdot)>0,\left|f^{\prime}\left(\theta_{s_{m}}-\epsilon\right)\right|>\left|f^{\prime}\left(\theta_{s_{m}}+\epsilon\right)\right|$ for all $\epsilon>0$, and all terms in square brackets on the right hand side of (C.6) are strictly positive, 


$$
\begin{aligned}
& \left|f^{\prime}\left(\theta_{s_{m}}-\Delta\right)\right|>\left|f^{\prime}\left(\theta_{s_{m}}+\Delta\right)\right| \\
& \left|f^{\prime}\left(\theta_{s_{m}}-\frac{\left(s_{m}-2\right) \Delta}{\mathcal{S}-s_{m}}\right)\right|>\left|f^{\prime}\left(\theta_{s_{m}}+\frac{\left(s_{m}-2\right) \Delta}{\mathcal{S}-s_{m}}\right)\right| \\
& \left|f^{\prime}\left(\theta_{s_{m}}-\frac{\Delta}{\mathcal{S}-s_{m}}\right)\right|>\left|f^{\prime}\left(\theta_{s_{m}}+\frac{\Delta}{\mathcal{S}-s_{m}}\right)\right|,
\end{aligned}
$$

such that $\partial \Delta u_{M M D} / \partial \Delta>0$ for all $\Delta>0$. Given $e_{s}=1-u_{s}$ for $s \in\{1, \ldots, \mathcal{S}\}, \Delta e_{M M D}=$ $-\Delta u_{M M D}$. Hence, $\partial \Delta e_{M M D} / \partial \Delta=-\partial \Delta u_{M M D} / \partial \Delta<0$, and this proves part (i) of the proposition. Part (ii). In any equilibrium of the model consistent with a constant exogenous rate of job destruction, the job-finding rate $\phi(\theta)$ follows a $\mathcal{S}$-state Markov chain with state space $\Phi=\left\{\phi\left(\theta_{1}\right), \ldots, \phi\left(\theta_{\mathcal{S}}\right)\right\}$. Given Assumption 1, the function $\phi(\theta)$ is differentiable, increasing, $\phi^{\prime}(\cdot)>0$, and concave, $\phi^{\prime \prime}(\cdot)<0$.

Let $\Delta \phi_{M M D} \equiv \mathbb{E}[\phi(\theta)]-\phi\left(\theta_{s_{m}}\right)$ denote the difference between the expected and the median value of the job-finding rate. Following the same steps as before for the unemployment rate, we rewrite $\Delta \phi_{M M D}$ as:

$$
\begin{aligned}
\Delta \phi_{M M D}= & \left(\pi_{\infty}^{s_{m}}-1\right) \phi\left(\theta_{s_{m}}\right)+\pi_{\infty}^{1}\left[\phi\left(\theta_{s_{m}}-\Delta\right)+\phi\left(\theta_{s_{m}}+\Delta\right)\right]+\ldots \\
& \ldots+\pi_{\infty}^{s_{m}-1}\left[\phi\left(\theta_{s_{m}}-\frac{\Delta}{\mathcal{S}-s_{m}}\right)+\phi\left(\theta_{s_{m}}+\frac{\Delta}{\mathcal{S}-s_{m}}\right)\right] .
\end{aligned}
$$

We are interested in how $\Delta \phi_{M M D}$ changes as $\Delta$ increases:

$$
\begin{aligned}
\frac{\partial \Delta \phi_{M M D}}{\partial \Delta}= & \pi_{\infty}^{1}\left[\phi^{\prime}\left(\theta_{s_{m}}+\Delta\right)-\phi^{\prime}\left(\theta_{s_{m}}-\Delta\right)\right]+\ldots \\
& \ldots+\frac{\pi_{\infty}^{s_{m}-1}}{\mathcal{S}-s_{m}}\left[\phi^{\prime}\left(\theta_{s_{m}}+\frac{\Delta}{\mathcal{S}-s_{m}}\right)-\phi^{\prime}\left(\theta_{s_{m}}-\frac{\Delta}{\mathcal{S}-s_{m}}\right)\right] .
\end{aligned}
$$


Since $\phi^{\prime}(\cdot)>0$ and $\phi^{\prime \prime}(\cdot)<0, \phi^{\prime}\left(\theta_{s_{m}}+\epsilon\right)<\phi^{\prime}\left(\theta_{s_{m}}-\epsilon\right)$ for all $\epsilon>0$, such that all terms in square brackets on the right hand side of (C.7) are strictly negative. Hence, $\partial \Delta \phi_{M M D} / \partial \Delta<0$ for all $\Delta>0$, and this proves part (ii) of the proposition. Part (iii). In any equilibrium of the model consistent with a constant exogenous rate of job destruction, vacancies follow a $\mathcal{S}$-state Markov chain with stochastic equilibrium $v_{s}=\theta_{s} u_{s}$, for $s \in\{1, \ldots, \mathcal{S}\}$. Let's write vacancies as $v_{s}=\theta_{s} f\left(\theta_{s}\right)$, where the function $f(\theta)$ is differentiable, decreasing, $f^{\prime}(\cdot)<0$, and convex, $f^{\prime \prime}(\cdot)>0$.

Let $\Delta v_{M M D} \equiv \mathbb{E}[v]-v_{s_{m}}$ denote the difference between the expected and the median value of vacancies. By using the symmetry assumption $\pi_{\infty}^{s}=\pi_{\infty}^{\mathcal{S}-s+1}$ for $s=1, \ldots, s_{m}$ (Assumption 3), we can write $\Delta v_{M M D}$ as,

$$
\begin{gathered}
\Delta v_{M M D}=\left(\pi_{\infty}^{s_{m}}-1\right) \theta_{s_{m}} f\left(\theta_{s_{m}}\right)+ \\
+\pi_{\infty}^{1}\left[\left(\theta_{s_{m}}-\Delta\right) f\left(\theta_{s_{m}}-\Delta\right)+\left(\theta_{s_{m}}+\Delta\right) f\left(\theta_{s_{m}}+\Delta\right)\right]+\ldots \\
\ldots+\pi_{\infty}^{s_{m}-1}\left[\left(\theta_{s_{m}}-\frac{\Delta}{\mathcal{S}-s_{m}}\right) f\left(\theta_{s_{m}}-\frac{\Delta}{\mathcal{S}-s_{m}}\right)+\left(\theta_{s_{m}}+\frac{\Delta}{\mathcal{S}-s_{m}}\right) f\left(\theta_{s_{m}}+\frac{\Delta}{\mathcal{S}-s_{m}}\right)\right] .
\end{gathered}
$$

We are interested in how $\Delta v_{M M D}$ changes as $\Delta$ increases:

$$
\begin{gathered}
\frac{\partial \Delta v_{M M D}}{\partial \Delta}=\pi_{\infty}^{1}\left[f\left(\theta_{s_{m}}+\Delta\right)-f\left(\theta_{s_{m}}-\Delta\right)+\right. \\
\left.+\left(\theta_{s_{m}}+\Delta\right) f^{\prime}\left(\theta_{s_{m}}+\Delta\right)-\left(\theta_{s_{m}}-\Delta\right) f^{\prime}\left(\theta_{s_{m}}-\Delta\right)\right]+\ldots \\
\ldots+\frac{\pi_{\infty}^{s_{m}-1}}{\mathcal{S}-s_{m}}\left[f\left(\theta_{s_{m}}+\frac{\Delta}{\mathcal{S}-s_{m}}\right)-f\left(\theta_{s_{m}}-\frac{\Delta}{\mathcal{S}-s_{m}}\right)+\right. \\
\left.+\left(\theta_{s_{m}}+\frac{\Delta}{\mathcal{S}-s_{m}}\right) f^{\prime}\left(\theta_{s_{m}}+\frac{\Delta}{\mathcal{S}-s_{m}}\right)-\left(\theta_{s_{m}}-\frac{\Delta}{\mathcal{S}-s_{m}}\right) f^{\prime}\left(\theta_{s_{m}}-\frac{\Delta}{\mathcal{S}-s_{m}}\right)\right] .
\end{gathered}
$$

Notice that each term in square brackets on the right hand side of (C.8) takes the form,

$$
\mathcal{E} \equiv f\left(\theta_{s_{m}}+\epsilon\right)-f\left(\theta_{s_{m}}-\epsilon\right)+\left(\theta_{s_{m}}+\epsilon\right) f^{\prime}\left(\theta_{s_{m}}+\epsilon\right)-\left(\theta_{s_{m}}-\epsilon\right) f^{\prime}\left(\theta_{s_{m}}-\epsilon\right)
$$


By substituing the expressions for $f(\cdot)$ and $f^{\prime}(\cdot)$ in $\mathcal{E}$, one can show that $\mathcal{E}<0$ for all $\epsilon>0$, such that all terms on the right hand side of (C.8) are strictly negative. Hence, $\partial \Delta v_{M M D} / \partial \Delta<0$ for all $\Delta>0$, and this proves part (iii) of the proposition. Part (iv). In any equilibrium of the model consistent with a constant exogenous rate of job destruction, output follows a $\mathcal{S}$-state Markov chain with state space $\mathcal{Y}=\left\{y_{1}, \ldots, y_{\mathcal{S}}\right\}$. At the stochastic equilibrium, output is $y_{s}=z_{s} e_{s}$, where the employment rate $e_{s}$ is a strictly increasing and concave function of the tightness ratio, $\xi(\theta)$ with $\xi^{\prime}(\cdot)>0$ and $\xi^{\prime \prime}(\cdot)<0$. From Lemma 1, we know that in equilibrium the tightness ratio is strictly increasing and convex in the aggregate shock $z$, i.e., $\theta=\varphi(z)$ with $\varphi^{\prime}(\cdot)>0$ and $\varphi^{\prime \prime}(\cdot)>0$. By inverting the function $\varphi(\cdot)$, it follows that $z=\phi(\theta)^{-1} \equiv \psi(\theta)$, with $\psi^{\prime}(\cdot)>0$ and $\psi^{\prime \prime}(\cdot)<0$. Let's rewrite output as $y_{s}=\psi(\theta) \xi(\theta)$, and $\ln y_{s}=\ln \psi(\theta)+\ln \xi(\theta)$. It is easily established that $\log$ output is strictly increasing and concave in the tightness ratio $\theta$, as such following the same steps of parts (ii) and (iii) one can show that $\partial \Delta y_{M M D} / \partial \Delta<0$ for all $\Delta>0$, and this completes the proof of the proposition.

Proof of Proposition 4. Part (i). Consider a mean-median-preserving spread $\Delta$ in the distribution of the generic endogenous variable $\tilde{x}$ with stochastic equilibrium,

$$
\tilde{x}_{s}=\tilde{x}_{s_{m}}+\frac{\left(s-s_{m}\right)}{\left(\mathcal{S}-s_{m}\right)} \cdot \Delta
$$

for $s \in\{1, \ldots, \mathcal{S}\}$ and $\Delta>0$. An increase in the parameter $\Delta$ raises the variance of $\tilde{x}$, leaving unaltered both the mean and the median of the stochastic process. Let $\Delta \tilde{x}_{s, s \prime} \equiv\left(\tilde{x}_{s \prime}-\tilde{x}_{s}\right)$ denote the change in the variable $\tilde{x}$ from the current state $s$ to the next period state $s^{\prime}$. From equation (C.9):

$$
\Delta \tilde{x}_{s, s \prime}=\frac{\left(s^{\prime}-s\right)}{\left(\mathcal{S}-s_{m}\right)} \cdot \Delta
$$

such that $\Delta \tilde{x}_{i, j}=-\Delta \tilde{x}_{j, i}>0$, for all $j>i$, and $\Delta \tilde{x}_{s, s_{m}}=\Delta \tilde{x}_{\mathcal{S}-s+1, s_{m}}$, for all $s \in$ $\left\{1, \ldots, s_{m}-1\right\}$. Since the model is stationary, $\mu_{\Delta \tilde{x}} \equiv \mathbb{E}[\Delta \tilde{x}]=0$, and the skewness coefficient of $\Delta \tilde{x}, S k e w[\Delta \tilde{x}]=\mathbb{E}\left[\left(\Delta \tilde{x}-\mu_{\Delta \tilde{x}}\right)^{3}\right] / \sigma_{\Delta \tilde{x}}^{3}$, reduces to $S k e w[\Delta \tilde{x}]=\mathbb{E}\left[\Delta \tilde{x}^{3}\right] / \sigma_{\Delta \tilde{x}}^{3}$. Because the sign of $S k e w[\Delta \tilde{x}]$ is determind by the sign of the numerator, I focus without loss of generality on $N S k e w[\Delta \tilde{x}] \equiv \mathbb{E}\left[\Delta \tilde{x}^{3}\right]$ : 


$$
\begin{aligned}
N \text { Skew }[\Delta \tilde{x}] & =\sum_{s=1}^{\mathcal{S}} \pi_{\infty}^{s} \sum_{s^{\prime}=1}^{\mathcal{S}} \pi_{s, s^{\prime}} \Delta \tilde{x}_{s, s}^{3}=\sum_{s=1}^{\mathcal{S}} \pi_{\infty}^{s}\left(\pi_{s, s_{m}} \Delta \tilde{x}_{s, s_{m}}^{3}+\pi_{s_{m}, s} \Delta \tilde{x}_{s_{m}, s}^{3}\right)+ \\
& +\sum_{s=1}^{s_{m}-1} \pi_{\infty}^{s}\left(\pi_{s, \mathcal{S}-s+1} \Delta \tilde{x}_{s, \mathcal{S}-s+1}^{3}+\pi_{\mathcal{S}-s+1, s} \Delta \tilde{x}_{\mathcal{S}-s+1, s}^{3}\right)
\end{aligned}
$$

Using Assumption 3 on the symmetry of transition probabilities $\pi_{s, s^{\prime}}$, and that by definition $\Delta \tilde{x}_{s, s}=0$, for all $s \in\{1, \ldots, \mathcal{S}\}$, I rewrite equation (C.11) as,

$$
\begin{aligned}
\text { NSkew }[\Delta \tilde{x}] & =\sum_{s=1}^{s_{m}-1} \pi_{\infty}^{s} \pi_{s, s_{m}}\left(\Delta \tilde{x}_{s, s_{m}}^{3}+\Delta \tilde{x}_{\mathcal{S}-s+1, s_{m}}^{3}\right)+ \\
& +\sum_{s=1}^{s_{m}-1} \pi_{\infty}^{s} \pi_{s_{m}, s}\left(\Delta \tilde{x}_{s_{m}, s}^{3}+\Delta \tilde{x}_{s_{m}, \mathcal{S}-s+1}^{3}\right)+ \\
& +\sum_{s=1}^{s_{m}-1} \pi_{\infty}^{s} \pi_{s, \mathcal{S}-s+1}\left(\Delta \tilde{x}_{s, \mathcal{S}-s+1}^{3}+\Delta \tilde{x}_{\mathcal{S}-s+1, s}^{3}\right) .
\end{aligned}
$$

Using equation (C.10) for the support of $\Delta \tilde{x}$, I rewrite equation (C.12) as,

$$
\begin{aligned}
\text { NSkew }[\Delta \tilde{x}] & =\frac{\Delta^{3}}{\left(\mathcal{S}-s_{m}\right)^{3}} \sum_{s=1}^{s_{m}-1} \pi_{\infty}^{s} \pi_{s, s_{m}}\left[\left(s_{m}-s\right)^{3}+\left(s_{m}-\mathcal{S}+s-1\right)^{3}\right]+ \\
& +\frac{\Delta^{3}}{\left(\mathcal{S}-s_{m}\right)^{3}} \sum_{s=1}^{s_{m}-1} \pi_{\infty}^{s} \pi_{s_{m}, s}\left[\left(s-s_{m}\right)^{3}+\left(\mathcal{S}-s+1-s_{m}\right)^{3}\right]+\quad(\mathrm{C} .13) \\
& +\frac{\Delta^{3}}{\left(\mathcal{S}-s_{m}\right)^{3}} \sum_{s=1}^{s_{m}-1} \pi_{\infty}^{s} \pi_{s, \mathcal{S}-s+1}\left[(\mathcal{S}-s+1-s)^{3}+(s-\mathcal{S}+s-1)^{3}\right] .
\end{aligned}
$$

After substituting the expression for the median state, $s_{m}=(\mathcal{S}+1) / 2$, into equation (C.13), it is straightforward to check that all terms in square brackets on the right hand side equal zero, such that $N$ Skew $[\Delta \tilde{x}]=0$, for all $\Delta>0$. Hence, regardless of the meanmedian-preserving spread $\Delta$, the unconditional distribution of $\Delta \tilde{x}_{s, s}$ is symmetric, and this proves part (i) of the proposition. Part (ii). Assume the support of the distribution of $\tilde{x}$ is left-skewed, such that $\left|\Delta \tilde{x}_{s, s_{m}}\right|>\left|\Delta \tilde{x}_{\mathcal{S}-s+1, s_{m}}\right|$, for $s \in\left\{1, \ldots, s_{m}-1\right\}$. Let's write again 
equation (C.12),

$$
\begin{aligned}
\text { NSkew }[\Delta \tilde{x}] & =\sum_{s=1}^{s_{m}-1} \pi_{\infty}^{s} \pi_{s, s_{m}}\left(\Delta \tilde{x}_{s, s_{m}}^{3}+\Delta \tilde{x}_{\mathcal{S}-s+1, s_{m}}^{3}\right)+ \\
& +\sum_{s=1}^{s_{m}-1} \pi_{\infty}^{s} \pi_{s_{m}, s}\left(\Delta \tilde{x}_{s_{m}, s}^{3}+\Delta \tilde{x}_{s_{m}, \mathcal{S}-s+1,}^{3}\right)+ \\
& +\sum_{s=1}^{s_{m}-1} \pi_{\infty}^{s} \pi_{s, \mathcal{S}-s+1}\left(\Delta \tilde{x}_{s, \mathcal{S}-s+1}^{3}+\Delta \tilde{x}_{\mathcal{S}-s+1, s}^{3}\right) .
\end{aligned}
$$

Since $\Delta \tilde{x}_{i, j}=-\Delta \tilde{x}_{j, i}$, for all $j>i$, the third term in square brackets on the right hand side of equation (C.14) equals zero. We can further rearrange equation (C.14),

$$
N \operatorname{Skew}[\Delta \tilde{x}]=\sum_{s=1}^{s_{m}-1} \pi_{\infty}^{s}\left(\pi_{s, s_{m}}-\pi_{s_{m}, s}\right)\left(\left|\Delta \tilde{x}_{s, s_{m}}^{3}\right|-\left|\Delta \tilde{x}_{\mathcal{S}-s+1, s_{m}}^{3}\right|\right)>0
$$

In equation (C.15), the inequality $N$ Skew $[\Delta \tilde{x}]>0$, holds because $\pi_{s, s_{m}}>\pi_{s_{m}, s}$, for $s \in\{1, \ldots, \mathcal{S}\}$, which is the condition that the stationary distribution of the Markov chain is uni-modal (Assumption 3), and $\left|\Delta \tilde{x}_{s, s_{m}}^{3}\right|>\left|\Delta \tilde{x}_{\mathcal{S}-s+1, s_{m}}^{3}\right|$, for $s \in\left\{1, \ldots, s_{m}-1\right\}$, and this proves part (ii) of the proposition. Part (iii). Assume the support of the distribution of $\tilde{x}$ is right-skewed, such that $\left|\Delta \tilde{x}_{s, s_{m}}\right|<\left|\Delta \tilde{x}_{\mathcal{S}-s+1, s_{m}}\right|$, for $s \in\left\{1, \ldots, s_{m}-1\right\}$. Following the same steps of part (ii),

$$
N \operatorname{Skew}[\Delta \tilde{x}]=\sum_{s=1}^{s_{m}-1} \pi_{\infty}^{s}\left(\pi_{s, s_{m}}-\pi_{s_{m}, s}\right)\left(\left|\Delta \tilde{x}_{s, s_{m}}^{3}\right|-\left|\Delta \tilde{x}_{\mathcal{S}-s+1, s_{m}}^{3}\right|\right)<0
$$

and this completes the proof of the proposition. 


\section{Integrated Labor Market}

This section details the building blocks of the integrated labor market version of the model presented in Section 3. I consider the labor market in steady state, i.e., $z_{t}=z_{s}$ for $s \in$ $\{1, \ldots, \mathcal{S}\}$ and all $t$. As in the segmented labor market version of the model, there are $M$ types of workers index by $x \in\left\{x_{1}, \ldots, x_{M}\right\}$. Total match surplus from being matched with a worker of type $x$ if the economy is in state $s \in\{1, \ldots, \mathcal{S}\}$ is

$$
S_{s}(x)=\max \left\{S_{s}^{c}(x), 0\right\}
$$

with

$$
S_{s}^{c}(x)=z_{s} x-\lambda+\beta\left[1-\delta_{s}(x)-\eta \phi\left(\theta_{s}\left(\pi_{s}\right)\right)\right] S_{s}(x)
$$

$S_{s}^{c}(x)$ is the value of continuing the match. The free-entry condition for employers is

$$
k=\rho\left(\theta_{s}\left(\pi_{s}\right)\right) \beta(1-\eta) \sum_{x} \pi_{s}(x) S_{s}(x)
$$

where the probability to come in contact with a worker of type $x$ is $\pi_{s}(x)=u_{s}(x) / U_{s}$ where $U_{s}=\sum_{x} u_{s}(x)$ is aggregate unemployment.

\section{References}

K.G. Abraham and L.F. Katz. Cyclical Unemployment: Sectoral Shifts or Aggregate Disturbances? Journal of Political Economy, 94(3):507-522, 1986.

D. Acemoglu and A. Scott. Asymmetric Business Cycles: Theory and Time-Series Evidence. Journal of Monetary Economics, 40(3):501-533, 1997.

D. Andolfatto. Business Cycles and Labor-Market Search. American Economic Review, 86 (1):112-132, 1996.

D. Andolfatto. Evidence and Theory on the Cyclical Asymmetry in Unemployment Rate Fluctuations. Canadian Journal of Economics, 30(3):709-21, 1997.

A. Auerbach and Y. Gorodnichenko. Measuring the Output Responses to Fiscal Policy. American Economic Journal: Economic Policy, 4(2):1-27, 2012. 
R. Bachmann, E. Engel, and R. Caballero. Aggregate Implications of Lumpy Investment: New Evidence and a DSGE Model. Unpublished manuscript, 2010.

J. Bai and S. Ng. Tests for Skewness, Kurtosis, and Normality for Time Series Data. Journal of Business \& Economic Statistics, 23(1):49-60, 2005.

L. Ball and N.G. Mankiw. Asymmetric Price Adjustment and Economic Fluctuations. Economic Journal, 104(423):247-61, 1994.

R. Barnichon. Building a Composite Help-Wanted Index. Economics Letters, 109(3):175$178,2010$.

R. Barnichon. Vacancy Posting, Job Separation and Unemployment Fluctuations. Journal of Economic Dynamics and Control, 36(3):315-330, 2012.

R. Barnichon and A. Figura. Labor Market Heterogeneities, Matching Efficiency, and the Cyclical Behavior of the Job Finding Rate. Unpublished manuscript, 2011.

J. Belaire-Franch and A. Peiro. Conditional and Unconditional Asymmetry in US Macroeconomic Time Series. Studies in Nonlinear Dynamics $\&$ Econometrics, 7(1), 2003.

D. Berger and J. Vavra. Consumption Dynamics During Recessions. Unpublished manuscript, 2012.

O.J. Blanchard, P. Diamond, R.E. Hall, and J. Yellen. The Beveridge Curve. Brookings Papers on Economic Activity, 1989(1):1-76, 1989.

O.J. Blanchard, P. Diamond, R.E. Hall, and K. Murphy. The Cyclical Behavior of the Gross Flows of US Workers. Brookings Papers on Economic Activity, 1990(2):85-155, 1990.

B. Brügemann. What Elasticity of the Matching Function is Consistent with US Aggregate Labor Market Data? Unpublished manuscript, 2008.

C. Carrillo-Tudela and L. Visschers. Unemployment and Endogenous Reallocation over the Business Cycle. Unpublished manuscript, 2013.

A. Cheremukhin and A. Tutino. Asymmetric Firm Dynamics under Rational Inattention. Unpublished manuscript, 2013.

K.B. Clark and L.H. Summers. Demographic Differences in Cyclical Employment Variation. Journal of Human Resources, 16(1):61-79, 1981. 
H.L. Cole and R. Rogerson. Can the Mortensen-Pissarides Matching Model Match the Business-Cycle Facts? International Economic Review, 40(4):933-959, 2001.

J.S. Costain and M. Reiter. Business Cycles, Unemployment Insurance, and the Calibration of Matching Models. Journal of Economic Dynamics and Control, 32(4):1120-1155, 2008.

S.J. Davis. Job Loss, Job Finding, and Unemployment in the US Economy over the Past Fifty Years. Comment. NBER Macroeconomics Annual, 20:139-157, 2005.

S.J. Davis, J.C. Haltiwanger, and S. Schuh. Job Creation and Destruction. MIT Press, 1998.

S.J. Davis, R.J. Faberman, and J.C. Haltiwanger. The Flow Approach to Labor Markets: New Data Sources and Micro-Macro Links. Journal of Economic Perspectives, 20(3):3-26, 2006.

S.J. Davis, R.J. Faberman, J.C. Haltiwanger, R. Jarmin, and J. Miranda. Business Volatility, Job Destruction, and Unemployment. American Economic Journal: Macroeconomics, 2 (2):259-287, 2010.

M.B. Devereux and H.E. Siu. State Dependent Pricing and Business Cycle Asymmetries. International Economic Review, 48(1):281-310, 2007.

M.W.L. Elsby, R. Michaels, and G. Solon. The Ins and Outs of Cyclical Unemployment. American Economic Journal: Macroeconomics, 1(1):84-110, 2009.

M.W.L. Elsby, B. Hobijn, and A. Şahin. The Labor Market in the Great Recession. Brookings Papers on Economic Activity, 2010(1):1-48, 2010.

M.W.L. Elsby, B. Hobijn, and A. Şahin. Unemployment Dynamics in the OECD. Review of Economics and Statistics, 95(2):530-548, 2013.

B. Falk. Further Evidence on the Asymmetric Behavior of Economic Time Series over the Business Cycle. Journal of Political Economy, 94(5):1096-1109, 1986.

C.J. Flinn and J.J. Heckman. Are Unemployment and Out of the Labor Force Behaviorally Distinct Labor Force States? Journal of Labor Economics, 1(1):28-42, 1983.

S. Fujita and G. Ramey. The Cyclicality of Separation and Job Finding Rates. International Economic Review, 50(2):415-430, 2009. 
S. Fujita and G. Ramey. Exogenous versus Endogenous Separation. American Economic Journal: Macroeconomics, 4(4):68-93, 2012.

M. Gervais, N. Jaimovich, H.E. Siu, and Y. Yedid-Levi. What Should I Be When I Grow Up? Occupations and Unemployment over the Life Cycle. Unpublished manuscript, 2013.

P. Gomme, R. Rogerson, P. Rupert, and R. Wright. The Business Cycle and the Life Cycle. NBER Macroeconomics Annual 2004, 19:415-592, 2005.

C. Görtz and J. Tsoukalas. Learning, Capital-Embodied Technology and Aggregate Fluctuations. Unpublished manuscript, 2013.

M. Hagedorn and I. Manovskii. The Cyclical Behavior of Equilibrium Unemployment and Vacancies Revisited. American Economic Review, 98(4):1692-1706, 2008.

R.E. Hall. Job Loss, Job Finding, and Unemployment in the US Economy over the Past Fifty Years. In NBER Macroeconomics Annual. MIT Press, 2005a.

R.E. Hall. Employment Efficiency and Sticky Wages: Evidence from Flows in the Labor Market. Review of Economics and Statistics, 87(3):397-407, 2005b.

R.E. Hall and P.R. Milgrom. The Limited Influence of Unemployment on the Wage Bargain. American Economic Review, 98(4):1653-1674, 2008.

D.S. Hamermesh and G.A. Pfann. Adjustment Costs in Factor Demand. Journal of Economic Literature, 34(3):1264-1292, 1996.

J.D. Hamilton. What's Real About the Business Cycle? Federal Reserve Bank of St. Louis Review, 87(4):435-52, 2005.

G.D. Hansen and E.C. Prescott. Capacity Constraints, Asymmetries, and the Business Cycle. Review of Economic Dynamics, 8(4):850-865, 2005.

B. Herz and T. van Rens. Structural Unemployment. Unpublished manuscript, 2012.

A.J. Hosios. On the Efficiency of Matching and Related Models of Search and Unemployment. Review of Economic Studies, 57(2):279-298, 1990.

N. Jaimovich and H.E. Siu. The Young, the Old, and the Restless: Demographics and Business Cycle Volatility. American Economic Review, 99(3):804-826, 2009. 
S.R.G. Jones and W.C. Riddell. The Measurement of Unemployment: An Empirical Approach. Econometrica, 67(1):147-162, 1999.

B. Jovanovic. Asymmetric Cycles. Review of Economic Studies, 73(1):145-162, 2006.

C. Juhn, K.M. Murphy, R.H. Topel, J.L. Yellen, and M.N. Baily. Why Has the Natural Rate of Unemployment Increased over Time? Brookings Papers on Economic Activity, 1991(2): 75-142, 1991.

N. Kocherlakota. Creating Business Cycles through Credit Constraints. Federal Reserve Bank of Minneapolis Quarterly Review, 24(3):2-10, 2000.

J. Long and L.H. Summers. Are Business Cycles Symmetric? NBER Working Paper, 1444, 1986.

A. McKay and R. Reis. The Brevity and Violence of Contractions and Expansions. Journal of Monetary Economics, 55(4):738-751, 2008.

G. McQueen and S. Thorley. Asymmetric Business Cycle Turning Points. Journal of Monetary Economics, 31(3):341-362, 1993.

G. Menzio and S. Shi. Directed Search on the Job, Heterogeneity, and Aggregate Fluctuations. American Economic Review, 100(2):327-332, 2010.

P. Michaillat. Do Matching Frictions Explain Unemployment? Not in Bad Times. American Economic Review, 102(4):1721-1750, 2012.

J.A. Mincer. Schooling, Experience, and Earnings. Columbia University Press, 1974.

W.C. Mitchell. Business Cycles. Berkeley: University of California Press, 1913.

W.C. Mitchell. Business Cycles: The Problem and Its Setting. New York: National Bureau of Economic Research, 1927.

W.C. Mitchell and A.F. Burns. Measuring Business Cycles. New York: National Bureau of Economic Research, 1946.

D.T. Mortensen and E. Nagypal. More on Unemployment and Vacancy Fluctuations. Review of Economic Dynamics, 10(3):327-347, 2007. 
D.T. Mortensen and C.A. Pissarides. Job Creation and Job Destruction in the Theory of Unemployment. Review of Economic Studies, 61(3):397-415, 1994.

S.N. Neftci. Are Economic Time Series Asymmetric over the Business Cycle? Journal of Political Economy, 92(2):307-328, 1984.

B. Petrongolo and C.A. Pissarides. Looking into the Black Box: A Survey of the Matching Function. Journal of Economic Literature, 39(2):390-431, 2001.

C.A. Pissarides. Equilibrium Unemployment Theory. MIT press, 2000.

M.O. Ravn and H. Uhlig. On Adjusting the Hodrick-Prescott Filter for the Frequency of Observations. Review of Economics and Statistics, 84(2):371-376, 2002.

R. Rogerson and R. Shimer. Search in Macroeconomic Models of the Labor Market. Handbook of Labor Economics, 4:619-700, 2011.

P. Rothman. Further Evidence on the Asymmetric Behavior of Unemployment Rates over the Business Cycle. Journal of Macroeconomics, 13(2):291-298, 1991.

A. Sahin, J. Song, G. Topa, and G. Violante. Mismatch Unemployment. NBER Working Paper, 18265, 2012.

R. Shimer. The Cyclical Behavior of Equilibrium Unemployment and Vacancies. American Economic Review, 95(1):25-49, 2005.

R. Shimer. Reassessing the Ins and Outs of Unemployment. Review of Economic Dynamics, 15(2):127-148, 2012.

D.E. Sichel. Are Business Cycles Asymmetric? A Correction. Journal of Political Economy, 97(5):1255-1260, 1989.

D.E. Sichel. Business Cycle Asymmetry: A Deeper Look. Economic Inquiry, 31(2):224-236, 1993.

C. Syverson. What Determines Productivity? Journal of Economic Literature, 49(2):326$365,2011$.

G. Tauchen. Finite State Markov-Chain Approximations to Univariate and Vector Autoregressions. Economics Letters, 20(2):177-181, 1986. 
S. Van Nieuwerburgh and L. Veldkamp. Learning Asymmetries in Real Business Cycles. Journal of Monetary Economics, 53(4):753-772, 2006.

R. Verbrugge. Investigating Cyclical Asymmetries. Studies in Nonlinear Dynamics \& Econometrics, 2(1):15-22, 1997.

Y. Yedid-Levi. Why Does Employment in All Major Sectors Move Together over the Business Cycle? Unpublished manuscript, 2013. 